\author{
Medizinische Fakultät \\ der \\ Universität Duisburg-Essen
}

Aus der Klinik für Endokrinologie

\title{
Häufigkeit von Schilddrüsenkarzinomen \\ in szintigraphisch vollständig kalten Knoten
}

\author{
In a u gura l-Dis sertation \\ zur \\ Erlangung des Doktorgrades der Medizin \\ durch die Medizinische Fakultät \\ der Universität Duisburg-Essen
}

\author{
Vorgelegt von \\ Theresa Ingeborg Auguste-Luise Graf \\ aus Freiburg i.Br. \\ 2005
}


Dekan: $\quad$ Univ.-Prof. Dr. rer. nat. K.-H. Jöckel

1. Gutachter: Univ.-Prof. Dr. med. K. Mann

2. Gutachter: Prof. Dr. med. B. P. Hauffa

Tag der mündlichen Prüfung: 25. August 2006 


\section{Widmung}

Meinen Eltern in Dankbarkeit gewidmet.

Meinem Vater danke ich ganz besonders

für die fachliche Betreuung und Unterstützung. 
2. Grundlagen 9

2.1 Intrathyreoidaler Jodmetabolismus 9

2.1.1 Natrium-Jod-Symporter (NJS) 9

2.1.1.1 Stimulation der funktionellen NJS-Expression 12

2.1.1.2 Hemmung der funktionellen NJS-Expression 13

2.1.1.3 NJS und benigne Schilddrüsenerkrankungen 13

2.1.1.4 NJS und maligne Schilddrüsenerkrankungen $\quad 14$

2.2 Ätiologie und Pathogenese der Bildung von Schilddrüsenknoten 19

$\begin{array}{ll}2.2 .1 & \text { Jodmangel und Strumabildung }\end{array}$

2.2.1.1 Autokrine und parakrine Wachstumsfaktoren $\quad 19$

2.2.1.2 Jodlipide 21

2.2.3 Klonalität von Schilddrüsenknoten 23

2.2.4 Heterogenität des Schilddrüsenwachstums 24

2.2.5 Molekulare Aspekte in der Pathogenese benigner Schilddrüsenknoten 26

2.2.6 Molekulare Aspekte in der Pathogenese maligner Schilddrüsenknoten 28

$2.3 \quad$ Zytologie benigner und maligner Schilddrüsenknoten 38

2.3.1 Zytologie von Schilddrüsenknoten - allgemeine Aspekte 38

2.3.2 Benigne Schilddrüsenknoten 41

2.3.2.1 Noduläre Hyperplasie 41

2.3.2.2 Das follikuläre Adenom 42

2.3.2.3 Das onkozytäre Adenom 43

2.3.2.4 Die follikuläre Neoplasie 43

2.3.3 Maligne Schilddrüsenknoten $\quad 44$

2.3.3.1 Papilläre Schilddrüsenkarzinome 46

2.3.3.2 Follikuläre Schilddrüsenkarzinome 49

2.3.3.3 Anaplastische (undifferenzierte) Schilddrüsenkarzinome 52

2.3.3.4 Medulläre Schilddrüsenkarzinome 53

2.3.3.5 Schilddrüsenlymphome $\quad 54$ 
3. Patientengut und Methodik 55

3.1 Patientenkollektiv 55

3.2 Schilddrüsenlaboruntersuchungen 55

3.3 Apparative Untersuchungen 58

3.3.1 Schilddrüsensonographie 58

$\begin{array}{lll}\text { 3.3.2 Schilddrüsenszintigraphie } & 64\end{array}$

$\begin{array}{lll}3.4 & \text { Punktionszytologie } & 67\end{array}$

$\begin{array}{lll}\text { 4. } & \text { Ergebnisse } & 70\end{array}$

$\begin{array}{llr}\text { 5. Diskussion } & 88\end{array}$

6. Zusammenfassung 103

$\begin{array}{lll}\text { 7. Literaturverzeichnis } & 104\end{array}$

8. Lebenslauf 115 


\section{1. $\quad$ Einleitung}

Knotige Veränderungen der Schilddrüse finden sich in Deutschland bei ca. 25 bis $30 \%$ aller Frauen und ca. $20 \%$ aller Männer (1).

Mindestens 16 Mio. Deutsche weisen somit solitäre oder multiple Knoten in der Schilddrüse auf. Die Frequenz von Schilddrüsenknoten nimmt mit dem Lebensalter $\mathrm{zu}$.

Als wichtiger ursächlicher Faktor für die hohe Zahl herdförmiger Läsionen gilt Jodmangel. Allerdings findet sich auch in Ländern mit ausreichender Jodversorgung eine relativ hohe Prävalenz knotiger Veränderungen der Schilddrüse um ca. 20 \% $(2,3)$.

Diese Ergebnisse legen den Schluss nahe, dass neben dem Jodmangel weitere Faktoren bestehen, die Knotenwachstum in der Schilddrüse begünstigen.

Histologisch handelt es sich in der überwiegenden Zahl der Fälle um Kolloidknoten oder benigne Adenome, die echten Neubildungen entsprechen.

Im Gegensatz zu den sehr häufigen benignen knotigen Läsionen ist die Prävalenz eines Schilddrüsenkarzinoms sehr gering. Das Risiko einer malignen Entartung wird in Deutschland auf 1,3 bis 1,6/100000 Einwohner für Männer und auf 2,5 bis 3,7/100000 Einwohner für Frauen geschätzt (44).

Bei der hohen Zahl von Schilddrüsenknoten und der geringen Zahl von Schilddrüsenmalignomen ist das Erkennen eines Karzinoms in einer Knotenstruma schwierig. Das Risiko einer malignen Entartung wird auf 1/1000 Knoten geschätzt (44). Nach verschiedenen Literaturangaben (4) sind ca. $5 \%$ aller Knoten mit verminderter bis vollständig fehlender Nuklidspeicherung (sogenannte „kalte” Knoten) maligne. 
Der Initiator der Studie, Dr. med. Dieter Graf / Endokrinologe, hat während seiner langjährigen Praxistätigkeit den subjektiven Eindruck gewonnen, dass sich hinter szintigraphisch vollständig kalten Knoten relativ häufig Schilddrüsenkarzinome verbergen.

Bei dem Studienkollektiv handelt es sich ausschließlich um Patienten aus der endokrinologisch - nuklearmedizinischen Praxisgemeinschaft Dr. med. Dieter Graf/ Brigitte Helmich-Kapp in Lüneburg.

Ziel der vorliegenden retrospektiven Studie war es, nach sonographischem Ausschluss einer Zyste, die Häufigkeit maligner Läsionen in szintigraphisch vollständig kalten Knoten festzustellen.

Zusätzlich sollte die Sensitivität der Punktionszytologie ermittelt werden. 
Abbildung 1

Szintigraphisch kalter Knoten rechts lateral

B. Helmich - Kapp
Aerzt in fuer Nuklearmedizin

Dr. med. D. Graf

Auf dem Meere 9, 21335 Lueneburg, Tel.:04131/31499, Fax:04131/390698

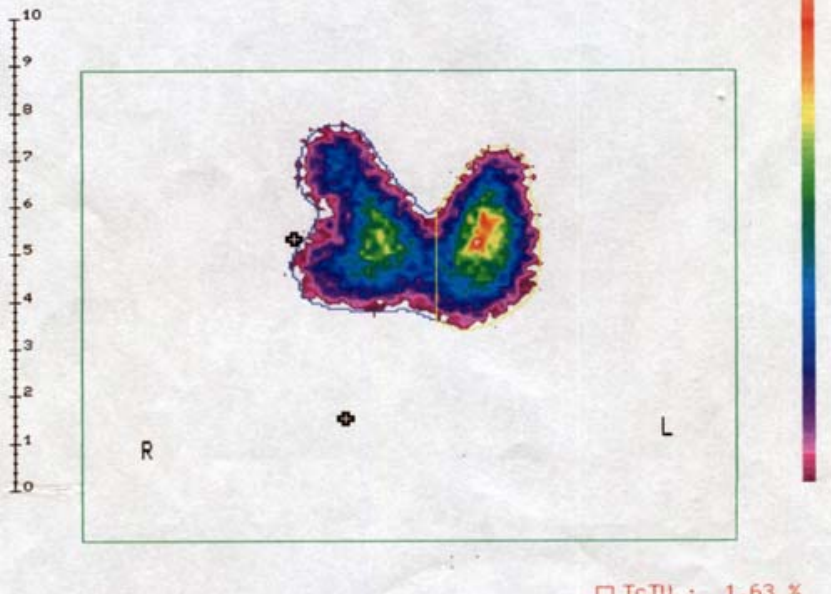

Zytologie: follikuläre Neoplasie

Histologie: follikuläres Adenom

Abbildung 2

Szintigraphisch kalter Knoten rechts lateral

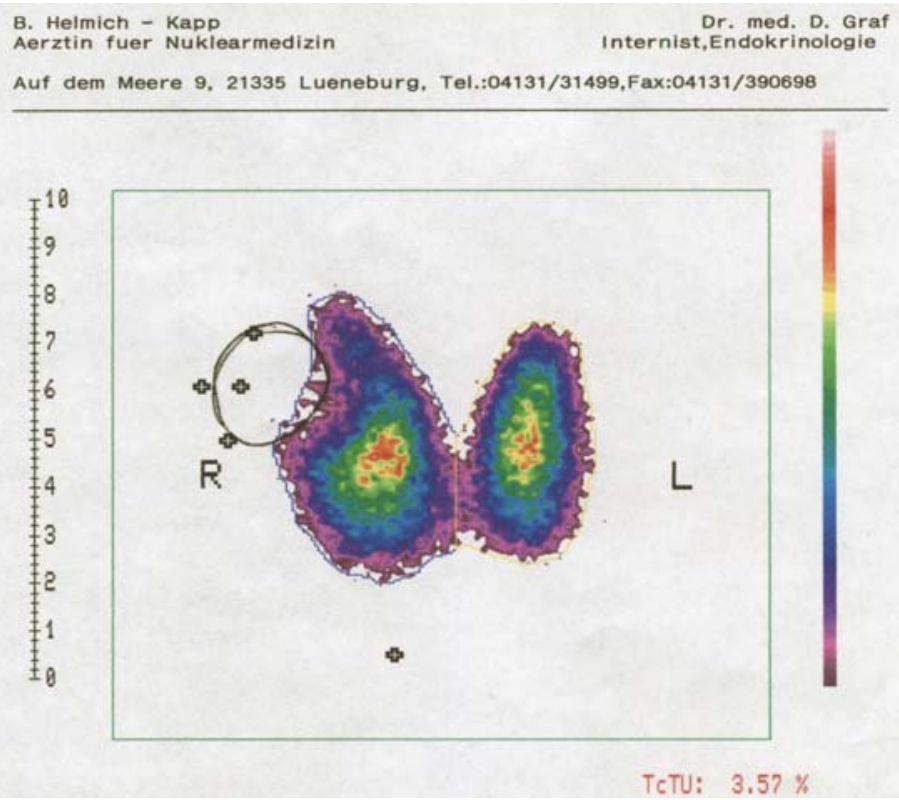

Zytologie: follikuläre Neoplasie

Histologie: follikuläres Karzinom (minimal invasiv) 


\section{Grundlagen}

\subsection{Intrathyreoidaler Jodmetabolismus}

Schilddrüsenhormone bestehen aus dem Spurenelement Jod und der Aminosäure Tyrosin. Das mit der Nahrung aufgenommene Jodid wird aus dem Blut gegen einen elektrochemischen Gradienten vom Plasma in die Schilddrüsenzelle befördert. Der Transport erfolgt mit Hilfe des laterobasal gelegenen zellmembranständigen Natrium-Jod-Symporters (NJS). Dieser Vorgang wird als Jodination bezeichnet.

Das Transportprotein Pendrin befördert das Jod weiter in das Follikellumen.

Hier findet die Organifizierung des Jods durch Bindung an Tyrosinreste statt (Jodisation) mit Bildung der Schilddrüsenhormone Trijodthyronin (T 3) und Tetrajodthyronin (T 4).

Die Hormonsynthese wird vermittelt durch das $\mathrm{H} 2 \mathrm{O} 2$ - generierende System NADPH-Oxidase in Verbindung mit der thyreoidalen Peroxidase (TPO).

\subsubsection{Natrium-Jod-Symporter (NJS)}

Eine ausreichende Schilddrüsenhormonsynthese ist abhängig von der nutritiven Verfügbarkeit des Jodid sowie von seiner effektiven Anreicherung in den Thyreozyten. Der Jodid-Transport vom Extrazellulärraum in den Thyreozyten wird durch den aktiven Transport des Natrium-Jod-Symporters (NJS) ermöglicht.

Dieser Transport findet an der basolateralen Membran des Thyreozyten statt.

NJS wird in den Thyreozyten in Abhängigkeit vom Funktionszustand der Zelle exprimiert. Im normalen Schilddrüsengewebe ist NJS in etwa $20 \%$ der Thyreozyten in heterogener Ausprägung nachweisbar (15). 
Dagegen wird NJS im Gewebe einer Basedowschilddrüse und in fokalen Autonomien erwartungsgemäß in einem erheblich höheren Ausmaß exprimiert (bis ca. $80 \%$ ). In benignen kalten Knoten und im Schilddrüsenkarzinomgewebe ist hingegen eine deutlich geringere bis gar keine NJS-Expression nachweisbar (15).

NJS ist ein membranständiges Protein, das seine Funktion als Jodid-Symporter erst dann erfüllen kann, wenn es regelrecht an der basolateralen Thyreozytenmembran verankert ist. Es reichert Jodid energieabhängig 20-fach in den Follikelzellen an.

Das menschliche NJS-Gen ist auf dem Chromosom 19p12-13.2 lokalisiert und besteht aus 15 Exons. Das NJS-Protein ist ein Glykoprotein und besteht aus 643 Aminosäuren. Es ist ein integrales Membranprotein mit 13 Transmembrandomänen. Es gehört zur großen Familie von Na-abhängigen Membrantransportern für kleine Moleküle und besitzt einen extrazellulären Amino-Terminus und einen intrazellulären Carboxy-Terminus. Nahe dem C-Terminus ist eine Phosphorylierungsstelle lokalisiert, die cAMP-abhängig über einen Proteinkinase-A-Weg phosphoryliert wird und damit die Symporterfunktion aktiviert $(45,8,9)$.

Der Symport ist relativ spezifisch für Jodid.

Das Anion Pertechnetat, das in der nuklearmedizinischen Diagnostik als 99m-TcPertechnetat bei der Schilddrüsenszintigraphie eingesetzt wird, ist ein guter Kompetitor für Jodid und wird wie Jodid als Substrat in den Thyreozyten transportiert $(6,7)$. 


\section{Abbildung 3}

aktualisiertes Modell des humanen Natrium-Jodid-Symporters aus:

Spitzweg C, Harrington KI, Pinke LA, Vile RG, Morris IC (2001):

The sodium iodide symporter and its potential role in cancer therapy.

J Endocrinol \& Metabol 86 (7): 3327-35

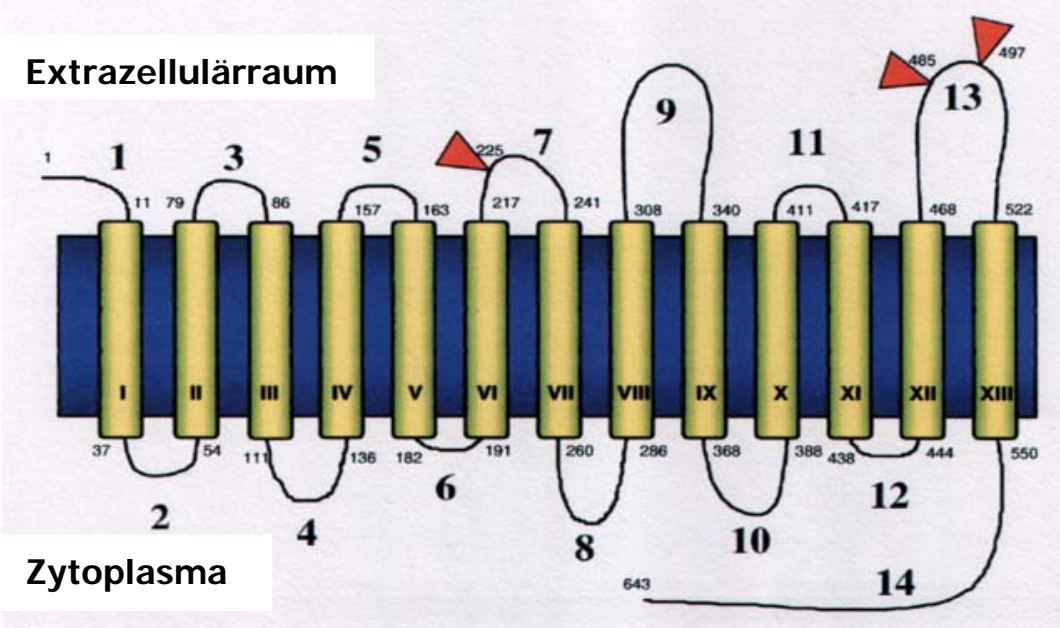

$$
\begin{aligned}
& 1=\text { Sequenznummern } \\
& \mathbf{I}=\text { Transmembrandomänen } \\
& \mathbf{1}=\text { ExMembrandomänen } \\
& \triangle=\text { N-verbundener Glykosylierungsort }
\end{aligned}
$$




\subsubsection{Stimulation der funktionellen NJS-Expression}

TSH stimuliert die NJS-Expression über den Adenylatzyklase-cAMP-Weg (10).

Darüber hinaus spielt TSH eine Rolle bei der subzellulären Orientierung von NJS, vor allem beim korrekten Plasma-Membran-Targeting. Von Bedeutung dabei ist die Phosphorylierung des NJS-Proteins über einen Proteinkinase-A-Weg, die über TSH reguliert wird.

Ohne die Anwesenheit von TSH wird NJS von der Zellmembran umverteilt in intrazelluläre Kompartments. Dadurch verliert es die Fähigkeit, Jodid aus der Blutbahn ins Zellinnere zu transportieren. Der Mechanismus, mit dem TSH die subzelluläre Verteilung reguliert, ist nicht bekannt.

NJS besitzt mehrere Bindungsstellen für Kinasen einschließlich der cAMPabhängigen Proteinkinase. Es scheint, dass es sich beim NJS um ein Phosphoprotein handelt, dessen Phosphorylierungstatus durch TSH moduliert wird.

Für die volle Funktionsfähigkeit von NJS spielen die Polarisierung und räumliche Organisation der Follikelzelle eine Rolle (10).

Abbildung 4

Intrazelluläre Signalvermittlung

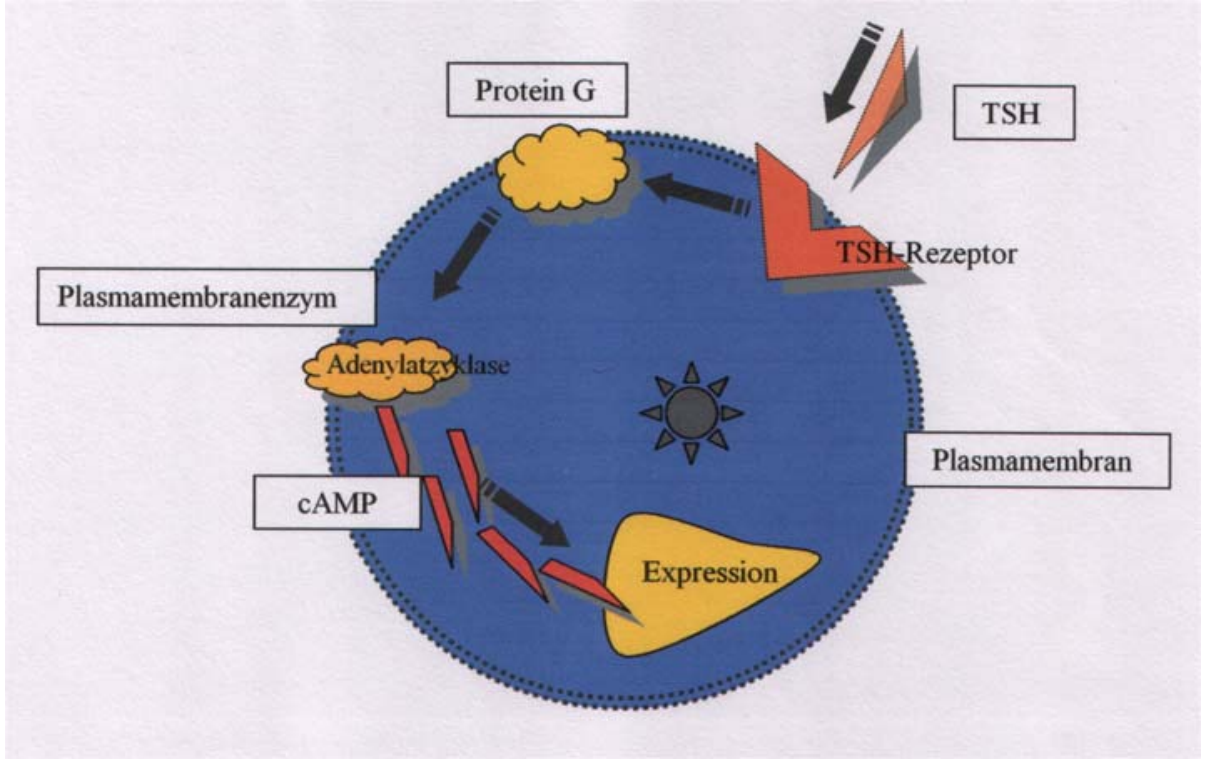




\subsubsection{Hemmung der funktionellen NJS-Expression}

Transforming Growth factor- $\beta 1$ (TGFß1), ein potenter Inhibitor von Wachstum und DNA-Synthese in Schilddrüsenzellen, supprimiert in Thyreozyten die TSHinduzierte NJS-Expression und damit auch die Jodaufnahme (11).

Auch IL-1 $\alpha$ reduziert die NJS-Expression wie auch die Jodaufnahmeaktivität (11).

Des Weiteren supprimiert Thyreoglobulin die TSH-induzierte NJS-PromotorAktivität, die NJS-RNA und Protein-Expression in-vitro sowie die Jodaufnahmeaktivität in-vitro (11).

Furlanetto et al (11) konnten zeigen, dass Östradiol die NJS-RNA-Expression vermindert, was die höhere Strumaprävalenz von Frauen miterklären könnte.

Auch Kaliumjodid supprimiert die NJS-RNA-Expression wie auch die Jodaufnahmeaktivität (11). Der Wolff-Chaikoff-Effekt dürfte mit auf eine DownRegulation von NJS zurückzuführen sein.

\subsubsection{NJS und benigne Schilddrüsenerkrankungen}

In normalem Schilddrüsengewebe zeigt sich eine immunhistochemisch heterogene NJS-Expression, vorwiegend an der basolateralen Membran einzelner Thyreozyten $(12,13)$. In Knotenstrumen findet man ebenfalls eine heterogene NJS-ProteinExpression, allerdings auf einem niedrigeren Niveau als in normalem Schilddrüsengewebe (13).

Szintigraphisch kalte Schilddrüsenknoten mit vermindertem Technetium-Uptake exprimieren NJS-RNA und-Protein vermindert $(14,15)$. In kalten Knoten zeigt sich zudem häufig ein defektes Zellmembran-Targeting des NJS-Proteins, was mitverantwortlich ist für die verminderte Nuklidaufnahme (16). 


\subsubsection{NJS und maligne Schilddrüsenerkrankungen}

Fast alle Schilddrüsenkarzinome weisen eine verminderte bis fehlende Nuklidaufnahme auf, d. h. sie sind szintigraphisch kalt. Die überwiegende Zahl maligner Schilddrüsenläsionen zeigt eine niedrigere NJS-Expression als das umliegende normale Schilddrüsengewebe.

Die NJS-Expression in Schilddrüsenkarzinomen wurde von verschiedenen Arbeitsgruppen untersucht. Smanik et al (17) wiesen eine im Vergleich zu normalem Schilddrüsengewebe deutlich erniedrigte NJS-Expression in papillären, follikulären und anaplastischen Schilddrüsenkarzinomen nach.

Arturi et al (18) fanden in Schilddrüsenkarzinomen eine Verminderung der NJSRNA-Expression (in 40 von 43 Schilddrüsenkarzinomen) sowie in 20 von 24 kalten benignen Knoten.

In Schilddrüsenkarzinomen zeigte sich in dieser Arbeit eine positive Korrelation zwischen der Expression von NJS, TPO, Thyreoglobulin und TSH-Rezeptor. Höhere Tumorstadien waren dabei mit niedrigeren NJS-Expressionsniveaus assoziiert (18).

Über ähnliche Ergebnisse berichteten Ringel et al (18).

Übereinstimmung besteht darin, dass die NJS-Expression bei den meisten Schilddrüsenkarzinomen erniedrigt ist. Des Weiteren zeigt sich in Schilddrüsenkarzinomen eine weniger deutliche basolaterale Orientierung von NJS.

Während follikuläre und papilläre Schilddrüsenkarzinome meist ein erniedrigtes NJS-Protein-Expressionsniveau zeigten, exprimierten anaplastische und onkozytäre Schilddrüsenkarzinome keinerlei NJS-Protein $(12,18,19)$. Das Expressionsniveau des NJS-Proteins korreliert mit dem Differenzierungsgrad des Karzinoms (18). 


\section{Abbildung 5}

Immunhistochemische Analyse der NJS-Expression in thyreoidalen Karzinomen aus:

Dohán O, Baloch Z, Bánrévi Z, Livolsi V, Carrasco N (2001):.

Predominant intracellular overexpression of the $\mathrm{Na}^{+} / J$ symporter (NJS) in a large sampling of thyroid cancer cases.

I Clin Endocrinol 86 (6): 2697-700
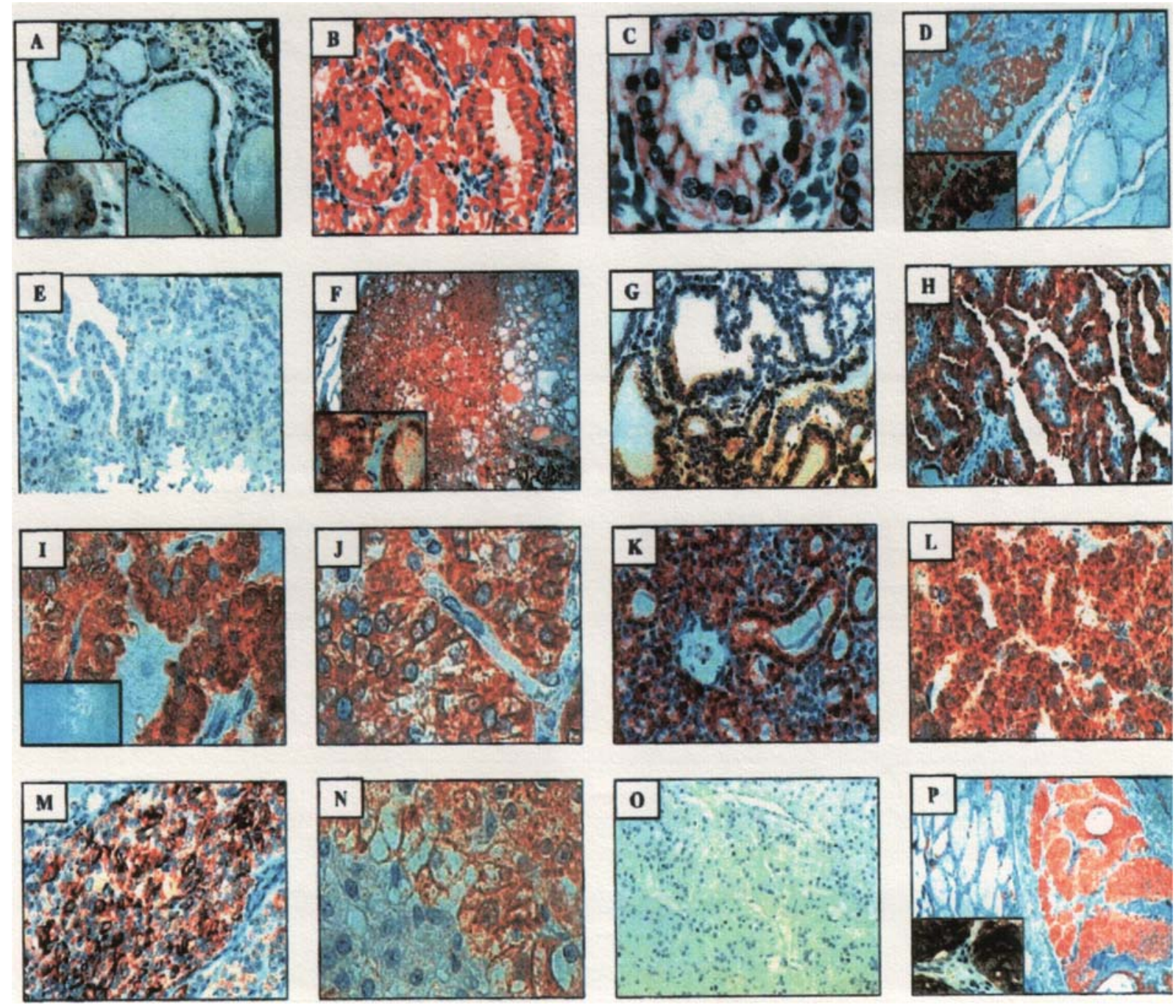


\section{$\underline{\text { Legende }}$}

A: normales Schilddrüsengewebe (Originalvergrößerung 250x, Bildeinsatz 1000x)

B,C: M. Basedowgewebe mit eindeutiger basolateraler Anfärbung (400x und 1000x)

D: $\quad$ Papilläres Karzinom und angrenzendes nicht tumoröses Gewebe kräftige Mehranfärbung im Tumorgewebe (250x und 1000x)

E: $\quad$ Papilläres Schilddrüsenkarzinom - negativ für NJS-Expression (400x)

F: $\quad$ Papilläres Karzinom, follikuläre Variante starke intrazelluläre, homogene Anfärbung (100x und 1000x)

G: Papilläres Karzinom heterogene Anfärbung, apikale Anhäufung/„Clustering” (400x)

H,I: Papilläres Karzinom - starke, meist intrazelluläre Anfärbung (400x und 1000x) Bildeinsatz in I: Immunreaktion durch NJS-Antikörper inhibiert (400x)

J: Papilläres Karzinom eindeutige Plasmamembrananfärbung: 1 von 4 Fällen (1000x)

K,L: Follikuläres Karzinom starke, meist intrazelluläre Anfärbung (400x und 1000x)

M: Follikuläres Karzinom Anhäufung „Cluster” von plasmamembrangefärbten Tumorzellen (400x)

N: Hürthlekarzinom - Membran und intrazelluläre Anfärbung (1000x)

O: $\quad$ Follikuläres Karzinom - negativ für NJS-Expression (400x)

P: $\quad$ Medulläres Karzinom starke, meist intrazelluläre Abfärbung und angrenzend „normales” extratumoröses Gewebe (originale Vergrößerung 100x, Bildeinsatz 1000x) 
Die Abnahme der NJS-Expression in Schilddrüsenkarzinomen geht einher mit einer verminderten TSH-Rezeptor-Expression. Da das TSH einen wichtigen Stimulationsfaktor für die NJS-Expression darstellt, könnte die verminderte TSHRezeptor-Expression mitverantwortlich sein für die verminderte NJS-Expression in Schilddrüsenkarzinomen (18).

Ein Vergleich der Radiojod-Aufnahme mit der NJS-Protein-Expression in Schilddrüsenmalignomen und ihren Metastasen zeigte eine deutliche positive Korrelation zwischen Nuklidaufnahme und NJS-Protein-Expression (18).

Eine neuere Arbeit (20) berichtete, dass eine Metastasierung nur in papillären Schilddrüsenkarzinomen ohne nachweisbare NJS-Protein-Expression auftrat.

Auch Rezidivtumoren traten nur bei Patienten mit differenzierten Schilddrüsenkarzinomen ohne NJS-Protein-Expression auf.

Aus den Ergebnissen kann geschlossen werden, dass eine nachweisbare NJSExpression in differenzierten Schilddrüsenkarzinomen mit einer günstigeren Prognose assoziiert ist (20).

Noch ungeklärt ist, über welche Mechanismen im Tumorgewebe die NJSExpression beeinflusst wird. NJS-Genmutationen konnten in Schilddrüsenkarzinomen bisher nicht nachgewiesen werden. Untersuchungen an onkogen transformierten Rattenthyreozyten mit verminderter NJS-RNA-Expression lassen vermuten, dass die Aktivierung von Onkogenen in Schilddrüsenkarzinomzellen über noch unbekannte Mechanismen eine Suppression der NJS-Expression bewirkt (18).

Im Gegensatz zu den oben aufgeführten Studien fanden Saito et al bei papillären Schilddrüsenkarzinomen bei ca. $50 \%$ der Tumoren eine signifikant erhöhte NJSExpression (3). Ähnliches berichteten Dohan et al (3). In beiden Untersuchungen konnte eine deutliche Umverteilung des NJS-Proteins weg von der Plasmamembran hin zu intrazellulären Kompartments gefunden werden. 
Diese Ergebnisse lassen auf ein defektes Membran-Targeting des NJS-Proteins im Rahmen der malignen Transformation schließen und einen resultierenden Funktionsverlust des NJS-Proteins. Dieses würde auch die fehlende Nuklidaufnahme in differenzierten Schilddrüsenkarzinomen erklären trotz teils erhöhter NJS-Protein-Expression bei einem Teil der Malignome (18). 


\section{2 Ätiologie und Pathogenese der Bildung von Schilddrüsenknoten}

\subsubsection{Jodmangel und Strumabildung}

\subsubsection{Autokrine und parakrine Wachstumsfaktoren}

In einer normalen Schilddrüse wird die Gesamtzellzahl konstant gehalten durch ein Gleichgewicht zwischen Zellproliferation und Apoptose (21). Daher findet sich in einer normalen Schilddrüse eine sehr geringe Expression von Wachstumsfaktoren, Wachstumsfaktor-Rezeptoren, Protoonkogenen und Apoptose-assoziierten Proteinen $(22,23)$.

\section{IGF1 (Insulin-like-growth-factor)}

Wachstumsfaktoren werden von den Thyreozyten selbst gebildet. Als wichtigster Wachstumsfaktor wurde IGF1 identifiziert. Ohne ihn findet kein Zellwachstum statt. In der Schilddrüsenzelle wird IGF1 reguliert durch TSH bzw. cAMP, den ,second messenger" des TSH.

Die TSH-abhängige IGF1-Expression ist abhängig vom intrathyreoidalen Jodgehalt. Durch Jod kann die IGF1-Bildung dosisabhängig vermindert bis ganz blockiert werden.

Jodmangel dagegen stimuliert die Zellproliferation in der Schilddrüse, da IGF1 vermehrt exprimiert wird. Über den Weg des zyklischen cAMP kann TSH die IGF1Freisetzung steigern, allerdings nur im Zustand des Jodmangels. Eine ausreichende Jodversorgung der Thyreozyten blockiert die IGF1-Expression und TSH kann in dieser Situation keinen wachstumsfördernden Effekt ausüben. 
Insbesondere unter den Bedingungen des Jodmangels jedoch ist eine TSHStimulation assoziiert mit einer vermehrten Expression von Wachstumsfaktoren, ihren Rezeptoren und Protoonkogenen:

vermehrte Expression von IGF1, des ras-Genprodukts p21 sowie des Gs $\alpha$-Proteins $(24,25,26)$.

Die Expressionsmuster dieser wachstumsassoziierten Proteine sind meist sehr heterogen sowohl innerhalb von polyklonalen wie auch innerhalb von klonalen Schilddrüsenknoten.

Jodmangel stellt einen chronischen Proliferationsreiz dar und steigert offenbar auch die Mutationsrate und verstärkt die klonale Proliferation einer mutierten Einzelzelle. Dokumentiert ist dieses in autonomen Adenomen mit aktivierenden Mutationen des TSH-Rezeptors und gelegentlich auch des Gs $\alpha$-Proteins.

Ein Zusammenhang zwischen Jodmangel und der Entwicklung einer malignen Transformation einer Follikelzelle ist nicht belegt.

Allerdings findet man in Jodmangelgebieten häufiger prognostisch ungünstigere Schilddrüsenkarzinome, so dass sich der andauernde Proliferationsreiz durch den Jodmangel offenbar auf bereits bestehende Tumorzellen ungünstig im Sinne einer Dedifferenzierung auswirkt.

\section{EGF (Epidermal growth factor)}

Im Gegensatz zu IGF1 stellt EGF einen entdifferenzierenden Wachstumsfaktor dar, der in-vitro alle spezifischen Funktionen der Thyreozyten hemmt. In-vivo wird EGF allerdings vorwiegend von malignen und nicht von beningen Schilddrüsenknoten exprimiert.

\section{TGF $\beta$ (Transforming growth factor $\beta$ )}

Dieser Faktor ist der einzige inhibierende Wachstumsfaktor. Er hemmt die Stimulation des Thyreozytenwachstums. Während der Thyreozyten- und Follikelproliferation wird er vermehrt exprimiert. Man vermutet eine Kontrollfunktion gegen überschießendes Schilddrüsenwachstum. 


\subsubsection{Jodlipide}

In der Zellwand sind ungesättigte Fettsäuren in großer Menge vorhanden: Arachidonsäure, Eicosapentaensäure und Dicosahexaensäure. Bei ausreichender Jodversorgung sind diese Fettsäuren jodiert und werden als Jodlaktone bezeichnet. Die Jodierung wird durch Peroxidasen katalysiert.

Grundsätzlich werden $\delta$ - und $\gamma$-Laktone unterschieden.

Ausschließlich die $\delta$-Laktone hemmen die Proliferation von Thyreozyten.

Die $\delta$-Laktone der Eicosapentaensäure gelten als die effektivsten Inhibitoren des Wachstums. Jodlaktone besitzen keinen Effekt auf die TSH-induzierte Wirkung des cAMP.

Ihre spezifische Wirkung beruht auf der Phospholipase C-vermittelten Signaltransduktion. Vermutet wird eine Interaktion der $\delta$-Laktone an oder proximal der Aktivierung der Phospholipase C durch Tyrosinkinase-Rezeptoren.

Durch Jodmangel kommt es zu einer verminderten Bildung von $\delta$-Jodlaktonen. Damit wird die Hemmung des Thyreozytenwachstums durch die Jodverbindungen aufgehoben.

Gleichzeitig führt der Jodmangel zu einer vermehrten Expression des Wachstumsfaktors IGF1. Die Folge ist eine vermehrte Proliferation des Schilddrüsengewebes.

Die Strumagenese ist somit zurückzuführen auf ein gestörtes Gleichgewicht zwischen proliferationshemmenden Wirkungen der $\delta$-Jodlaktone und der stimulierenden Wirkung lokaler Wachstumsfaktoren (insbesondere IGF1).

Eine retrospektive Studie (27) konnte einen signifikanten inversen Zusammenhang zeigen zwischen der Serumkonzentration ungesättigter Fettsäuren und dem Schilddrüsenkarzinomrisiko. In dieser Studie wird ein möglicher Zusammenhang zwischen dem Jodlakton-Mechanismus und Schilddrüsenkarzinomhemmung diskutiert. 
Als einer von zahlreichen Faktoren bei der Entwicklung von Schilddrüsenneoplasien werden Proteinkinase-C-Mutationen (28) ins Spiel gebracht. Die Hemmung der Phosphatidylinositol-Kaskade und damit der PKC durch Jodlaktone besitzt möglicherweise einen Einfluss auf die Tumorentstehung. In diesem Zusammenhang sind jedoch weitere Studien erforderlich. 


\subsubsection{Klonalität von Schilddrüsenknoten}

Histopathologisch lassen sich Schilddrüsenadenome, die von einer Kapsel umgeben sind, abgrenzen von oft nicht gekapselten, hyperplastischen, oft sehr heterogenen Schilddrüsenknoten.

Neuere Klonalitätsanalysen $(33,34)$ haben gezeigt, dass nicht nur Schilddrüsenadenome, sondern auch andere Strumaknoten nicht selten klonal sind.

Klonale Schilddrüsenknoten haben ihren Ursprung in einer Einzelzelle, die durch eine Sequenz von Mutationen oder andere genetische Alterationen eine Veränderung erfährt, die dieser Ursprungszelle einen Wachstumsvorteil gegenüber den Nachbarzellen verleiht (29).

Kopp et al (30) konnten zeigen, dass in einer Knotenstruma verschiedene klonale Knoten und auch polyklonale Knoten nebeneinander nachweisbar sind.

$\mathrm{Da}$ viele Schilddrüsenknoten klonaler Herkunft sind, müssen die großen Unterschiede in der Morphologie der Knoten auf sekundäre molekulare Mechanismen zurückzuführen sein, die ursprünglich homogene Knoten in heterogene, polymorphe Knoten umwandeln $(31,34)$.

Bei Nachweis eines sehr homogenen Knotens kann man allerdings in der Regel von einem klonalen Ursprung ausgehen.

In einem Jodmangelgebiet kommt es nach Jahren und Jahrzehnten fortbestehender chronischer Wachstumsstimulation zur Entstehung von polyklonalen Strumaknoten und klonalen Adenomen.

Aber auch in Regionen mit ausreichender Jodversorgung bilden sich nicht selten Schilddrüsenknoten. Bei der Entstehung dieser meist solitären Knoten spielt der Jodmangel in der Pathogenese keine Rolle. Im Vordergrund stehen molekulare Alterationen in einer ansonsten normal großen Schilddrüse. 


\subsubsection{Heterogenität des Schilddrüsenwachstums}

Schilddrüsenzellen, wie auch die Gewebe anderer Organe des Körpers, weisen eine natürliche Heterogenität des Wachstums und der Funktion auf (22).

Tabelle 1

Beispiele für die Heterogenität verschiedener Funktionen und des Wachstums in der Schilddrüse (mod. nach Studer und Derwahl, 1995 [22])

Bei der Zellteilung werden die individuellen Eigenschaften der Einzelzelle weitergegeben an die Tochterzellen. In der Schilddrüse entwickeln sich so Areale, die in Bezug auf Morphologie, Wachstum und Funktion zunehmende Unterschiede aufweisen können. Die interzelluläre Heterogenität scheint wesentlich an der Entstehung der Heterogenität in der Schilddrüse beteiligt zu sein (22).

Die normale Schilddrüse weist eine individuell unterschiedliche Heterogenität des Wachstums auf. Jeder Thyreozyt besitzt ein eigenes konstitutives Wachstumspotential, das er an die Tochterzellen vererbt $(32,33)$.

Dieses Konzept der natürlicherweise vorkommenden Heterogenität der einzelnen Schilddrüsenzellen erlaubt eine plausible Erklärung der Pathogenese der Knotenstruma. Allerdings sind die molekularen Mechanismen noch nicht im Einzelnen bekannt. 
In einer wachsenden Struma liegt in der Regel ein sehr langwieriger, langsamer Wachstumsprozess vor. Erst durch unphysiologische Wachstumsstimulation, wie z.B. durch Jodmangel oder durch molekulare Alterationen, können geringe Unterschiede im physiologischen Wachstumsverhalten zur Hyperplasie oder zu Knoten führen.

Dieser Prozess dauert wegen der letztlich nicht sehr großen Unterschiede zwischen schneller und weniger schnell proliferierenden Thyreozyten meist Jahre oder Jahrzehnte. 


\subsubsection{Molekulare Aspekte in der Pathogenese benigner Schilddrüsenknoten}

Zytogenetische und molekulare Ursachen in der Pathogenese von Schilddrüsenknoten sind erst in ihren Grundzügen bekannt. Sie stimulieren das klonale Wachstum einzelner Zellen, was schließlich zur Entstehung klonaler Schilddrüsentumoren führt.

Grundsätzlich werden drei verschiedene Veränderungen unterschieden (34):

1. Überexpression von Wachstumsfaktoren und ihren Rezeptoren

2. Überexpression und mutationelle Aktivierung von Signalproteinen

3. Veränderungen innerhalb der TSH-Rezeptor-abhängigen Signalübertragung

Mit zunehmendem Lebensalter kommt es, insbesondere unter den Bedingungen einer chronischen Stimulation, zu chromosomalen Aberrationen mit der Folge einer „genomischen” Instabilität (34). Es wird vermutet, dass diese chromosomalen Veränderungen mitverantwortlich sind für die Überexpression von wachstumsassoziierten Proteinen in Strumaknoten.

Es gibt experimentelle Hinweise (35), dass diese Überexpression bedingt sein kann durch

a) eine Genamplifikation

b) Alterationen in den regulatorischen Regionen des Gens

c) eine veränderte Interaktion mit Transskriptionsfaktoren

Allerdings ist die Entstehung von Strumaknoten und Adenomen nicht nur zurückzuführen auf eine Überexpression von Protoonkogenen, Wachstumsfaktoren und ihren Rezeptoren.

Vermutlich spielen auch lokal unterschiedlich wirksame wachstumsstimulierende Mutationen eine Rolle in der Pathogenese benigner Knoten. 
Das Konzept der „konstitutiven zellulären Wachstumsheterogenität” (36) erklärt, warum einzelne Zellgruppen infolge ihres stärkeren Wachstums Knoten bilden, während benachbarte Zellen kein oder nur ein geringes Wachstum zeigen.

Zellen mit einem erhöhten Wachstumspotential besitzen kürzere Wachstumsintervalle und weisen damit höhere Wachstumsraten auf. Jede Stimulation verstärkt den Proliferationsvorteil dieser privilegierten Zellen weiter. Die kürzere Verdopplungszeit dieser Zellen begünstigt das Auftreten unterschiedlicher Mutationen. Am Ende dieser Entwicklung entstehen schließlich aus derartigen protegierten Zellen Schilddrüsentumoren (34).

In klonalen Knoten können dann durch sekundäre molekulare Mechanismen polymorphe Knoten entstehen. 


\subsubsection{Molekulare Aspekte in der Pathogenese maligner Schilddrüsenknoten}

Krebs stellt eine genetische Erkrankung dar, die gekennzeichnet ist durch eine Akkumulation unterschiedlicher genetischer Veränderungen im Genom der Tumorzelle.

Karzinome sind letztlich die Folge einer Deregulation von Genen, die für die Kontrolle des Zellwachstums von zentraler Bedeutung sind.

Typischerweise finden sich nicht nur in der Initialphase der Tumorentwicklung, sondern auch in der Progression des Tumors unterschiedliche genetische Mutationen.

Nur in wenigen Ausnahmefällen konnten hingegen in differenzierten Schilddrüsenkarzinomen mehr als eine genetische Alteration als vermutlicher Mitursache einer malignen Transformation nachgewiesen werden. Für die Karzinomentstehung ist jedoch nach heutigem Wissen eine Akkumulation unterschiedlicher genetischer Veränderungen im Genom der Tumorzelle erforderlich. Es ist daher zu vermuten, dass die für die Entwicklung von differenzierten Schilddrüsenkarzinomen relevanten molekulargenetischen Veränderungen noch nicht gefunden worden sind.

Dennoch spielen wie auch bei Karzinomen anderer Organe Onkogene und inaktivierte Tumorsuppressorgene eine wesentliche Rolle bei der Transformation einer Follikelzelle in eine Schilddrüsenkarzinomzelle.

\section{Onkogene}

Ein Onkogen entsteht aus seiner inaktiven Vorstufe, dem Protoonkogen. Jedes Onkogen kodiert ein Protein, das im komplexen Netzwerk der Signaltransduktion eine Rolle spielt.

Viele Protoonkogene sind beteiligt an der Regulation des Zellwachstums bzw. der Zellteilung. Sie sind als Schlüsselgene für die Transduktion physiologischer Signale vom Zelläußeren zum Zellkern verantwortlich. 
Folge einer Protoonkogen-Mutation zum Onkogen ist die konstitutive Anschaltung eines Signaltransduktionsweges, auch wenn kein exogenes Wachstumssignal vorliegt.

Eine zentrale Rolle kommt hierbei der Phosphorylierung zu. Es wird geschätzt, dass bei der Signalvermittlung mehr als 2000 Proteinkinasen beteiligt sind, die Phosphatgruppen von ATP auf die Aminosäuren Tyrosin, Serin oder Threonin übertragen (31).

Eine derartige Phosphorylierungsreaktion kann die enzymatische Aktivität des betreffenden Proteins induzieren und eine Kaskade nachgeschalteter Signalmediatoren aktivieren.

Auf der anderen Seite werden durch die Phosphorylierung von Tyrosin auch Konfirmationsänderungen im Protein selbst bewirkt, wodurch Andockstellen für andere Proteine geschaffen werden. Auf diese Weise kann es zu einer vorübergehenden Rekrutierung von Proteinkomplexen kommen, die z. B. die Innenseite der Zellmembran in ihrer Funktion modulieren.

Eine andere Gruppe von Onkogen-Proteinen ist im Zellkern lokalisiert und bindet an spezifische DNA-Sequenzen. Diese Onkogen-Proteine fungieren als Transskriptionsfaktoren. Zu den bekanntesten gehört MYC. Dieses Onkoprotein spielt eine zentrale Rolle bei der Regulation der Zellproliferation. Es kann wachstumsstimulierende Signale vermitteln, aber auch bei Bedarf genetische Programme aktivieren, die zu Wachstumsstillstand oder Apoptose führen.

Eine Deregulation des Transkriptionsfaktors MYC im Sinne einer Onkogenaktivierung findet sich in unterschiedlichen Tumoren, unter anderem auch in differenzierten Schilddrüsenkarzinomen.

Die Umwandlung eines Protoonkogens in ein Tumorgen (Onkogen) kann über verschiedene Mechanismen erfolgen. Nicht selten kommt es durch eine aktivierende Punktmutation zur Bildung des Onkogens aus seinem Protoonkogen.

Die Aktivierung zum Onkogen kann aber auch durch Genrekombinationen im Rahmen chromosomaler Translokationen zustande kommen, so dass es zu einer Überexpression des Protoonkogens kommt, das damit zum Onkogen wird. 


\section{RAS}

Die Familien der „ras-Protoonkogene” (H-ras, K-ras, N-ras) stellen wichtige Schaltpunkte der intrazellulären Signalwege dar. Ein extrazelluläres Signal (z. B. ein Wachstumsfaktor als Ligand) aktiviert über den membranständigen TyrosinKinase-Rezeptor das kleine G-Protein „Ras”.

Die aktive Form des Ras-Proteins (Ras-GTP) ist in einen Multiproteinkomplex integriert, der durch die Aktivierung des Tyrosin-Kinase-Rezeptors induziert worden ist.

Die Aktivierung des G-Proteins Ras durch den ligandenstimulierten TK-Rezeptor führt zur schrittweisen und nacheinander ablaufenden Aktivierung von drei zytoplasmatischen Proteinkinasen.

Schließlich werden im Zellkern spezifische Transkriptionsfaktoren phosphoryliert und damit aktiviert. Diese wiederum aktivieren unter anderem Gene, die die Zellteilung steuern (z. B. den Übergang von der G1-Phase in die S-Phase).

Diese kaskadenartige Aktivierung stellt eine der wichtigsten Signalwege der Zelle zur Regulierung der Zellteilung dar.

Um eine Daueraktivierung der Zelle durch das Ras-Protein zu verhindern, wird der aktive Ras-GPT-Komplex in den inaktiven Ras-GDP-Komplex umgewandelt. Dadurch wird die beteiligte Signalkaskade wieder abgeschaltet.

In Tumorzellen findet man häufig unterschiedliche Mutationen von Ras, die letztlich zu einer Daueraktivierung des aktivierten Ras-GTP-Komplexes führen.

Häufig wird dabei durch die Mutation eine Inaktivierung von Ras verhindert. So sind viele Mutationen in der GTP-Bindungstasche des Ras-Proteins lokalisiert und beeinträchtigen so die enzymatische Aktivität der GTP-Spaltung und verhindern somit eine Inaktivierung des Ras-Proteins.

Ras-Protoonkogen-Mutationen finden sich in ca. $30 \%$ der humanen Tumoren. Punktmutationen der „ras-Protoonkogene” wurden sowohl in benignen (vor allem in mikrofollikulären Adenomen) als auch malignen Schilddrüsentumoren (insbesondere bei follikulären Schilddrüsenkarzinomen) gefunden. 
Ein erhöhter Nachweis von „ras-Protein bzw. RNA” per se ist somit kein sicherer Marker für eine maligne Entartung der Thyreozyten.

Rearrangements der „ras-Protoonkogene” sind ebenfalls nicht spezifisch für Schilddrüsenkarzinome.

\section{RET}

Das „RET-Protoonkogen” ist auf dem Chromosom 10q lokalisiert und findet sich nur in den parafollikulären C-Zellen, nicht jedoch in Thyreozyten.

Das Protoonkogen ist am Zellwachstum und an der Zelldifferenzierung beteiligt.

Es kodiert einen spezifischen Tyrosinkinase-Rezeptor, der eine Rolle spielt in der neuronalen Differenzierung und er wird häufig in neuroendothelialen Tumoren überexprimiert.

RET-Rearrangements finden sich gehäuft in spontan entstandenen, sporadischen papillären Schilddrüsenkarzinomen (5 bis $30 \%$ ). Nach Strahlenbelastung nehmen diese RET-Rearrangements deutlich zu.

Nach dem Reaktorunfall von Tschernobyl traten bei Kindern in Weißrussland gehäuft RET/PTC 3 -Mutationen auf (in ca. 85 \% der Fälle) mit der Folge eines papillären Schilddrüsenkarzinoms.

Die resultierenden RET/PTC-Onkogene sind das Ergebnis einer Fusion der Tyrosinkinasedomäne des RET-Protoonkogens mit verschiedenen anderen Gensequenzen. Die Folge ist die atypische Expression eines Hybridproteins und damit die konstitutive Aktivierung der entsprechend translozierten ret-Tyrosinkinasedomänen.

Eine Studie von Unger et al aus dem Jahre 2004 (47) untersuchte 32 Patienten, die 20 Jahre nach dem Ereignis von Tschernobyl in Kiew operiert worden waren.

Es fanden sich 29 papilläre Karzinome und 1 follikuläres Karzinom. Bei 2 Tumoren handelte es sich um follikuläre Adenome.

Bei 23 von 32 Patienten (72\%) wurden RET/PTC-Rearrangements nachgewiesen. In allen Fällen fand sich eine Mischung aus Zellen, die positiv für RET/PTC waren und anderen Tumorzellen, die diesen Marker nicht aufwiesen. 
Diese intratumorale genetische Heterogenität wurde bei Schilddrüsenkarzinomen und auch anderen soliden Tumoren bereits nachgewiesen (47).

Diese Tatsache lässt vermuten, dass die Entwicklung dieser Tumoren nicht nur auf einem uniklonalen Ursprung beruht, sondern dass in der Regel die Tumorentwicklung wesentlich komplexer ist und ein multifaktorielles Geschehen darstellt.

Das RET-Protoonkogen besitzt auch eine Schlüsselrolle in der Karzinogenese des medullären Schilddrüsenkarzinoms. In $95 \%$ der MEN 2A-Familien und in 85-90 \% der Familien mit einem familiären medullären Schilddrüsenkarzinom ohne Beteiligung weiterer Organe werden aktivierende Keimbahnmutationen des RETProtoonkogens gefunden.

Bei einem Teil der sporadischen medullären Schilddrüsenkarzinome werden aktivierende somatische Mutationen des RET-Protoonkogens gefunden.

\section{PAX-8 / PPAR $\gamma$}

Auch beim follikulären Schilddrüsenkarzinom wurden in neueren Untersuchungen erstmals spezifische chromosomale Translokationen gefunden $(37,38)$.

Es kommt dabei zur Bildung eines Fusionsproteins aus der DNA-bindenden Domäne des Schilddrüsentransskriptionsfaktors PAX-8 und des PeroxisomeProliferator-Activated-Receptor- $\gamma 1$ (PPAR $\gamma 1)$.

PPAR $\gamma 1$ sind nukleäre Hormonrezptoren, die eine Rolle in der Zelldifferenzierung spielen. Der Rezeptor stellt einen Schlüsselfaktor in der Regulation der Differenzierung von Fettzellen dar. In der Schilddrüse wird normalerweise das PPAR $\gamma$-Protein nur im geringen Maße exprimiert. Weshalb PPAR $\gamma$ in follikulären Schilddrüsenkarzinomen exprimiert wird, ist noch nicht geklärt.

In einer Studie von Kroll et al (49) aus dem Jahre 2000 fanden sich bei 5 von 8 follikulären Schilddrüsenkarzinomen PAX-8/PPAR $\gamma$-Rearrangements, nicht jedoch bei follikulären Adenomen (0/20), papillären Karzinomen (0/10) und in benignen Knoten (0/10). 
Es handelt sich hierbei um die erste Beschreibung eines spezifischen Markers für das follikuläre Schilddrüsenkarzinom.

Ob PAX-8/PPAR $\gamma$-Rearrangements valide Marker für das follikuläre Schilddrüsenkarzinom darstellen, müssen weitere Untersuchungen zeigen.

\section{Tumorsuppressorgene}

Tumorsuppressorgene bzw. ihre Genprodukte hemmen die Zellproliferation.

Erst durch die Inaktivierung bzw. den Verlust beider Allele kommt es zu einer neoplastischen Transformation der Zelle.

Das häufigste bei menschlichen Neoplasien von Deletionen oder Mutationen betroffene Tumorsuppressorgen ist das p53-Gen. Es hat den Beinamen „Guardian of the genome".

Es kodiert für ein Kernprotein, das die Expression des CDK-Inhibitor P21 und somit den G1/S-Übergang des Zellzyklus reguliert.

DNA-Schäden können zur Anreicherung potentiell gefährlicher Mutationen unterschiedlichster Gene führen und so zu einer Transformation von Zellen beitragen.

Die Inaktivierung des Tumorsuppressorgens würde proliferative Signale direkt in den Zellzyklus weiterleiten und damit die Transformation von Zellen entscheidend begünstigen.

Um diese Entwicklung zu verhindern, wird p53 nach genomischem Stress hochreguliert und ein adäquates Schutzprogramm in Gang gesetzt.

P53 ist in über $50 \%$ aller menschlichen Malignome inaktiviert.

Auch in Schilddrüsenkarzinomen finden sich p53-Mutationen. Die Inzidenz steigt mit dem Grad der Dedifferenzierung des Karzinoms. In differenzierten Schilddrüsenkarzinomen und in C-Zell-Karzinomen kommen p53-Mutationen üblicherweise nicht vor. In undifferenzierten Schilddrüsenkarzinomen (anaplastische Schilddrüsenkarzinome) beträgt der Anteil der p53-Inaktivierungen über $40 \%$. 


\section{Maligne Transformation}

Die Entwicklung der malignen Transformation einer Follikelzelle beginnt vermutlich damit, dass zu einem relativ frühen Zeitpunkt eine Einzelzelle gegenüber Nachbarthyreozyten einen Wachstumsvorteil erwirbt, z. B. durch eine Onkogenaktivierung, was zu einer klonalen Expansion dieser protegierten Zelle führt.

Diese Onkogenaktivierung muss jedoch keineswegs $\mathrm{zu}$ einer malignen Entartung dieses Zellklons führen. Aus dem klonalen Zellverband kann sich ein follikuläres Adenom entwickeln, jedoch auch ein follikuläres oder ein papilläres Schilddrüsenkarzinom.

Durch weitere, zum Teil noch nicht im Einzelnen aufgedeckte genetische Veränderungen kommt es schließlich zu einer Ausbildung eines malignen Subklons innerhalb des in der Regel langsam wachsenden Knotens.

Beim differenzierten Schilddrüsenkarzinom muss es sich somit nicht zwangsläufig um einen monoklonalen Tumor handeln. Es kann auch bereits ein polyklonaler Tumor vorliegen. Dieses gilt in besonderem Maße für die undifferenzierten Schilddrüsenkarzinome.

Im Laufe der weiteren Dedifferenzierung des Schilddrüsenkarzinoms kommt es zu einer fortschreitenden chromosomalen Instabilität. Hierzu gehört insbesondere der Verlust oder aber die Verdopplung von Chromosomen oder von Chromosomenteilen auf denen „,kritische Gene” liegen.

Damit kommt es zur Entwicklung weiterer maligner Subklons mit zunehmender Dedifferenzierung, verbunden mit einer progredienten Aggressivität.

Bei diesen zunehmend dedifferenzierten Neoplasien handelt es sich somit nicht mehr um einen homogenen Klon identischer Zellen, sondern um eine Ansammlung verschiedenster Subklone, die sich zum Teil von ihrer Ursprungszelle im genetischen Sinne deutlich entfernt haben (polyklonale Karzinomzellen).

Verschiedene Untersuchungen haben deutliche Hinweise dafür gegeben, dass die chromosomale Instabilität mit einer Tumorprogression assoziiert ist (50, 51, 52, 53). 
Die gelegentlich zu beobachtende Progression lange bestehender papillärer und follikulärer Schilddrüsenkarzinome hin zum wenig differenzierten Tumor und schließlich zum entdifferenzierten anaplastischen Schilddrüsenkarzinom ist eine Bestätigung für einen zwar langsam ablaufenden aber dennoch dynamischen Prozess genetischer Alterationen in bestehenden differenzierten Schilddrüsenkarzinomen.

Nach den bisher vorliegenden Untersuchungsergebnissen spielen in der Entwicklung differenzierter Schilddrüsenkarzinome in erster Linie unterschiedliche Onkogenaktivierungen eine ursächliche Rolle. Supprimierte Tumorsuppressorgene wurden hingegen bei diesen Karzinomtypen nicht gefunden. Auch chromosomale Veränderungen größeren Umfangs ließen sich ebenfalls nicht belegen.

In anaplastischen Schilddrüsenkarzinomen dagegen bestehen neben unterschiedlichen Onkogenaktivierungen auch gehäuft stillgelegte Tumorsuppressorgene mit ausgeprägten chromosomalen Veränderungen (Deletionen oder aber zusätzliches genetisches Material, die „kritische Gene” enthalten).

Der Verlust von Tumorsuppressorgenen ist vermutlich zumeist nicht Folge einer Mutation, sondern das Ergebnis von den ausgedehnten chromosomalen Deletionen $(50,51,52,53)$.

Die Frage, ob sich aus mikrofollikulären Adenomen auch follikuläre Karzinome entwickeln können, ist derzeit noch offen. Im Gegensatz zur bereits durch molekulargenetische Untersuchungen belegten Adenom-Karzinom-Sequenz beim Colon-Karzinom steht der Beweis beim follikulären Schilddrüsenadenom noch aus. Nach den derzeitigen Vorstellungen der malignen Transformation einer Zelle ist bei einem Teil der follikulären Karzinome die Entwicklung aus einem klonalen follikulären Adenom mit bereits bestehenden genetischen Alterationen (Onkogenaktivierungen) durchaus zu vermuten.

Ein Hinweis für diese Hypothese könnte die Tatsache sein, dass „Ras-OnkogenMutationen" sowohl in benignen follikulären Adenomen als auch in follikulären Schilddrüsenkarziomen gefunden werden. 
Die Ras-Onkogen-Aktivierung stellt offenbar einen wichtigen Schritt in Richtung Tumorentwicklung dar, ohne dass diese bereits zu einer malignen Transformation führen muss.

Möglicherweise sind weitere, zurzeit noch nicht bekannte genetische Veränderungen notwendig, damit sich im noch benignen Tumor ein maligner Subklon herausbildet, der sich zum follikulären Karzinom entwickelt.

Dem Jodmangel kommt offenbar eine gewisse Bedeutung bei der Entwicklung von Schilddrüsenkarzinomen zu. Als Ursache wird der andauernde Proliferationsreiz durch den Jodmangel vermutet.

In Jodmangelgebieten finden sich vermehrt wenig bis undifferenzierte Schilddrüsenkarzinome.

In diesen Regionen ist zudem der Anteil follikulärer Schilddrüsenkarzinome relativ hoch (bei ca. $40 \%$ ). Nach Ausgleich des Jodmangels sinkt die Inzidenz auf 10 bis $20 \%$. 
Abbildung 6

„multiple hit”- Modell der Karzinogenese (38)

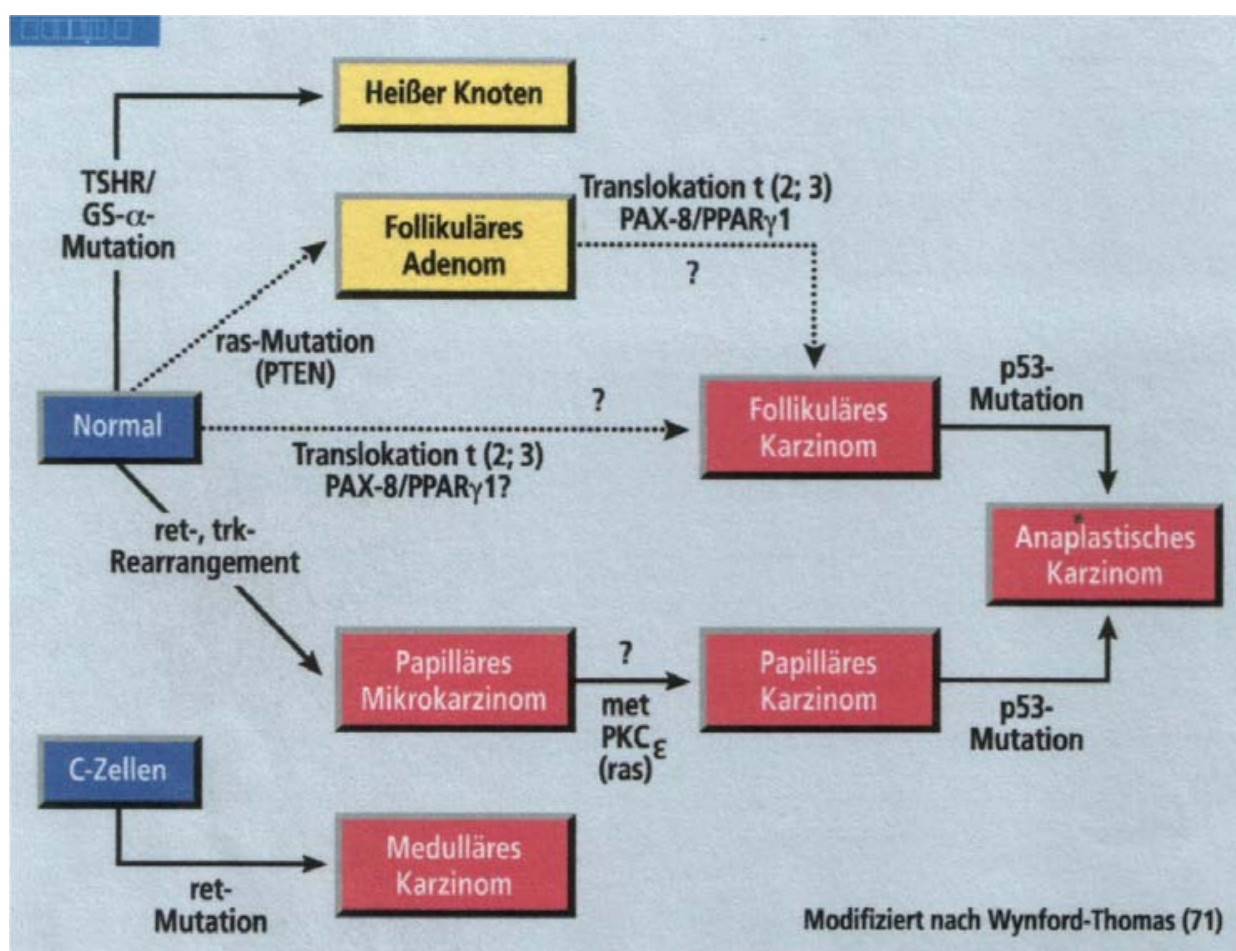

Modell der molekularen Pathogenese epithelialer Schilddrüsentumoren. Die Zuordnung der einzelnen Kandidatengene zu spezifischen Schilddrüsenpathologien ist nicht ausschließend, vor allem ras-Mutationen sind neben follikulären Neoplasien auch in multinodösen Strumen sowie bei papillären Schilddrüsenkarzinomen beschrieben.

Für die vielfach postulierte Sequenz vom follikulären Adenom zum Karzinom gibt es bislang keine eindeutigen Hinweise.

Die funktionelle Relevanz der kürzlich in follikulären Karzinomen erstmals beschriebenen PAX-8/PPAR $\gamma 1$-Translokationen ist noch offen. Das „multiple hit”- Modell der Karzinogenese impliziert neben den bekannten genetischen Defekten auch bei differenzierten Schilddrüsenkarzinomen weitere, derzeit noch nicht identifizierte molekulare Veränderungen (38). 


\subsection{Zytologie benigner und maligner Schilddrüsenknoten}

\subsubsection{Zytologie von Schilddrüsenknoten - allgemeine Aspekte}

Enthält ein Ausstrichpräparat reichlich diffus verteiltes Kolloid, liegt in der Regel eine benigne Schilddrüsenläsion vor. Bei einer Punktion kann jedoch neben dem eigentlichen Tumorgewebe auch normales kolloidhaltiges Schilddrüsengewebe miterfasst werden, so dass auf dem Präparat trotz des Vorliegens eines kolloidarmen Schilddrüsenkarzinoms dennoch Kolloid vorhanden sein kann. Diagnostisch verwirrend kann ein solches Zellbild bei einem mikrofollikulären Schilddrüsenkarzinom sein, da Malignitätskriterien fehlen und definitionsgemäß die Bedingungen für die Diagnose einer follikulären Neoplasie nicht voll erfüllt sind (siehe 2.3.2.4 sowie 2.3.3.2).

Eine Besonderheit stellt das Kolloid aus Punktaten eines papillären Schilddrüsenkarzinoms dar. Durch die erhöhte Viskosität des Kolloids (Kautschuk-Kolloid) entstehen streifen- oder kugelförmige Partikel, zum Teil mit starker Septierung.

Aus einem proliferierenden Knotengewebe werden in der Regel mehr Zellen aspiriert als aus einem nicht proliferierenden Schilddrüsengewebe. Zudem ist in malignen Tumoren die Zelladhäsion geringer als in benignen Läsionen. Schilddrüsenkarzinome weisen somit zumeist zellreiche Zellbilder auf.

Ringförmige Anordnungen der Follikelzellen, sogenannte follikuläre Formationen, sind typisch für mikrofollikuläre Adenome wie auch für follikuläre Karzinome. Papillenförmige Zellverbände sind ein wichtiger Hinweis auf das Vorliegen eines papillären Karzinoms (weitere zytologische Hinweise siehe 2.5.2.1).

Die Dignität von Tumoren wird in der Zytopathologie vor allem anhand typischer Kernveränderungen beurteilt. 
Als Malignitätskriterien gelten insbesondere eine Verschiebung der KernZytoplasma-Relation zugunsten des Zellkerns, außerdem Kernpolymorphie, prominente Nukleolen sowie atypische Mitosen.

In der Schilddrüsenzytologie stellen die genannten Kriterien .mit Ausnahme atypischer Mitosen jedoch allenfalls einen Hinweis auf eine mögliche maligne Läsion dar, da die genannten Kernveränderungen auch bei benignen Knoten vorkommen können: z. B. in degenerativen Veränderungen oder bei therapeutisch induzierten Hormonsynthesestörungen (z. B. Thyreostatika-Therapie bei Hyperthyreose mit starker Stimulierung der Follikelzellen).

\section{Immunzytologische Diagnostik}

Im Rahmen der Studie, bei der es sich um eine retrospektive Untersuchung handelt, wurde nur in Einzelfällen eine immunzytologische Diagnostik durchgeführt.

$\mathrm{Da}$ diese Untersuchungsmethoden in der Zukunft vermutlich eine größere Bedeutung bekommen werden, soll an dieser Stelle kurz auf den derzeit wichtigsten Marker eingegangen werden.

Es handelt sich hierbei um Galectin-3, ein Protein, dessen Expression während der Zellproliferation, Zelltransformation und Tumorprogression verändert ist.

In der Schilddrüse scheint dessen Nachweis auf Neoplasien beschränkt zu sein (54). Die Ergebnisse einer internationalen Multicenter-Studie (1009 Schilddrüsenpräparate, 226 FNAC) zeigten eine Sensitivität von $99 \%$ und eine Spezifität von 98 \% zur Diskriminierung von benignen und malignen Schilddrüsenknoten (55).

Durch diese neue immunzytologische Methode könnte die Differentialdiagnostik suspekter Schilddrüsenknoten möglicherweise verbessert werden.

Aufgrund einer jüngeren Untersuchung könnte in Zukunft ein weiterer immunhistochemischer Marker in der präoperativen Diagnostik kalter Knoten hilfreich sein. 
Specht et al (56) konnten - in einer allerdings erst kleinen Fallzahl - eine vermehrte COX-2-Expression (Cycloxygenase-2) in differenzierten Schilddrüsenkarzinomen nachweisen (überwiegend papilläre Schilddrüsenkarzinome).

Im umgebenden Normalgewebe des Tumors und in benignen Knoten dagegen fand sich eine signifikant geringere COX-2-Expression (9-fache Überexpression in Karzinomen).

COX-2 ist ein im endoplasmatischen Reticulum lokalisiertes Transmembranenzym. Es ist wesentlich beteiligt an der Synthese der Prostaglandine sowie des Thromboxan A2.

Die Cycloxygenase-2 wird durch Wachstumsfaktoren und Onkogene stimuliert. In früheren Untersuchungen fand sich in unterschiedlichen Tumoren (Colon-, Magen-, Pankreas-, Prostata-Karzinome) eine Hochregulation des Enzyms.

Da auch in Feinnadelaspiraten eine COX-2-Überexpression über RT-PCR gefunden wurde, könnte dieser Marker auch bei der immunzytologischen Diagnostik hilfreich sein.

Weitere Untersuchungen müssen den praktischen Wert dieser Methode für die präoperative Unterscheidung zwischen benignen und malignen Knoten allerdings noch erhärten. 


\subsubsection{Benigne Schilddrüsenknoten}

\subsubsection{Noduläre Hyperplasie}

Grundsätzlich zu unterscheiden sind knotige Hyperplasien von monoklonalen follikulären Adenomen, bei denen es sich um echte benigne Tumore handelt. Am Beginn der Entwicklung einer knotigen Hyperplasie steht zumeist eine diffuse Hyperplasie der Schilddrüse auf dem Boden eines Jodmangels (Struma diffusa parenchymatosa). Ist durch die Anpassungs-Follikelhyperplasie eine ausgeglichene Hormonbildung gegeben, speichern die Follikel vermehrt Kolloid.

Die Follikel werden insgesamt größer (Makrofollikel), während die Follikelzellen eher atrophischer werden (Struma diffusa kolloides).

In den entstehenden Makrofollikeln können sich gelegentlich makropapilläre Strukturen entwickeln, die differentialdiagnostisch von Papillen eines papillären Karzinoms unterschieden werden müssen.

Die durch Wachstumsfaktoren (siehe 2.2.1.1) induzierte Proliferation der Follikelzellen verläuft nicht immer gleichmäßig, da die Zellen eine individuell unterschiedliche Wachstums- bzw. Zellteilungsgeschwindigkeit besitzen.

Auf dieser Grundlage entstehen schließlich in einer Jodmangelstruma knotige Umwandlungen (knotige Hyperplasie).

Im Laufe der Zeit können diese knotigen Hyperplasien gelegentlich eine Kapsel ausbilden. In diesen Fällen kann eine zytologische und histologische Unterscheidung zwischen knotiger Hyperplasie und benignem Adenom schwierig werden.

In langebestehenden Knoten treten häufig zunehmend regressive Veränderungen auf in Form von zystischen Anteilen, Blutungen, Verkalkungen und Fibrosen. 


\subsubsection{Das follikuläre Adenom}

Beim follikulären Adenom handelt es sich um einen echten benignen monoklonalen Tumor, der aus dem Follikelepithel hervorgeht. Er ist vollständig verkapselt und zeigt zumeist ein uniformes Wachstumsmuster.

Nach der strukturellen Differenzierung der Follikel unterscheidet der Pathologe vier Subtypen:

1. Das normofollikuläre Adenom

2. Das makrofollikuläre Adenom (kolloidreich)

3. Das mikrofollikuläre Adenom (fetales follikuläres Adenom)

4. Das trabekuläre Adenom (embryonales follikuläres Adenom)

Die Ausstriche normo- und makrofollikulärer Adenome enthalten freie sowie in Verbänden angeordnete Follikelzellen. Die Punktate sind zumeist mäßig zellreich und enthalten diffus verteiltes Kolloid. Sie sind zytologisch von nodulären Hyperplasien oft nicht zu unterscheiden.

Im Gegensatz zu den normo- und makrofollikulären Adenomen sind die Punktate mikrofollikulärer Adenome in der Regel sehr zellreich. Neben freien Follikelzellen finden sich meist ringförmige follikuläre Formationen. Die Ausstriche enthalten nur wenig oder kein Kolloid.

Trabekuläre Adenome zeigen eine trabekuläre Struktur im Punktatausstrich und sind wie die mikrofollikulären Adenome ebenfalls zellreich. 


\subsubsection{Das onkozytäre Adenom}

Gelegentlich kommen in Knotenstrumen fokale onkozytäre Läsionen vor.

Sie bestehen aus oxyphilen, follikulären Zellen, Onkozyten genannt (synonym: Hürthle-Zelle, Askanazy-Zelle, große eosinophile Zelle).

Tumoren dieses Zelltyps werden als Onkozytome oder Hürthle-Zell-Tumoren bezeichnet. Wegen ihres überwiegend follikulären Wachstumsmusters werden Onkozytome zu den follikulären Tumoren (Adenome oder Karzinome) gezählt.

Onkozyten weisen eine Mitochondrien-Hyperplasie auf und zeigen eine verminderte Immunreaktivität für Thyreoglobulin. Dieser Zelltyp exprimiert kein NJS. Benigne und maligne Onkozytome speichern daher kein 131 Jod oder Tc-99m Pertechnetat, sie sind daher immer szintigraphisch vollständig kalt.

\subsubsection{Die follikuläre Neoplasie}

Das entscheidende diagnostische Dilemma der Schilddrüsenzytologie stellt das Zellbild der „follikulären Neoplasie” dar. Bei zytologischem Nachweis der Trias einer hohen Zellzahl, einer dominant follikulären Formation und geringer bis fehlender Kolloidbildung, spricht der Zytopathologe von einer „follikulären Neoplasie”. Die Punktate mikrofollikulärer Adenome und minimal invasiver follikulärer Schilddrüsenkarzinome zeigen ein nahezu identisches Bild und lassen keine Unterscheidung zwischen einem benignen und einem malignen Tumor zu.

Erschwerend kommt hinzu, dass gelegentlich Punktate aus nodulären Hyperplasien ähnliche Zellbilder liefern können. Das gleiche gilt für adenomähnliche Proliferationen nach Thyreostatika-Langzeittherapie. Hinzu kommt, dass auch die follikuläre Variante des papillären Schilddrüsenkarzinoms ein vergleichbares Bild zeigen kann (Lindsay-Tumor).

In den genannten Fällen stößt die zytologische Diagnostik an ihre Grenzen. Generell ist in derartigen Fällen eine Schilddrüsen-OP indiziert. 


\subsubsection{Maligne Schilddrüsenknoten}

Bei der überwiegenden Mehrzahl (über 90 \%) der bösartigen Neubildungen der Schilddrüse handelt es sich um differenzierte Karzinome, die von den Thyreozyten ihren Ausgang nehmen. Unterschieden werden papilläre Karzinome (50 bis 80 \%) mit überwiegend lymphogener Ausbreitung sowie follikuläre Karzinome (20 bis $30 \%$ ) mit überwiegend hämatogener Ausbreitung.

Die medullären Schilddrüsenkarzinome, auch als C-Zell-Karzinome bezeichnet, leiten sich von den parafollikulären C-Zellen ab und machen ca. $5 \%$ aller Schilddrüsenmalignome aus.

Undifferenzierte Schilddrüsenkarzinome (anaplastische Schilddrüsenkarzinome), die fast ausschließlich beim älteren Menschen vorkommen, sind selten (ca. 2 \%) und weisen eine extrem ungünstige Prognose auf. Sie exprimieren keinerlei NJS, speichern daher kein Nuklid und sind somit immer szintigraphisch vollständig kalt. Selten sind primär von der Schilddrüse ausgehende maligne Schilddrüsenlymphome, die in ca. 30 \% mit einer Immunthyreoiditis assoziiert sind. 
Tabelle 2

Klinische TNM-Klassifikation der Schilddrüsekarzinome (nach UICC 1987)

\section{T: Primärtunor}

TX Primärtumor kann nicht beurteilt werden

T0 Kein Anhalt für Primärtumor

T1 Tumor $1 \mathrm{~cm}$ oder weniger in größter Ausdehnung, begrenzt auf Schilddrüse

T2 Tumor mehr als $1 \mathrm{~cm}$, aber nicht mehr als $4 \mathrm{~cm}$ in größter Ausdehnung, begrenzt auf Schilddrüse

T3 Tumor mehr als $4 \mathrm{~cm}$ in größter Ausdehnung, begrenzt auf Schilddrüse

T4 Tumor jeder Größe mit Ausbreitung jenseits der Schilddrüse Jede T-Kategorie kann unterteilt werden in

a solitärer Tumor

b multifokaler Tumor (der größte Tumor ist für die Klassifikation bestimmend)

\section{N: Regionäre Lymphknoten}

NX Regionäre Lymphknoten können nicht beurteilt werden

N0 Kein Anhalt für regionäre Lymphknotenmetastasen

N1 Regionäre Lymphknotenmetastasen

N1a Metastasen in ipsilateralen Halslymphknoten

N1b Metastasen in bilateralen, in der Mittellinie gelegenen oder kontralateralen Halslymphknoten oder in mediastinalen Lymphknoten

\section{M: Fernmetastasen}

MX Das Vorliegen von Fernmetastasen kann nicht beurteilt werden

M0 Keine Fernmetastasen

M1 Fernmetastasen 


\subsubsection{Papilläre Schilddrüsenkarzinome}

Abbildung 7

Papilläres Karzinom (zytologisches Bild [39])

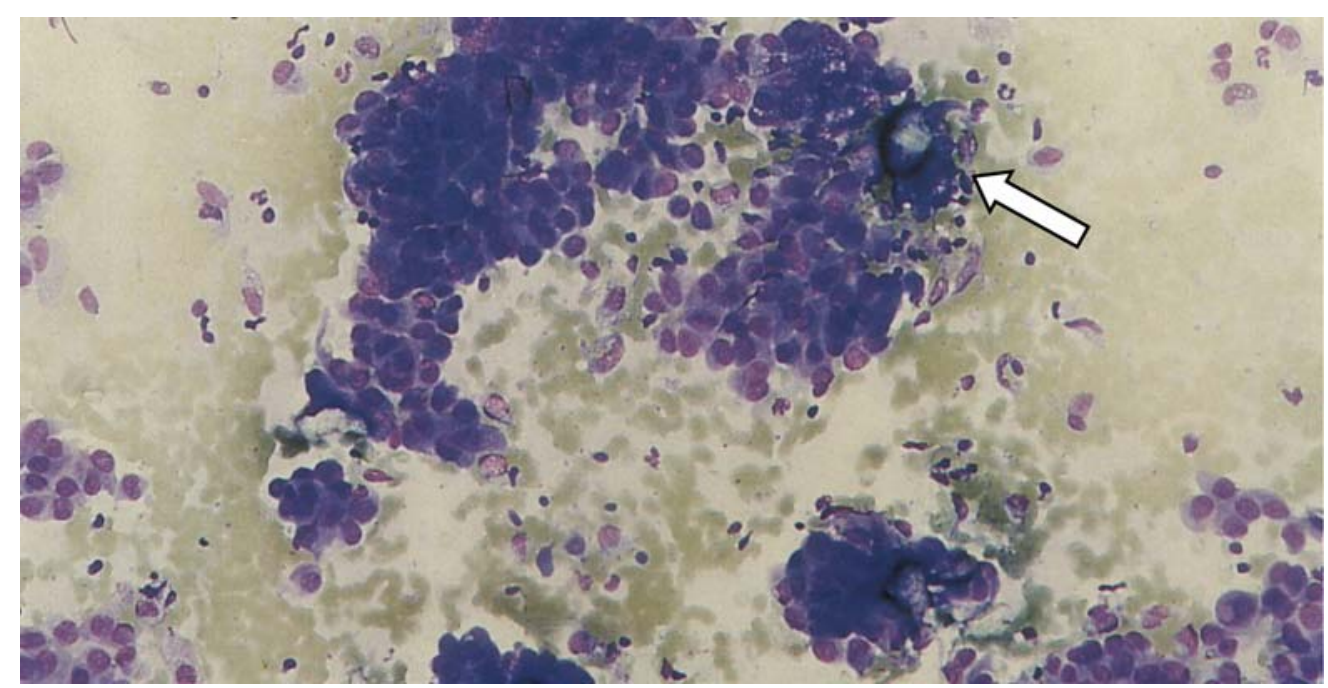

Papillenförmige Zellverbände, freie Tumorzellen und ein Psammonkörper, der in der Peripherie blau-schwarz gefärbt ist und ein farbloses Zentrum aufweist (siehe Pfeil [39]).

Das klassische papilläre Schilddrüsenkarzinom besteht aus Papillen mit einem gefäßreichen Bindegewebsstock, der mit einschichtigem Epithel ausgekleidet ist. Das Papillenstroma kann durchsetzt sein von Lymphozyten. Die lymphozytäre Infiltration kann als immunologische Reaktion auf den Tumor gedeutet werden.

Der Nachweis einer umschriebenen lymphozytären Thyreoiditis im gesunden Schilddrüsengewebe in der Umgebung des papillären Karzinoms stellt einen prognostisch eher günstigen Faktor für den weiteren Verlauf der Erkrankung dar (46).

Eine zytologisch nachgewiesene fokale lymphozytäre Thyreoiditis im peritumorösen Gewebe bei Karzinomverdacht ohne gleichzeitiges Bestehen einer Autoimmunthyreoiditis der gesamten Schilddrüse, kann als möglicher Hinweis auf ein papilläres Schilddrüsenkarzinom gedeutet werden. 
Im Bereich der Papillenspitzen des papillären Karzinoms findet man in 30 bis $60 \%$ der Fälle kleine, runde verkalkte Konkremente mit konzentrischer Schichtung, sogenannte Psammonkörper. Sie entstehen aus nekrotischen Tumorzellen.

In typischen papillären Karzinomen finden sich nicht ausschließlich nur Papillen. Auch follikuläre Strukturen sind häufig.

Von besonderer diagnostischer Bedeutung sind nukleäre Veränderungen.

In ca. $50 \%$ der Fälle findet man intranukleäre Zytoplasmaeinschlüsse sowie Milchglaskerne. Letztere sind leer erscheinende Zellkerne mit peripherer Kondensation des Chromatins.

Diese nukleären Auffälligkeiten sind spezifisch für das papilläre Schilddrüsenkarzinom. Bei Nachweis dieser Kernveränderungen lässt sich ein Schilddrüsenmalignom auch bei überwiegend follikulär gebautem Gewebe als papilläres Karzinom identifizieren.

Eine Sonderform des papillären Schilddrüsenkarzinoms stellt das papilläre Mikrokarzinom dar mit ausgesprochen günstiger Prognose. In Einzelfällen geht das Mikrokarzinom, das definitionsgemäß eine Tumorgröße unter $10 \mathrm{~mm}$ aufweist, mit cervicalen Lymphknotenmetastasen einher, die sich nicht selten zystisch darstellen und als cervicale Halszyste fehlgedeutet werden können. In diesen Fällen sind häufig die zytologischen Merkmale des papillären Schilddrüsenkarzinoms nicht nachweisbar.

Der zytologische Ausstrich eines papillären Schilddrüsenkarzinoms ist meist zellreich und enthält in der Regel wenig oder kein Kolloid. Typisch, wenn auch nur in einem Teil der Fälle präsent, sind intranukleäre Zytoplasmaeinschlüsse (in ca. $50 \%$ der Punktate) sowie Milchglaskerne.

Das zumeist nur sehr spärliche Kolloid zeigt charakteristischerweise ein sehr zähes, visköses Aussehen (Kautschuk-Kolloid) mit zum Teil starker Septierung. 
In 20 bis $30 \%$ der Punktate finden sich sogenannte Psammonkörper mit einem Durchmesser bis zu $100 \mu$, die relativ häufig assoziiert sind mit zystischen papillären Karzinomen. Mehrkernige Riesenzellen findet man in bis zu 50 \% der Punktate.

Die follikuläre Variante des papillären Schilddrüsenkarzinoms (synonym: LindsayTumor) erfüllt nicht selten die zytologischen Kriterien einer follikulären Neoplasie (zellreich, mikrofollikulär, kolloidarm - siehe 2.3.2.4).

Eine zytologische Unterscheidung zwischen follikulärem Adenom und Karzinom (follikuläres Schilddrüsenkarzinom oder aber Lindsay-Tumor) ist in diesen Fällen nicht möglich. Erst bei der histologischen Aufarbeitung des Knotens weisen die typischen Kernveränderungen oder Psammonkörper auf das papilläre Karzinom hin.

Sehr selten sind papilläre Karzinome, die ausschließlich aus oxyphilen Zellen bestehen. Die typischen Kernveränderungen finden sich bei dieser oxyphilen Variante nicht.

Relativ selten sind faserreiche papilläre Schilddrüsenkarzinome (ca. $5 \%$ aller papillären Neoplasien). Sie sind zellarm und lassen sich lediglich in rund $40 \%$ der Fälle zytologisch diagnostizieren.

Eine Besonderheit papillärer Schilddrüsenkarzinome stellt das relativ häufige multilokuläre Auftreten in einem oder auch in beiden Schilddrüsenlappen dar. 


\subsubsection{Follikuläre Schilddrüsenkarzinome}

\section{Abbildung 8 \\ Histologische Bilder}

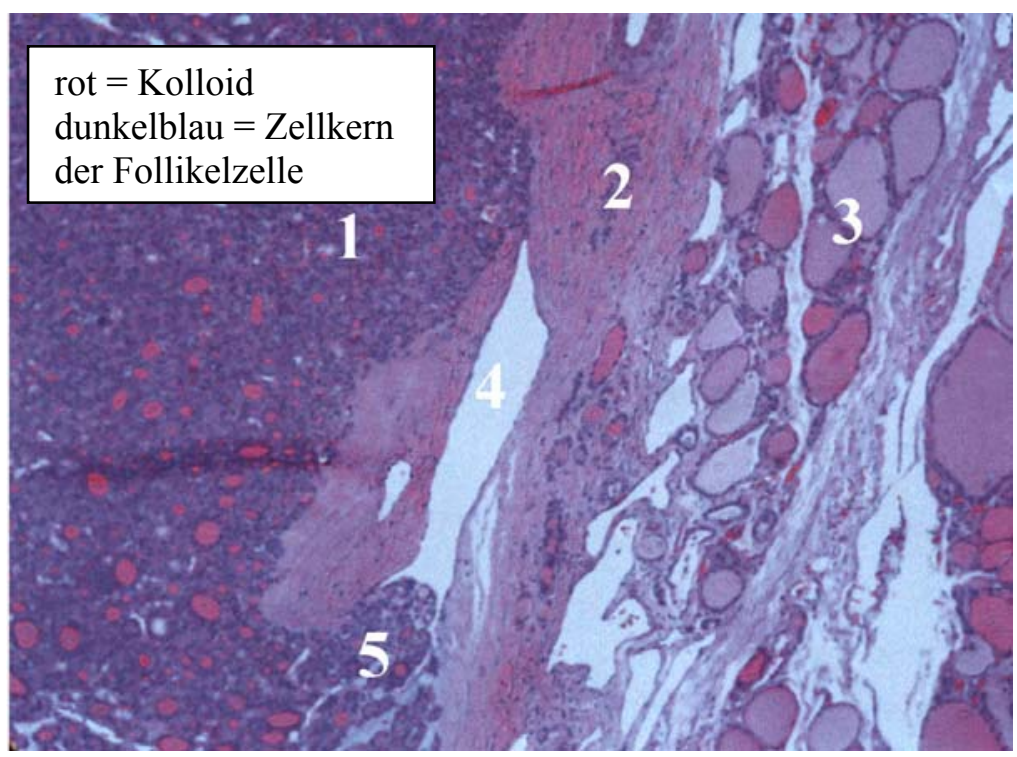

Zytologie: follikuläre Neoplasie

Histologie: follikuläres Karzinom

\section{Abbildung 9}

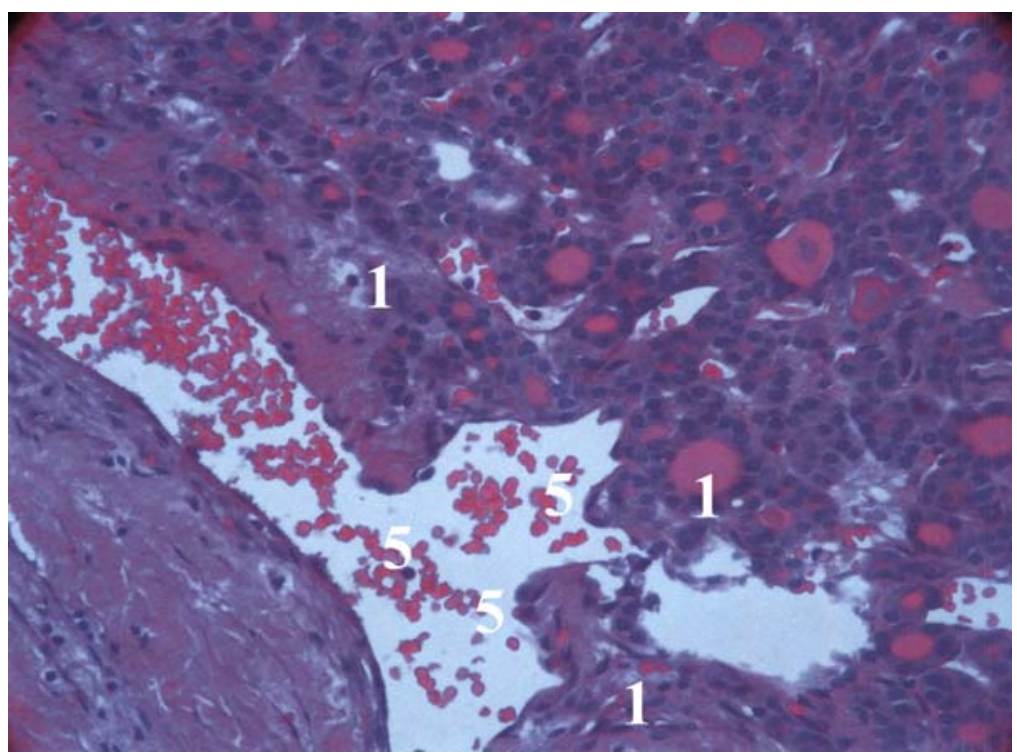

Zytologie: follikuläre Neoplasie

Histologie: follikuläres Karzinom

1. follikuläres Karzinom (minimal invasiv)

2. Kapsel des Karzinoms

3. normales Schilddrüsengewebe

4. Kapselgefäß

5. Tumorinvasion in ein Kapselgefäß des Tumors (Gefäßinvasion) 
Die Pathologen unterscheiden nach dem Ausmaß der Invasivität zwei grundsätzlich unterschiedliche Formen des follikulären Karzinoms:

Das minimal invasive und das grob invasive follikuläre Schilddrüsenkarzinom.

Das minimal invasive follikuläre Karzinom hat eine sehr günstige Prognose. Es ist vollständig von einer Kapsel umgeben. Das zytologische Zellbild unterscheidet sich nicht von dem eines benignen follikulären Adenoms.

Adenom und Karzinom zeigen hochdifferenzierte Strukturen, die Follikel und Kolloid bilden. Die Kolloidbildung ist jedoch in mikrofollikulären Adenomen wie auch in follikulären Karzinomen deutlich geringer als in makro- und normofollikulären Adenomen.

Erst durch einen histologisch nachgewiesenen Kapseleinbruch- oder Durchbruch und/oder einen Gefäßeinbruch (siehe Fotos) kann die Malignität des Tumors belegt werden.

Zytologisch lassen sich minimal invasive follikuläre Schilddrüsenkarzinome von benignen mikrofollikulären Adenomen nicht unterscheiden.

Bei Nachweis der Trias einer hohen Zellzahl, einer dominant follikulären Formation und geringer oder fehlender Kolloidbildung spricht der Zytopathologe von einer „follikulären Neoplasie” (siehe 2.3.2.4). Eine Unterscheidung zwischen Adenom und Karzinom ist nur nach sorgfältiger histologischer Aufarbeitung des operativ entfernten Knotens möglich. 
Abbildung 10

Zytologie (Pat. Nr. 18)

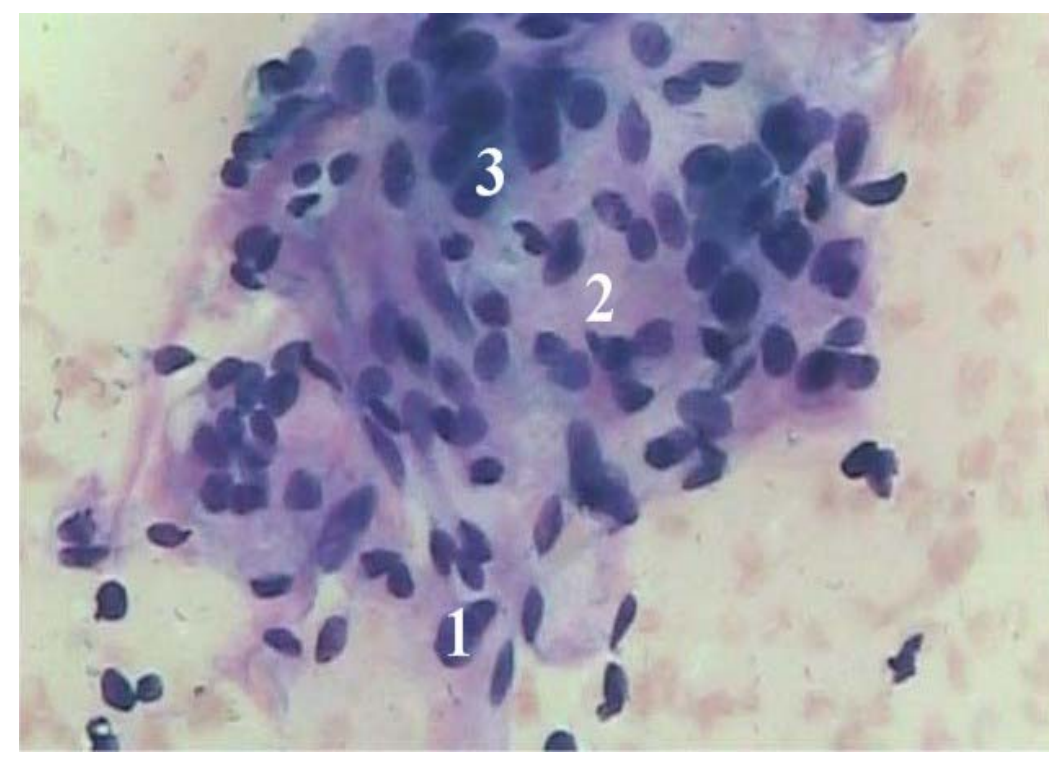

1. Zellkerne der Follikelzellen (dunkelblau)

2. Zytoplasma

3. Kolloid (blau)

\section{Abbildung 11}

Zytologie desselben Pat.

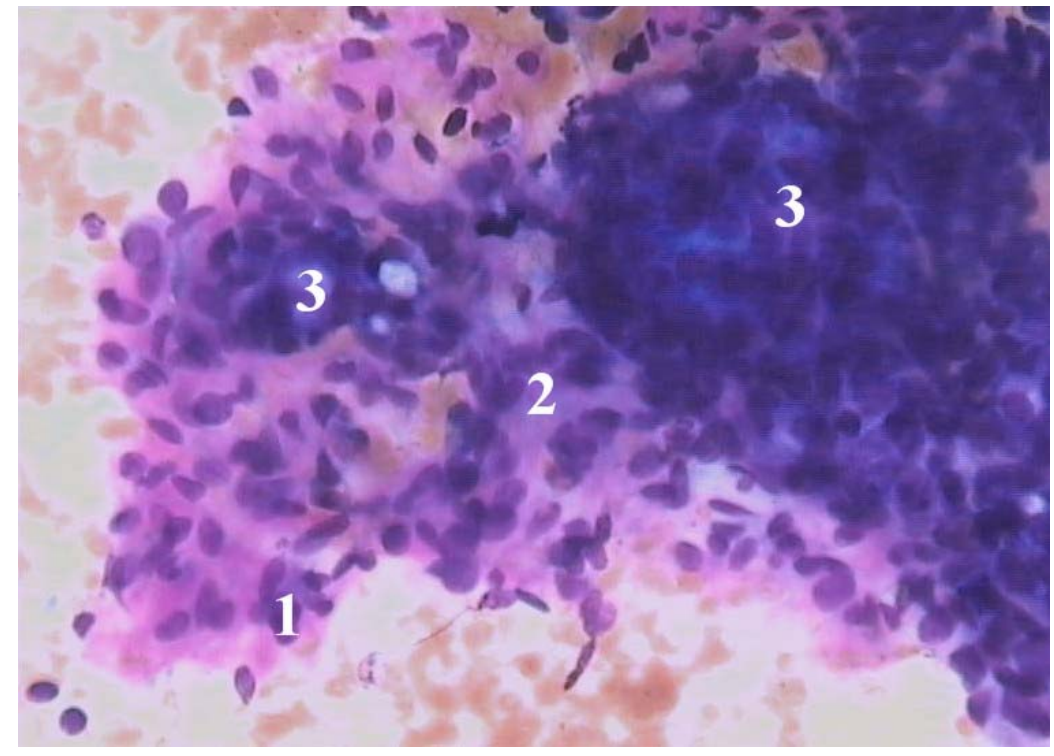

1. Zellkerne

2. Zytoplasma

3. Kolloid (blau)

Zytologie: mikrofollikuläre Proliferation (erfüllte nicht die Kriterien einer follikulären Neoplasie wegen des Kolloidreichtums)

Histologie: follikuläres Schilddrüsenkarzinom 
Grob invasive Schilddrüsenkarzinome sind unvollständig gekapselt oder aber ganz ohne Kapsel und sie infiltrieren das benachbarte Gewebe (grob invasiv). Es finden sich meist zahlreiche Gefäßinvasionen. Die zytologische Diagnostik ist in der Regel unproblematisch.

Eine eigenständige Variante des follikulären Schilddrüsenkarzinoms stellt der oxyphile Tumor dar mit überwiegend oxyphilen Zellen (Hürthle-Zell-Karzinom, onkozytäres Schilddrüsenkarzinom, malignes Onkozytom). Das maligne Onkozytom wird ebenfalls unterteilt in minimal invasive und in grob invasive Varianten. Das Zellbild des Karzinoms unterscheidet sich nicht von dem eines onkozytären Adenoms oder dem des seltenen oxyphilen papillären Karzinoms.

Zytologisch wird die Diagnose einer „oxyphilen” Neoplasie gestellt in Analogie zum Konzept der „follikulären Neoplasie” (2.3.2.4).

\subsubsection{Anaplastische (undifferenzierte) Schilddrüsenkarzinome}

Das extrem aggressive anaplastische Karzinom tritt meist im höheren Lebensalter auf und zeigt eine frühe lymphogene und hämatogene Metastasierung mit infauster Prognose (mittlere Überlebungszeit maximal ein Jahr). Dieses undifferenzierte Karzinom kann sich aus langebestehenden papillären und follikulären Karzinomen entwickeln. 


\subsubsection{Medulläre Schilddrüsenkarzinome}

Medulläre Schilddrüsenkarzinome, auch als C-Zell-Karzinome bezeichnet, stammen von den parafollikulären Zellen der Schilddrüse ab und exprimieren fast immer Calcitonin sowie in der überwiegenden Mehrzahl der Fälle auch CEA. Calcitonin ist das Sekretionsprodukt der C-Zellen und ein hochsensitiver Tumormarker bei Vorliegen eines C-Zell-Karzinoms (medulläres Schilddrüsenkarzinom).

Leicht bis mäßig erhöhte Konzentrationen finden sich in seltenen Fällen jedoch auch bei anderen Tumorerkrankungen, besonders beim kleinzelligen Bronchialkarzinom und beim Karzinoid, sehr selten auch beim Mamma- und Magenkarzinom.

Mäßig erhöhte Werte findet man auch bei fortgeschrittener Niereninsuffizienz.

In ca. $75 \%$ der Fälle tritt das C-Zell-Karzinom sporadisch auf. Etwa $25 \%$ der CZell-Karzinome treten familiär auf im Rahmen einer MEN-2 oder eines familiären medullären Schilddrüsenkarzinoms.

Als Auslöser dieser familiär auftretenden Variante konnten heterozygote Keimbahnmutationen im Bereich des RET-Protoonkogens (Chromosom 10q13) nachgewiesen werden.

Das RET-Protein ist eine Transmembran-Tyrosinkinase, die vorwiegend von Geweben exprimiert wird, die sich von der Neuralleiste ableiten.

Bisher wurden Keimbahnmutationen im Bereich der Exone 10, 11, 13 und 16 identifiziert.

Für den Nachweis der Keimbahnmutationen im RET-Protoonkogen wird eine EDTA-Blutprobe des Patienten benötigt. 


\subsubsection{Schilddrüsenlymphome}

Eine Sonderform des Schilddrüsenmalignoms stellt das maligne Schilddrüsenlymphom dar, das in ca. $30 \%$ mit einer Autoimmunthyreoiditis assoziiert ist. Patienten mit einer Autoimmunthyreoiditis haben ein signifikant höheres Risiko, ein niedrig malignes B-Zell-Lymphom der Schilddrüse zu entwickeln. 


\section{Patientengut und Methodik}

\subsection{Patientenkollektiv}

Für die vorliegende retrospektive Studie sind die Patienten ausschließlich nach dem szintigraphischem Befund ausgewählt worden. In der Szintigraphie musste ein „vollständig kalter" Knoten (siehe 3.3.2) nachgewiesen werden. Der betroffene Knoten durfte also keinerlei Restspeicherung in der Szintigraphie aufweisen.

Unter Berücksichtigung dieser Vorgabe wurde ein Subkollektiv kalter Knoten zusammengestellt. Nach sonographischem Ausschluss einer Zyste als möglicher Ursache eines vollständig kalten Knotens konnte ein Kollektiv von 130 Patienten erfasst werden.

Sämtliche kalten Knoten wurden punktionszytologisch untersucht. Unabhängig vom Ergebnis der Punktionszytologie war allen Patienten eine Operation empfohlen worden.

Von den rekrutierten 130 Patienten wurden nach Abschluss der Diagnostik 112 operiert. Die kalten Knoten wurden histologisch untersucht.

Bei 18 Patienten erfolgte aus unterschiedlichen Gründen keine Operation (Kontaktverlust, Ablehnung der Operation).

\subsection{Schilddrüsenlaboruntersuchungen}

Bei jedem Patienten wurde die Schilddrüsenfunktion untersucht.

Bestimmt wurden TSH, FT3, FT4, TPO-AK sowie bei suspekten kalten Knoten die Tumormarker für das C-Zell-Karzinom Calcitonin und CEA.

Wichtigster Parameter zur Feststellung der Stoffwechsellage der Schilddrüse ist das TSH. Verwendet wurden immunologische Methoden, die eine Sensitivität von $0,005-0,05 \mathrm{mU} / \mathrm{ml}$ aufwiesen. 
Der Referenzbereich für das hypersensitive TSH (Drittgenerations-TSH-Assay) liegt bei dem verwendeten Test zwischen 0,3 und 3,0 $\mu \mathrm{U} / \mathrm{ml}$.

Zur Bestimmung der Schilddrüsenfunktion wurden die freien Schilddrüsenhormone FT3 und FT4 bestimmt. Sowohl das TSH wie auch das FT3 und FT4 wurden mit Kits der Firma Biermann gemessen (verwendetes Analysegerät: Immulite 2000).

Die Bestimmung der TPO-AK sowie der Tumormarker CEA und Calcitonin erfolgte ebenfalls mit Kits der Firma Biermann. Sämtliche Untersuchungen erfolgten auf dem Analysegerät der Firma Biermann, dem Immulite 2000.

Tabelle 3

Referenzbereiche der verwendeten Laborparameter

\begin{tabular}{|l|l|}
\hline freies T3 & $1,5-4,1 \mathrm{pg} / \mathrm{ml}$ \\
\hline freies T4 & $0,8-1,9 \mathrm{ng} / \mathrm{dl}$ \\
\hline TSH & $0,3-3,0 \mu \mathrm{U} / \mathrm{ml}$ \\
\hline TPO-AK & bis $40 \mathrm{U} / \mathrm{ml}$ \\
\hline Calcitonin & bis $12,0 \mathrm{pg} / \mathrm{ml}$ \\
\hline CEA & $0,5-3,3 \mathrm{ng} / \mathrm{dl}$ \\
\hline
\end{tabular}

Zur Abklärung der Frage, ob ein C-Zell-Karzinom vorliegt, wird in der Regel ein sogenannter Pentagastrin-Stimulationstest durchgeführt.

Die Untersuchung wird beim nüchternen, liegenden Patienten durchgeführt.

\section{Pentagastrin Test}

- Legen einer Verweilkanüle

- 0,5 ug Pentagastrin/kg Körpergewicht über 15 sec. i. v.

- Bestimmung des Calcitonins basal sowie nach 2 und 5 Min. 
Bei der überwiegenden Mehrzahl der C-Zell-Karzinome ist auch das carzinoembryonale Antigen (CEA) erhöht und wird ebenfalls als Tumormaker bei der Diagnostik des C-Zell-Karzinoms verwendet.

Die Calcitoninbestimmung und der Pentagastrin-Test finden ebenfalls Verwendung im Rahmen von Familienuntersuchungen bei der multiplen endokrinen Neoplasie Typ 2 (MEN 2) bzw. dem familiären medullären Schilddrüsenkarzinom.

Etwa 25\% der medullären Schilddrüsenkarzinome treten familiär im Rahmen einer MEN 2 oder eines familiären medullären Schilddrüsenkarzinoms auf.

Bei jedem Patienten mit einem C-Zell-Karzinom sollte daher heute für den Nachweis einer Keimbahnmutation im RET-Protoonkogen (siehe 2.2.3.4) eine humangenetische Untersuchung durchgeführt werden. Hierzu werden 5 ml EDTABlut benötigt.

Diese Untersuchungen werden entsprechend den Empfehlungen der Sektion Schilddrüse der Deutschen Gesellschaft für Endokrinologie durchgeführt. 


\subsection{Apparative Untersuchungen}

\subsubsection{Schilddrüsensonographie}

Die Schilddrüsensonographie stellt heute das Basisverfahren einer jeden Schilddrüsendiagnostik dar. Vorteile für den Arzt und Patienten sind die einfache Durchführbarkeit, die problemlose Zugänglichkeit des Organs aufgrund der anatomischen Lage und die fehlende Belastung für den Patienten.

Herdbefunde bis zu einem Minimaldurchmesser von etwa 2 bis $3 \mathrm{~mm}$ sollten heute zuverlässig sonographisch erkannt werden.

Die Schilddrüsensonographie stellt im Rahmen der Schilddrüsendiagnostik die erste bildgebende Untersuchung dar. Erst vom Ergebnis des Ultraschallbildes wird abhängig gemacht, ob ein ergänzendes Schilddrüsenszintigramm notwendig ist.

Bei der vorliegenden Studie wurde ein Ultraschallgerät der Firma Siemens verwendet (Adara, Sonoline). Es handelt sich um ein B-Mode-Ultraschallgerät mit einem linearen 7,5 MHZ-Schallkopf mit einer Länge von $6 \mathrm{~cm}$.

Neben der Abbildung und Dokumentation beider Schilddrüsenlappen in drei Ebenen mit anschließender Volumenbestimmung der Gesamtschilddrüse erfolgt eine Ausmessung der Größe jedes einzelnen Knotens in drei Ebenen. 


\section{Sonographie - Dokumentationsbogen}

SCHILDDRÜSENVOLUMEN (Frauen: > $18 \mathrm{ml}$; Männer: > $25 \mathrm{ml}$; maximal $60 \mathrm{ml}$ ) Sonogramm bitte beilegen!

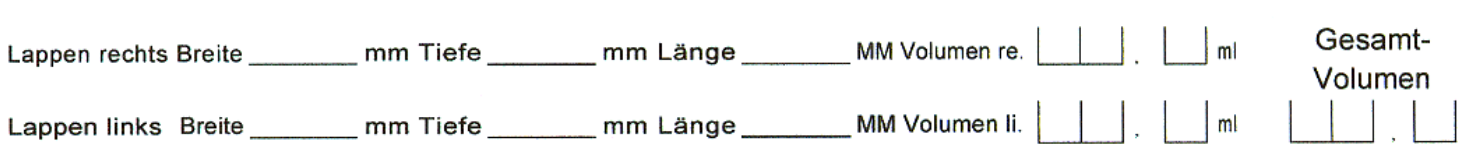

\section{BEURTEILUNG DES SCHILDDRÜSENPARENCHYMS}

$\begin{array}{llll}\begin{array}{l}\text { Homogenität } \\ \text { (bitte nur } 1 \text { Kreuz) } \\ \text { Echodichte }\end{array} & \square \text { homogen } & \square \text { gering inhomogen } & \square \text { inhomogen }\end{array}$

(bitte nur $1 \mathrm{Kreuz}$ )

\section{HERDBEFUNDE}

Knoten/ Herdbefunde nachweisbar $\square$ nein $\square$ ja Vollständiger knotiger Umbau $\square$ rechts $\square$ links

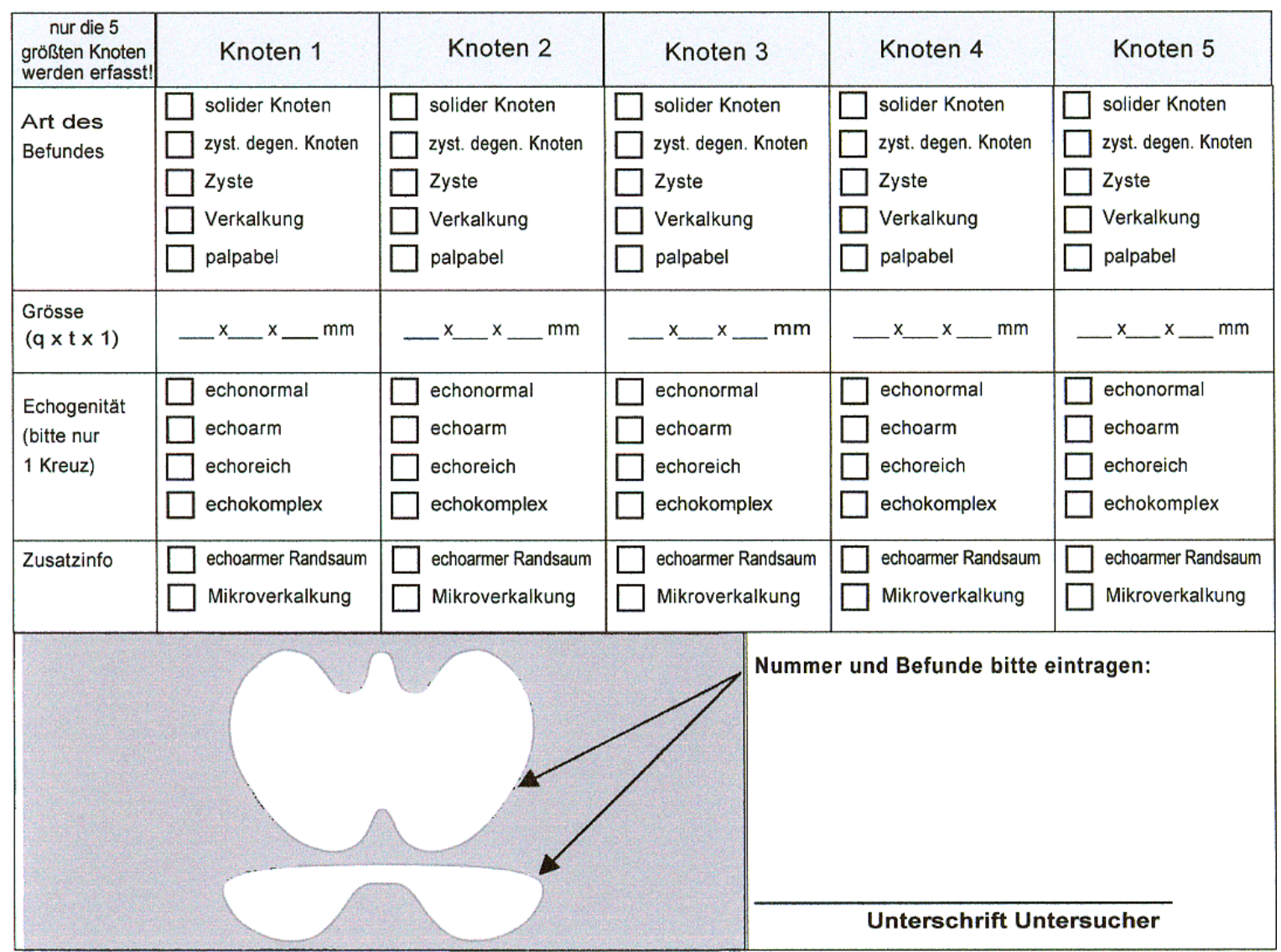




\section{Sonographische Volumetrie}

Meßmethode nach Brunn

Länge $x$ Breite $x$ Tiefe (in $\mathrm{mm}$ )

2

Tabelle 4

Referenzwerte des Schilddrüsenvolumens

\begin{tabular}{|l|c|c|}
\hline & Jahre & $\mathrm{ml}$ \\
\hline Kinder & 8 & $<4$ \\
\hline Kinder & 10 & $<8$ \\
\hline Jugendliche & $15-18$ & $<15$ \\
\hline Frauen & & $<18$ \\
\hline Männer & & $<25$ \\
\hline
\end{tabular}

Die Sonographie beschreibt die Binnenstruktur der Schilddrüsenlappen sowie der vorgefundenen Schilddrüsenknoten. Verwendet werden deskriptive Adjektive der Echogenität wie echonormal, echoarm, echokomplex oder echofrei sowie Beschreibungen der Homogenität (homogen, inhomogen).

Beschrieben werden zystische Veränderungen sowie kleinere und größere Verkalkungen.

Neben der Größe und der Echogenität der Knoten wird auch ihre Lokalisation in der Schilddrüse festgehalten.

Echonormal ist eine Struktur der gesunden Schilddrüse mit normal großen Follikeln. Eine echoarme, verminderte Echogenität findet sich in mikrofollikulären Strukturen. Makrofollikuläre Strukturen stellen sich mit vermehrter Echogenität dar und werden als echoreich bezeichnet. 
Sogenannte echokomplexe Bilder zeigen Knoten mit inhomogenen und zum Teil echoreichen und echoarmen Schallmustern, die oft nicht scharf abgrenzbar sind.

Echofreie Bilder mit dorsaler Schallverstärkung entsprechen flüssigen, $d$. $h$. zystischen Anteilen.

Die nicht selten in Knoten zu findenden Kalkherde weisen echodichte Strukturen auf mit dorsaler Schallauslöschung.

Herdförmige Läsionen der Schilddrüse werden auf ihre exakte Lokalisation, ihre Echogenität und Größe beschrieben und bildlich dokumentiert. Auch die Randbegrenzung der Knoten (scharf, unscharf) sollte in die Beschreibung mit eingehen.

Bei Nachweis einer unscharfen Randbegrenzung eines echoarmen oder echokomplexen Knotens steigt das Risiko einer malignen Entartung deutlich an.

Allerdings gibt es zahlreiche differenzierte Schilddrüsenkarzinome, die scharf begrenzt sind, so dass das Fehlen einer unscharfen Randbegrenzung nicht für einen benignen Befund sprechen muss.

Sonographisch echonormale und echoreiche Knoten, oft mit echoarmem Randsaum, sind in Jodmangelgebieten häufig und fast immer benigne. Das Risiko eines Malignoms liegt bei diesen Knoten unter $1 \%$.

Es handelt sich meist um noduläre Hyperplasien oder um normo- oder makrofollikuläre Adenome.

Der echoarme Randsaum, der sogenannte „Halo-Saum”, entspricht einer Zone vermehrter Durchblutung und gilt als Hinweis für das Vorliegen einer benignen Läsion.

Sonographisch echoarme Knoten sind in der Regel Ausdruck eines mikrofollikulär veränderten Gewebes. Es kann sich um benigne autonome Adenome handeln, die nicht selten (in ca. $70 \%$ ) ein mikrofollikuläres Bild aufweisen und sich dann sonographisch echoarm darstellen. 
Meist entsprechen echoarme Knoten jedoch mikrofollikulären Adenomen oder aber seltener auch mikrofollikulären Karzinomen. Sonographisch sind die Ultraschallbilder identisch.

Neben der unscharfen Randbegrenzung im Ultraschallbild können grobschollige Verkalkungsstrukturen (Makroverkalkungen) in einem echoarmen Knoten ein möglicher Hinweis auf ein Malignom sein, insbesondere auf ein C-Zell-Karzinom. Mikroverkalkungen, d. h. kleinste, echodichte Strukturen, können Hinweis auf ein papilläres Schilddrüsenkarzinom sein (Psammonkörper). 
Abbildung 12

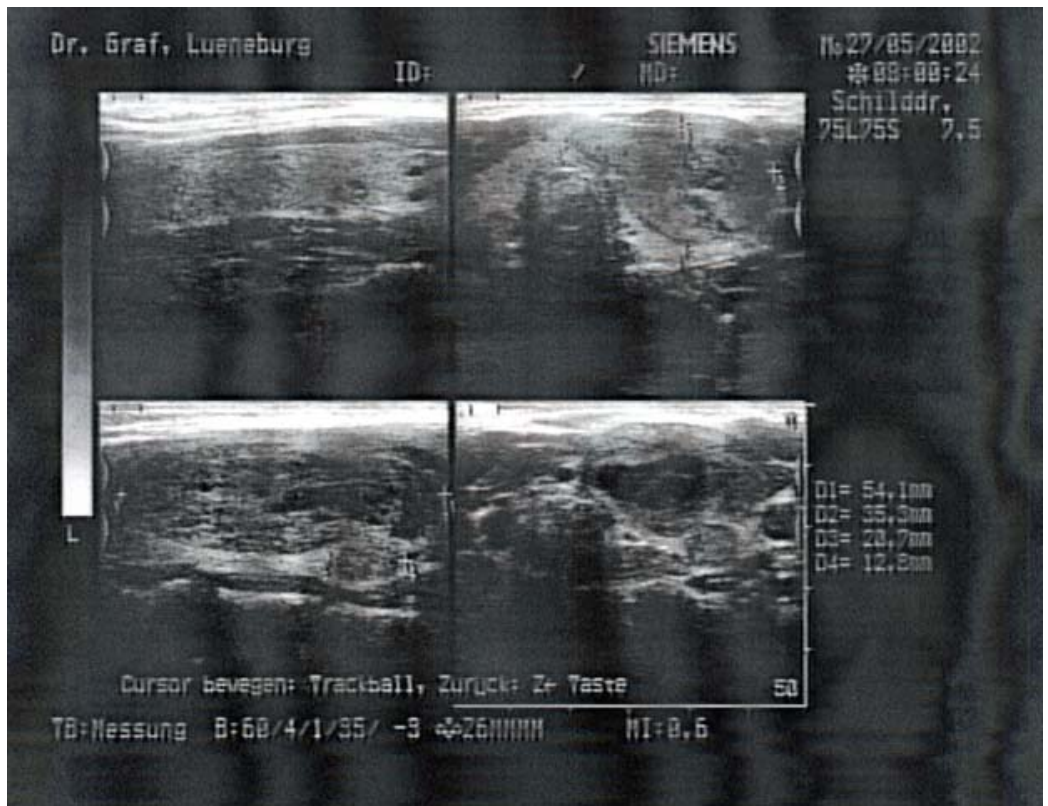

Sonographie: großer echoarmer bis echokomplexer Knoten linker SD-Lappen

\section{Abbildung 13}

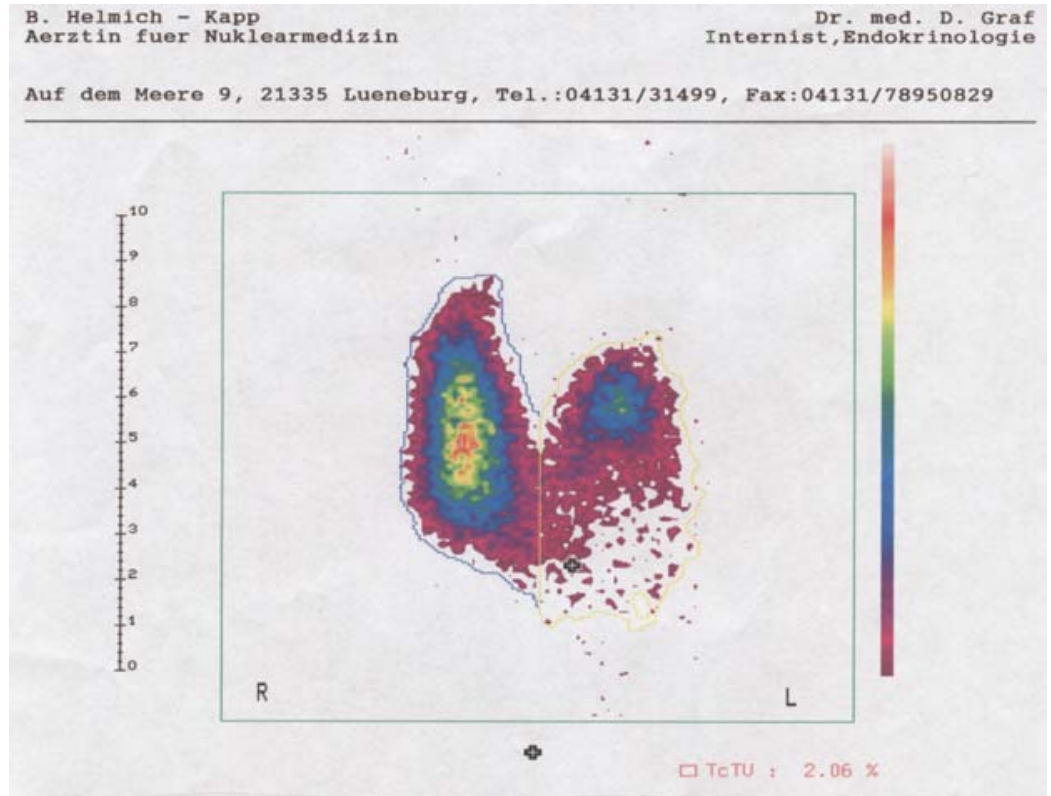

Szintigraphie: dieselbe Pat. wie oben; großer szintigraphisch vollständig kalter Knoten. Zytologie: Partiell mikrofollikuläre Proliferation. Erfüllt nicht die Kriterien einer follikulären Neoplasie. Histologie: minimal invasives follikuläres Schilddrüsenkarzinom 


\subsubsection{Schilddrüsenszintigraphie}

Während die Sonographie morphologische Veränderungen der Schilddrüse darstellt, liefert die Szintigraphie ergänzende Informationen über den globalen und den regionalen Funktionszustand des Schilddrüsengewebes.

Die Technik der Szintigraphie beruht auf der Fähigkeit der Thyreozyten, Jod aufzunehmen. Jod wird über den Natrium-Jod-Symporter (siehe 2.1.1) in die Schilddrüse gepumpt. Die quantitative Schilddrüsenszintigraphie erlaubt die Beurteilung der Aktivität der thyreoidalen Jodaufnahme.

In der Routinediagnostik wird in der Regel das Radionuklid Tc-99m-Pertechnetat verwendet. Die Pertechnetat-Jonen konkurrieren mit dem Jodid um die Aufnahme in die Schilddrüse. Es wird ähnlich wie Jodid in die Thyreozyten aufgenommen.

Nach intravenöser Injektion von Tc-99m-Pertechnetat ist die maximale Anreicherung des Nuklids nach 15 bis 20 Min. erreicht.

Der Vorteil des Tc-99m-Pertechnetat liegt in seinen physikalischen Eigenschaften mit Emission einer reinen Gammastrahlung und einer kurzen physikalischen Halbwertszeit von ca. 6 Stunden. Die Strahlenbelastung des untersuchten Patienten ist deutlich geringer als bei der Verwendung radioaktiven Jods. Die Strahlenexposition bei Verwendung von Tc-99m-Pertechnetat liegt für die Schilddrüse bei 3,4 mGy und ist damit im Vergleich zu J-131 um das 300-fache geringer.

Bei allen in der Praxis untersuchten Patienten wurde die Szintigraphie mit Tc-99mPertechnetat durchgeführt. Es wurden 35 bis $70 \mathrm{MBq}(1-2 \mathrm{mCi})$ des Nuklids intravenös appliziert.

Nach ca. 20 Minuten erfolgte im Sitzen die Aufzeichnung der Schilddrüse vor einer Gammakamera mit speziellem Schilddrüsenkollimator (Gammakamera der Fa. MIE).

Bei jedem Patienten wurde, wie allgemein üblich, auch der Tc-99m-Uptake bestimmt. Dieser ist als Äquivalent der thyreoidalen Jodidclearance anzusehen. 
Der Tc-99m-Uptake hängt von der Stimulation des TSH-Rezeptors ab, andererseits aber auch vom intrathyreoidalen Jodgehalt. Bei gesunden Schilddrüsen mit ausreichender Jodversorgung liegt der Tc-Uptake zwischen 0,5 und 2,0\%. In Jodmangelgebieten kann der Uptake in Abhängigkeit vom Ausmaß des Jodmangels bis auf $8 \%$ ansteigen.

Die Szintigraphie ist indiziert bei Knoten über 1,0 cm Größe. Sie soll klären, ob der Knoten einem hypofunktionellen („,kalter” Knoten) oder einem hyperfunktionellen Areal („heißer” Knoten) entspricht. Nicht wenige Knoten sind jedoch szintigraphisch nicht differenzierbar, demnach szintigraphisch weder heiß noch kalt. Dieses gilt insbesondere für kleinere Knoten bis $2 \mathrm{~cm}$.

Bei szintigraphisch kalten Knoten handelt es sich definitionsgemäß um hypofunktionelle Areale mit verminderter bis fehlender Speicherung.

Die graduellen Unterschiede zwischen lediglich vermindert speichernden Arealen und vollständig fehlender Nuklidanreicherung werden bei der Bezeichnung „kalter” Knoten nicht berücksichtigt. In der vorliegenden Studie haben sich die Autoren ausschließlich auf vollständig kalte Knoten beschränkt, die keinerlei Restaktivität aufwiesen.

Hinter einem szintigraphisch nicht differenzierbaren Knoten kann sich ein kompensiertes autonomes Adenom verbergen, das erst mit Hilfe einer Suppressionsszintigraphie zur Darstellung kommt. Es kann sich jedoch auch um einen kalten Knoten handeln, der in der Szintigraphie nicht als kalt dargestellt werden kann. 
Nicht selten wird ein an sich kalter Knoten durch darüber - oder darunterliegendes Schilddrüsengewebe „,̈̈berstrahlt”, da die Szintigraphie ein Summationsbild der in der Schilddrüse gespeicherten Radioaktivität darstellt.

Diese Einschränkungen in der szintigraphischen Beurteilbarkeit von Knoten ergeben sich vor allem immer dann, wenn kleinere Knoten mit einem Durchmesser von weniger als $1,5 \mathrm{~cm}$ vorliegen und wenn ventral und/oder dorsal noch genügend funktionell intaktes Schilddrüsengewebe vorliegt.

Das gleiche Problem tritt auf in einer sehr großen Knotenstruma mit einer Lappendicke von 4 bis $6 \mathrm{~cm}$. In derart großen Schilddrüsen können gelegentlich auch größere kalte Knoten mit einem Dickendurchmesser von 2 bis $3 \mathrm{~cm}$ möglicherweise nicht als kalte Knoten identifiziert werden.

So ist es zu erklären, dass sich nur etwa $75 \%$ aller Schilddrüsenkarzinome eindeutig als kalte Knoten darstellen, während die restlichen malignen Knoten szintigraphisch nicht abgrenzbar sind. 


\subsection{Punktionszytologie}

Die hohe Inzidenz knotiger Schilddrüsenläsionen in Strumaendemiegebieten erschwert die frühzeitige Diagnose von Schilddrüsenkarzinomen, da Schilddrüsenknoten zumeist benigne sind und in diesen Regionen bei älteren Patienten bei bis zu 40 \% der Bevölkerung vorkommen.

Die Differenzierung zwischen benignen und malignen Herdbefunden ist in der Mehrzahl der Fälle durch die Feinnadelpunktion möglich.

Die Punktion wird in der Regel nur bei Knoten mit einem Durchmesser eindeutig über 1,0 cm durchgeführt.

Der Punktion vorausgehen sollten immer eine Ultraschalluntersuchung der Schilddrüse und in der Regel auch eine Szintigraphie.

Szintigraphisch kalte Knoten sollten immer punktiert werden, da sich Schilddrüsenkarzinome in der überwiegenden Mehrzahl der Fälle als kalte Areale darstellen.

Sonographisch echoarme Knoten, die szintigraphisch nicht differenzierbar sind, weil dorsal und ventral normales Schilddrüsengewebe vorhanden ist, sollten ebenfalls punktiert werden. Ein an sich szintigraphisch kalter Knoten, hinter dem sich eine maligne Läsion verbergen könnte, wird in der Szintigraphie „überstrahlt” und kann so szintigraphisch nicht erfasst werden.

\section{Technik der Feinnadelpunktion (39)}

Die Punktion wird am liegenden Patienten nach Hautdesinfektion ohne Lokalanästhesie mit einer $10 \mathrm{ml}$ Einmalspritze und einer Einmalkanüle (Durchmesser 0,7 mm) durchgeführt (Freihandpunktion).

Bei Knoten über $3 \mathrm{~cm}$ Durchmesser wird das Punktionsziel nach vorheriger Ultraschalllokalisierung auf der Haut markiert. Bei kleineren und insbesondere schwer tastbaren Knoten erfolgt die Punktion soweit möglich unter permanenter sonographischer Kontrolle.

Nach Einstich der Nadel in den Knoten wird durch schnelles Zurückziehen des Spritzenkolbens der für die Aspiration notwendige Unterdruck hergestellt. 
Innerhalb der Läsion wird die Nadel drei- bis viermal schnell vor- und zurückgezogen. Die Nadel wird dabei fächerförmig geführt.

Im Anschluss daran erfolgt zunächst der Druckausgleich, indem der Kolben in die Ausgangsstellung zurückgleitet. Hierdurch wird vermieden, dass beim Herausziehen der Nadel nicht repräsentatives Zellmaterial der Umgebung des Knotens aspiriert wird.

Nach Beendigung der Punktion wird die Nadel von der Spritze entfernt und die Spritze wird mit Luft gefüllt.

Die Nadel wird erneut auf die Spritze aufgesteckt und das Aspirat wird unter mäßigem Druck aus der Nadel herausgedrückt und in Tropfenform auf die bereitgelegten Objektträger aufgetragen. Die Nadelspitze liegt dabei dem Objektträger auf.

Die Aspirattropfen auf den Objektträgern werden dann in einem Zug ohne allzu große Druckausübung (zur Vermeidung von Quetschartefakten) mit einem Objektträger ausgestrichen.

Waren größere Blutbeimengungen auf dem Objektträger, ließen die Autoren das Blut vorsichtig abtropfen (Literaturempfehlung: Lehrbuch Pfannenstiel, 40).

Dann erst erfolgte der Ausstrich.

\section{Abbildung 14}

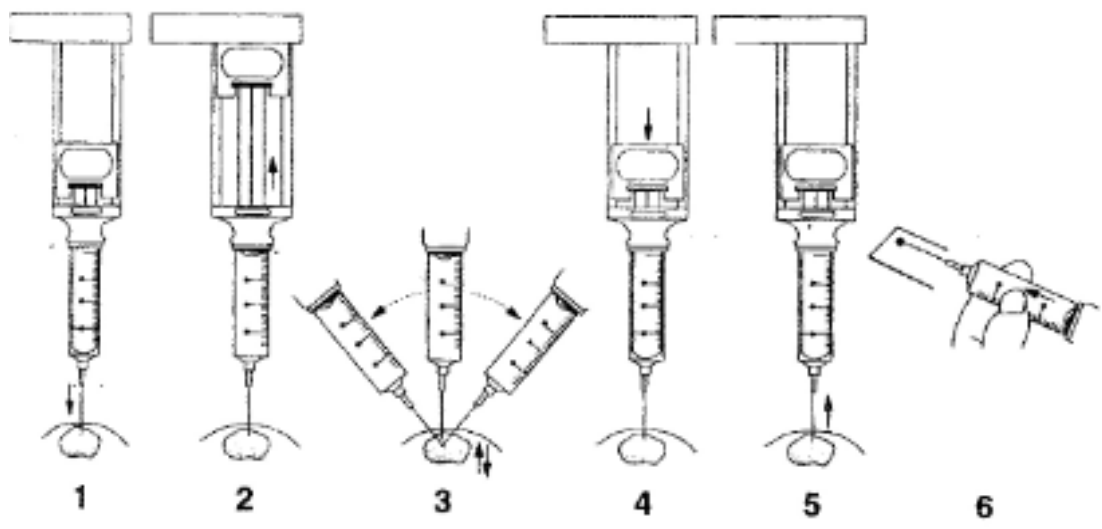


Nicht alle Punktate sind diagnostisch ausreichend verwertbar. Die Häufigkeit von Punktaten, die wegen Zellarmut nicht beurteilbar sind, sollte unter $10 \%$ liegen.

Dieses Kriterium war bei den Studienpatienten weitgehend erfüllt (13\%; siehe Punkt 4).

Ein Punktat gilt aus zytologischer Sicht als qualitativ ausreichend, wenn in zwei Präparaten mindestens sechs Follikelzellverbände, bestehend aus zehn oder mehr Follikelzellen vorliegen $(42,67,68)$.

Sämtliche Punktate wurden an die Universität Göttingen / Abteilung Zytopathologie versandt und von Frau Dr. I. Ruschenburg / Oberärztin untersucht.

Beurteilungskriterien der Punktionszytologie der Schilddrüse (39, 63):

- positiv (sicheres Malignom)

- weiter abklärungsbedürftig (Histologie erforderlich)

- negativ (keine Hinweise auf Malignom)

- nicht verwertbar (Wiederholung der Punktion) 


\section{4. $\quad$ Ergebnisse}

Von insgesamt 130 Patienten mit szintigraphisch vollständig kalten Knoten wurden 112 operiert. Bei 8 Patienten wurde keine Operation durchgeführt.

Trotz Bemühungen von unserer Seite kam es entweder zu einem Kontaktverlust oder aber die Operation wurde vom Patienten abgelehnt.

112 Patienten stellten somit das Kollektiv unserer Studie dar. Bei 24 von ihnen fand sich ein Schilddrüsenkarzinom.

\section{Tabelle 5}

Histologie maligner Schilddrüsentumore $(n=24)$

\begin{tabular}{|lrc|}
\hline papilläres Schilddrüsenkarzinom & 14 & $(58 \%)$ \\
follikuläres Schilddrüsenkarzinom & 8 & $(33 \%)$ \\
anaplastisches Schilddrüsenkarzinom & 1 & $(4 \%)$ \\
Non-Hodgkin-Lymphom der Schilddrüse & 1 & $(4 \%)$ \\
medulläres Schilddrüsenkarzinom & 0 & \\
\hline
\end{tabular}

Tabelle 6

Altersverteilung der Schilddrüsenkarzinome $(n=24)$

- unter 50 Jahre : 7 Patienten

- 50 bis 59 Jahre : 3 Patienten

- 60 bis 69 Jahre : 6 Patienten

- älter als 70 Jahre : 8 Patienten

Tabelle 7

Geschlechts- und Altersverteilung der Schilddrüsenkarzinome $(n=24)$

- Frauen : 16 Patientinnen mit Schilddrüsenkarzinom

8 Patientinnen älter als 60 Jahre (50\%)

- Männer： 8 Patienten mit Schilddrüsenkarzinom

6 Patienten älter als 60 Jahre (75\%) 
Die Knotengröße betrug 2,2 bis 8,0 cm. Die mittlere Knotengröße lag bei 3,5 cm.

Bei allen Schilddrüsenkarzinomen fand sich ein echoarmes oder ein echokomplexes Echomuster.

Betrachtet man die benignen szintigraphisch „vollständig kalten” Knoten (insgesamt 88 Patienten), so ergibt sich folgendes Ergebnis:

1. Bei $56 \%$ fand sich histologisch ein follikuläres Adenom (49 Pat. von 88).

2. Bei $44 \%$ fand sich ein hyperplastischer Knoten (38 Pat. von 88 ).

Auffällig ist der hohe Anteil an Schilddrüsenkarzinomen bei Männern über 65 Jahren. $75 \%$ dieser Patientengruppe wiesen ein Schilddrüsenkarzinom auf (6 von 8 Männern).

Bei 3 von 24 Karzinombefunden war die Zytologie wegen einer zu geringen Zellzahl nicht beurteilbar (13\% nicht diagnostisch). Malignitätshinweise fanden sich bei diesen Ausstrichen nicht. Bei den übrigen 21 Karzinompatienten zeigte die Zytologie ausreichendes Zellmaterial.

Insgesamt fanden wir 14 papilläre Schilddrüsenkarzinome. 8 von Ihnen wurden zytologisch richtig diagnostiziert. Bei 3 der 14 papillären Neoplasien war die Zellzahl für die Beurteilung unzureichend (,nicht diagnostisch”).

Bei den verbliebenen 3 Fällen mit zytologisch nicht diagnostizierten Karzinomen fand sich im Punktat eine fokale Thyreoiditis bei ansonsten fehlenden Hinweisen auf eine Autoimmunthyreoiditis der gesamten Schilddrüse.

Bei 8 von 24 Neoplasien handelte es sich um ein follikuläres Schilddrüsenkarzinom. Bei 4 der 8 follikulären Karzinome ergab die Zytologie keinen malignitätsverdächtigen Befund. Bei 3 der zytologisch negativen Punktate wurde eine mikrofollikuläre Proliferation beschrieben, die allerdings die Kriterien einer follikulären Neoplasie nicht voll erfüllte. 
Bei 13 von 24 Zytologien fand sich zytologisch ein Schilddrüsenkarzinom oder aber es bestand zytologisch der Verdacht auf das Vorliegen eines Karzinoms.

Unter Berücksichtigung der Tatsache, dass Zytologien, die unzureichendes Zellmaterial („,nicht diagnostisch”) aufweisen, bei der Berechnung der Sensitivität nicht berücksichtigt werden, lag die Treffsicherheit unserer zytologischen Befunde in der Gruppe der Karzinompatienten lediglich bei $62 \%$.

Im Untersuchungszeitraum der letzten 5 Jahre fanden sich in unserem Patientenkollektiv insgesamt 96 Schilddrüsenkarzinome. Bei 24 von ihnen (25\%) zeigte die Szintigraphie einen szintigraphisch vollständig kalten Knoten. Diese Patienten stellen die Gruppe der Karzinompatienten dieser retrospektiven Studie.

Die Verteilung der Schilddrüsenkarzinome nach dem szintigraphischem Befund zeigt die folgende Tabelle.

Tabelle 8

\section{Schilddrüsenkarzinome}

Aufteilung nach dem szintigraphischen Befund:

1. Große Knotenstruma Ш 24 Pat. $(25 \%)$ mit sonographisch schwer abgrenzbaren Knoten (mit „kühlen und kalten ”Arealen)

2. Szintigraphisch „kühle” Knoten 6 Pat. $\quad(6 \%)$ mit verminderter, jedoch vorhandener Nuklidspeicherung

3. Szintigraphisch „nicht differenzierbare” Knoten 22 Pat. $(23 \%)$

4. Kalte Knoten mit minimaler Nuklidbelegung 20 Pat. $(21 \%)$

5. Szintigraphisch „vollständig kalter” Knoten 24 Pat. $(25 \%)$ (es handelt sich bei diesem Kollektiv um die Karzinompatienten der vorliegenden Studie) 
Tabelle 9

\section{Schilddrüsenkarzinome}

Aufteilung nach dem histologischen Befund:

papilläres Schilddrüsenkarzinom

$65(56 \%)$

follikuläres Schilddrüsenkarzinom

$24(21 \%)$

medulläres Schilddrüsenkarzinom

$20(17 \%)$

anaplastisches Schilddrüsenkarzinom

$2(2 \%)$

Bei 95 Patienten ist es bisher zu keinem Rezidiv gekommen. Ein Patient ist erwartungsgemäß an seinem Karzinom verstorben (anaplastisches Schilddrüsenkarzinom).

Es ergaben sich keine Hinweise dafür, dass szintigraphisch vollständig kalte maligne Knoten möglicherweise eine schlechtere Prognose hätten als szintigraphisch kühle maligne Knoten mit nur reduzierter (aber zum Teil noch nachweisbarer) Nuklidspeicherung.

\section{Papilläres Mikrokarzinom}

Bei 4 (= 3,5\%) von 112 operierten Patienten fand der Pathologe bei der histologischen Aufarbeitung des Operationsresektats ein papilläres Mikrokarzinom (T1NoMo).

Bei diesen 4 Patienten handelte es sich bei dem szintigrafisch kalten Knoten um einen benignen Befund.

Diese 4 Patienten mit einem papillären Mikrokarzinom wurden nicht in die Gruppe der papillären Karzinome aufgenommen $(\mathrm{n}=14)$, da sie nicht dem szintigraphisch kalten Knoten entsprachen.

Bei den genannten 4 Patienten mit szintigraphisch kalten Knoten (Durchmesser 2,5 bis 3,8 cm) und dem Zufallsbefund eines papillären Mikrokarzinoms wurde eine Hemithyreoidektomie auf der Seite des kalten Knotens durchgeführt sowie eine subtotale Resektion auf der Gegenseite. 


\section{Papilläre Schilddrüsenkarzinome und Autoimmunthyreoiditis}

Bei einer Patientin mit papillärem Schilddrüsenkarzinom $(n=14)$ fand sich das Vollbild einer Autoimmunthyreoiditis.

Bei weiteren 8 Patienten fanden sich Hinweise auf eine fokale Autoimmunthyreoiditis. 6 von ihnen wiesen deutlich erhöhte TPO-AK als Hinweise auf eine Thyreoiditis auf.

Insgesamt zeigten somit 9 von 14 Patienten mit einem papillären Schilddrüsenkarzinom laborchemische und/oder zytologische und histologische Hinweise auf eine Autoimmunthyreoiditis, bei der es sich bis auf eine Ausnahme um eine fokale Thyreoiditis in der unmittelbaren Umgebung des Tumors handelte (bei $64 \%$ der Patienten mit papillärem Schilddrüsenkarzinom).

Die follikulären Karzinome $(n=8)$ zeigten in keinem Fall erhöhte TPO-AK oder zytologische/histologische Hinweise auf eine fokale Autoimmunthyreoiditis.

Tabelle 10

Papilläre Schilddrüsenkarzinome und Autoimmunthyreoiditis

\begin{tabular}{|l|l|l|l|}
\hline Patient & \multicolumn{1}{|c|}{ Zytologie } & \multicolumn{1}{|c|}{ Histologie } & $\begin{array}{l}\text { TPO- } \\
\text { AK }\end{array}$ \\
\hline M. S. & kein Hinweis a. Thyreoiditis & keine Thyreoiditis beschrieben & 0 \\
B. I. & kein Hinweis a. Thyreoiditis & keine Thyreoiditis beschrieben & 0 \\
I. S. & kein Hinweis a. Thyreoiditis & fokale Thyreoiditis & 7056 \\
T. K. & Thyreoiditis & fokale Thyreoiditis & 0 \\
K. W. & kein Hinweis a. Thyreoiditis & fokale Thyreoiditis & 714 \\
L. S. & Thyreoiditis & fokale Thyreoiditis & 0 \\
E. M. & kein Hinweis a. Thyreoiditis & keine Thyreoiditis beschrieben & 0 \\
M. F. & kein Hinweis a. Thyreoiditis & keine Thyreoiditis beschrieben & 300 \\
G. H. & kein Hinweis a. Thyreoiditis & keine Thyreoiditis beschrieben & 1440 \\
H. R. & kein Hinweis a. Thyreoiditis & keine Thyreoiditis beschrieben & 0 \\
A. F. & Thyreoiditis & Thyreoiditis & 4966 \\
B. B. & kein Hinweis a. Thyreoiditis & fokale Thyreoiditis & 2985 \\
I. S. & kein Hinweis a. Thyreoiditis & keine Thyreoiditis beschrieben & 2307 \\
A. R. & kein Hinweis a. Thyreoiditis & keine Thyreoiditis beschrieben & 0 \\
& \multicolumn{2}{|l}{} & \\
\hline
\end{tabular}


Beispiele für Schilddrüsenkarzinome

bei szintigraphisch vollständig kalten Knoten

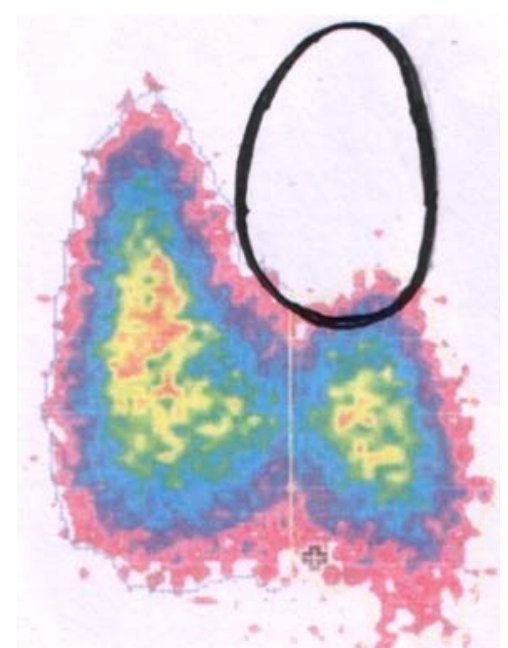

Pat.-Nr. 2: papilläres Schilddrüsenkarzinom (follikuläre Variante)

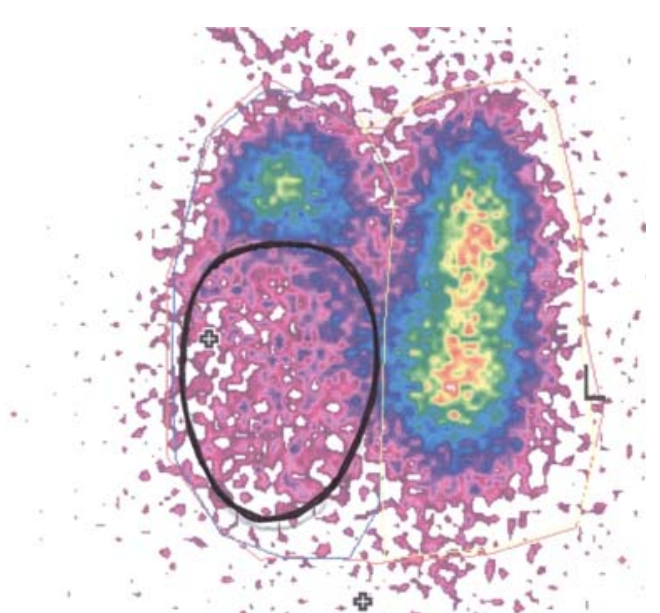

Pat.-Nr. 3: onkozytäres Schilddrüsenkarzinom

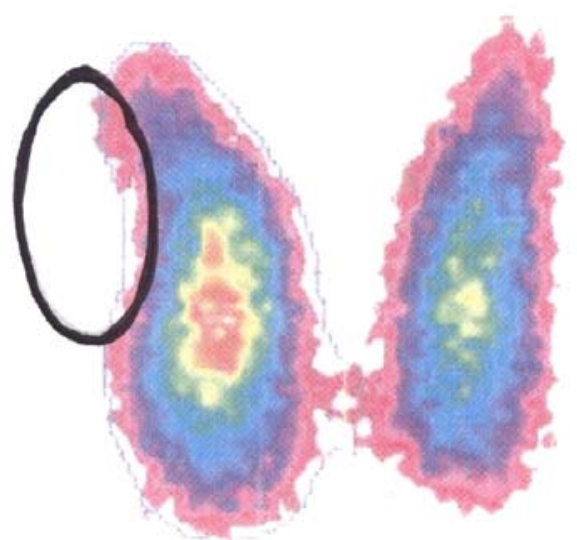

Pat.-Nr. 4: papilläres Schilddrüsenkarzinom 


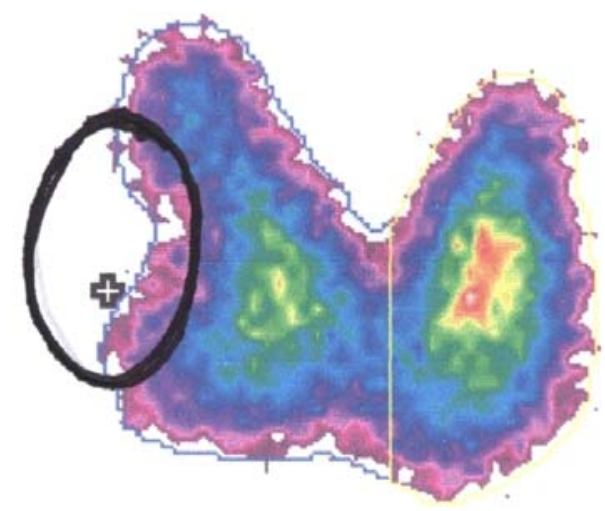

Pat.-Nr. 6: papilläres Schilddrüsenkarzinom

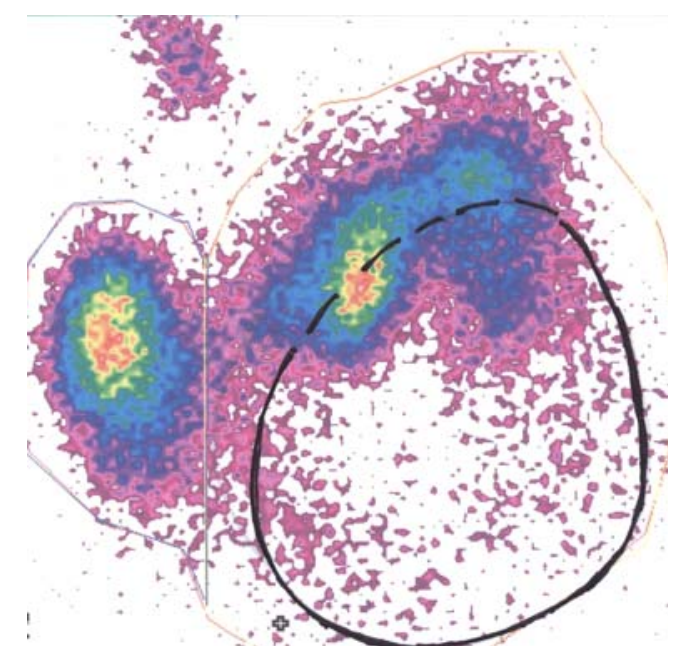

Pat.-Nr. 11: anaplastisches Schilddrüsenkarzinom

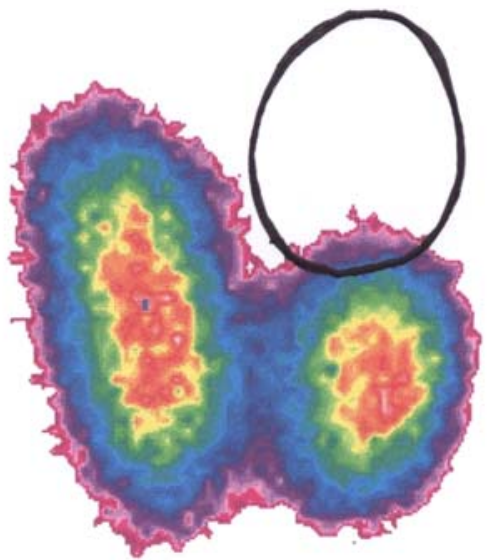

Pat.-Nr. 19: papilläres Schilddrüsenkarzinom 


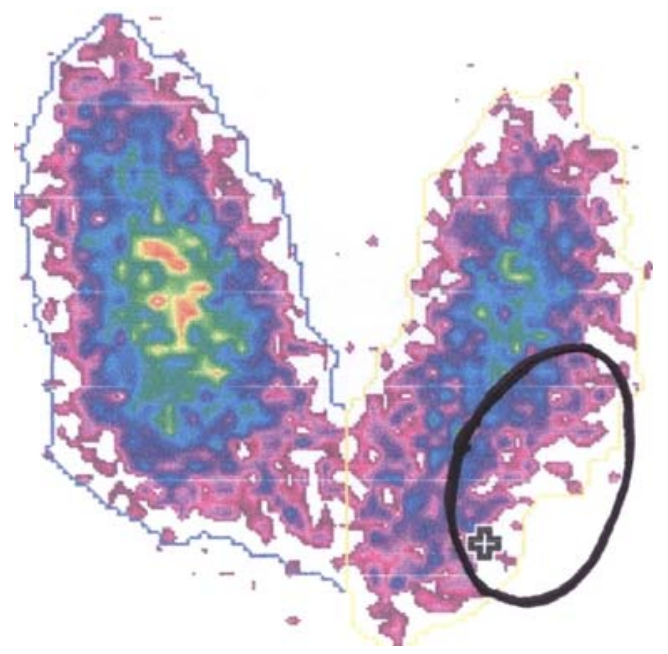

Pat.-Nr. 20:: papilläres Schilddrüsenkarzinom

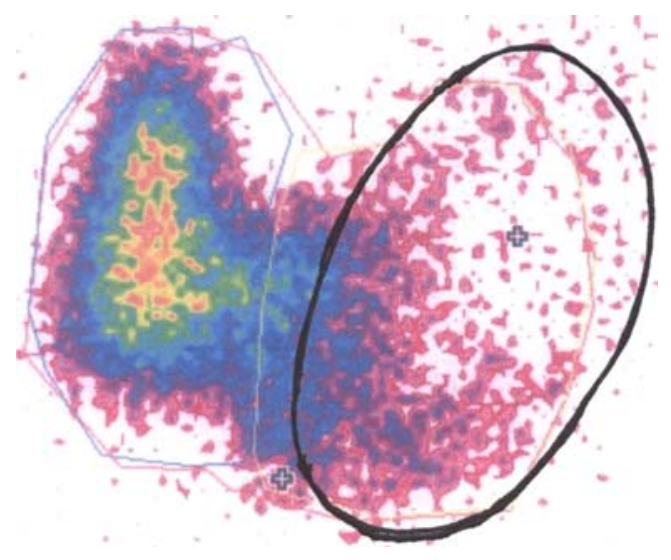

Pat.-Nr. 21: follikuläres Schilddrüsenkarzinom 
Beispiele für ,benigne Knoten“" in szintigraphisch vollständig kalten Knoten
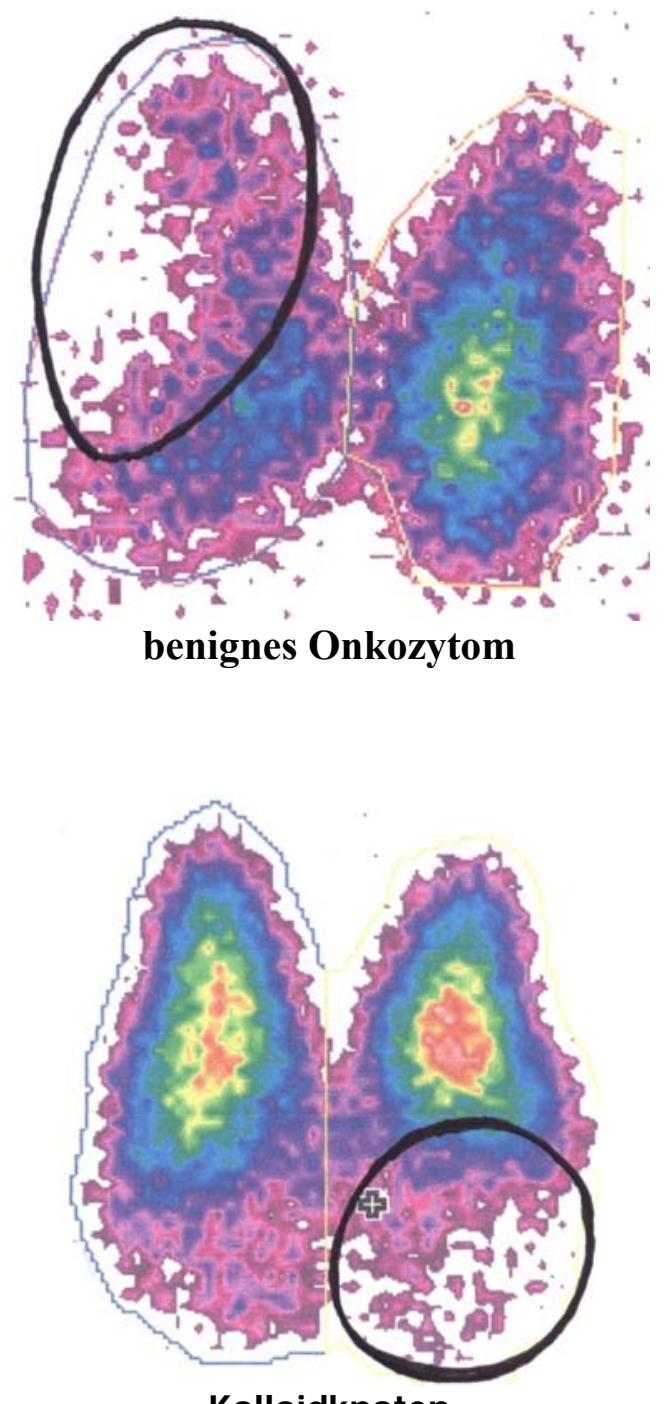

Kolloidknoten

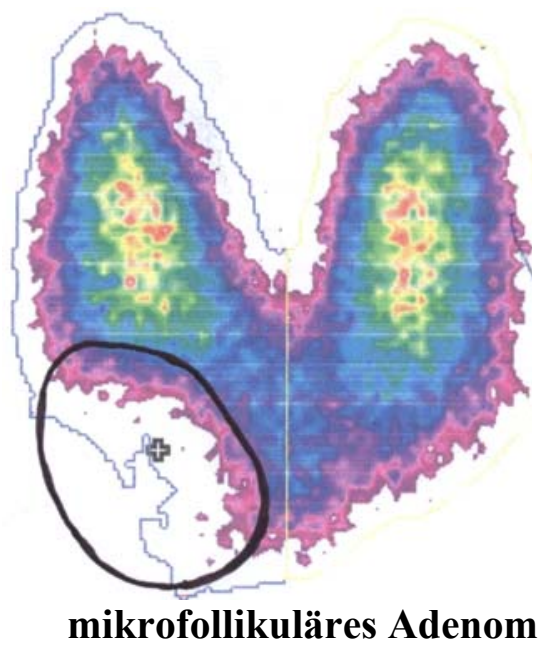


Beispiele für szintigraphisch ,kühle“6 bis ,kalte“6 Knoten mit reduzierter, aber noch vorhandener Nuklidspeicherung

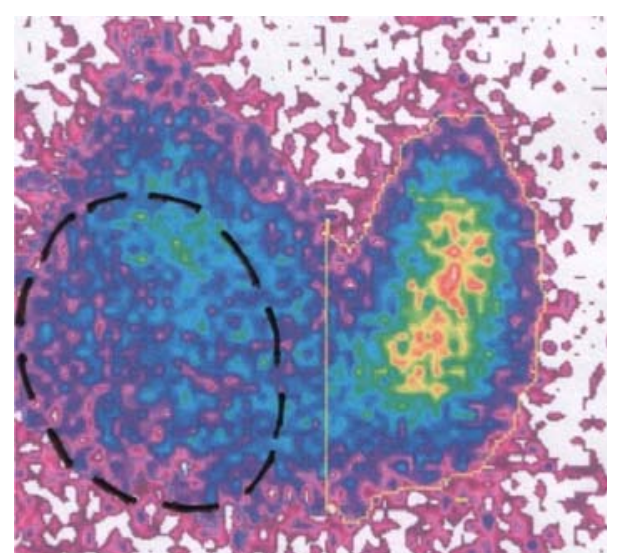

Beispiel eines szintigraphisch „,kühlen“ Knotens mit deutlich nachweisbarer Nuklidspeicherung. minimal invasives follikuläres Schilddrüsenkarzinom

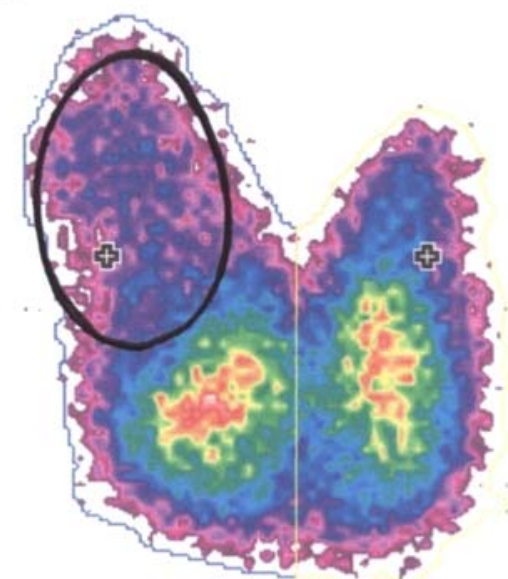

Beispiel eines szintigraphisch „,kalten“Knotens mit deutlich verminderter, aber zum Teil noch vorhandener Nuklidspeicherung. papilläres Schilddrüsenkarzinom

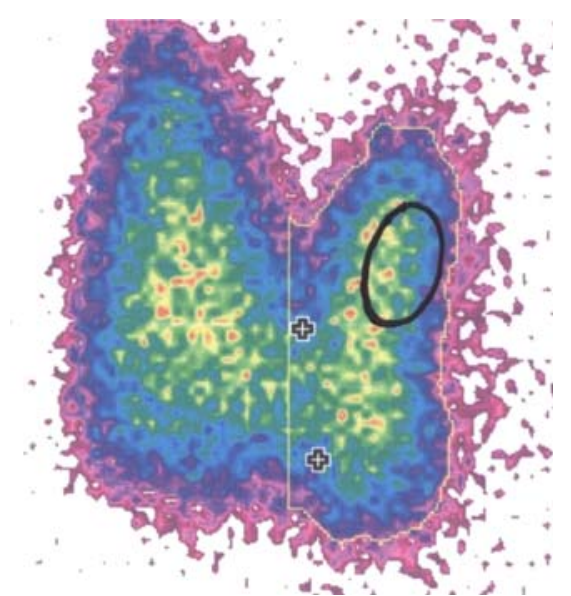

Beispiel eines szintigraphisch ,nicht differenzierbaren“Knotens lymphogen metastasiertes papilläres Schilddrüsenkarzinom 


\section{Die Ergebnisse im Einzelnen}

\begin{tabular}{|c|c|c|c|c|}
\hline Patient & $\begin{array}{c}\text { Sonographie } \\
\text { Knotengröße }\end{array}$ & Zytologie & Histologie & Labor \\
\hline $\begin{array}{l}\text { 1.) M. S. } \\
65 \text { Jahre, } \\
\text { männlich }\end{array}$ & $\begin{array}{l}\text { - echokomplexer Knoten } \\
\text { - Durchmesser: } 2,0 \mathrm{~cm}\end{array}$ & $\begin{array}{l}\text { - Wenige nackte Follikelepithelien. } \\
\text { Etwas Kolloid. } \\
\text { - zytologisch knapp ausreichend } \\
\text { beurteilbar } \\
\text { - Beurteilung: } \\
\text { kein Hinweis auf Malignität }\end{array}$ & $\begin{array}{l}\text { - pT2 N0M0 } \\
\text { - Tumordurchmesser: } 2 \mathrm{~cm} \\
\text { - follikulär-papillärer Aufbau mit } \\
\text { großen geschwollenen Epithelien, } \\
\text { die milchglasförmige Kerne besitzen } \\
\text { Die kapselförmige Begrenzung } \\
\text { bleibt intakt. } \\
\text { - Beurteilung: } \\
\text { papilläres Schilddrüsenkarzinom } \\
\end{array}$ & $\begin{array}{l}\mathrm{fT} 3 \text {, fT4, TSH und TPO-AK } \\
\text { im Normbereich; } \\
\text { Calcitonin und CEA } \\
\text { im Normbereich }\end{array}$ \\
\hline $\begin{array}{l}\text { 2.) B. I. } \\
\text { 51 Jahre, } \\
\text { weiblich }\end{array}$ & $\begin{array}{l}\text { - echoarmer bis } \\
\text { echokomplexer Knoten } \\
\text { - Durchmesser: } \\
\text { 3,2 x 3,5 x } 3,3 \mathrm{~cm}\end{array}$ & $\begin{array}{l}\text { - wenig, meist eingedicktes Kolloid } \\
\text { - vereinzelt Follikelepithelien } \\
\text { - zytologisch knapp ausreichend } \\
\text { beurteilbar } \\
\text { - Beurteilung: } \\
\text { kein Hinweis auf Malignität }\end{array}$ & $\begin{array}{l}\text { - pT2 N0M0 } \\
\text { - Tumordurchmesser: ca. } 3 \mathrm{~cm} \\
\text { - Der Knoten zeigt größere teilweise } \\
\text { sklerosierte Narbenfelder mit } \\
\text { Verkalkungen und umschriebenen } \\
\text { Verknöcherungszonen. } \\
\text { - dicht gelagerte, unterschiedlich } \\
\text { große Follikel } \\
\text { - herdförmig vereinzelt auch papilläre } \\
\text { Formationen mit Milchglaskernen } \\
\text { und Psammonkörpern } \\
\text { - Beurteilung: } \\
\text { follikuläre Variante eines papillären } \\
\text { Schilddrüsenkarzinoms }\end{array}$ & $\begin{array}{l}\mathrm{fT} 3 \text {, fT4, TSH und TPO-AK } \\
\text { im Normbereich; } \\
\text { Calcitonin und CEA } \\
\text { im Normbereich }\end{array}$ \\
\hline $\begin{array}{l}\text { 3.) H. A. } \\
85 \text { Jahre, } \\
\text { weiblich }\end{array}$ & $\begin{array}{l}\text { - echokomplexer Knoten } \\
\text { - Durchmesser: } \\
4,1 \text { x } 3,5 \text { x } 4,1 \mathrm{~cm}\end{array}$ & $\begin{array}{l}\text { - Wenige erhaltene Onkozyten. } \\
\text { Zahlreiche nackte Zellkerne, die beim } \\
\text { Ausstreichen teils gequetscht wurden } \\
\text { und wahrscheinlich aus Onkozyten } \\
\text { stammen } \\
\text { - ferner kapillarhaltige Stromapartikel, } \\
\text { die für einen gefäßreichen Tumor } \\
\text { sprechen } \\
\text { - Beurteilung: } \\
\text { Das Bild ist vereinbar mit einem } \\
\text { Onkozytom (oxyphile follikuläre } \\
\text { Neoplasie). }\end{array}$ & $\begin{array}{l}\text { - pT2 N0M0 } \\
\text { - Tumordurchmesser: } 4 \mathrm{~cm} \\
\text { - Bild des follikulären Karzinoms vom } \\
\text { oxyphilen bzw. onkozytären Typ. } \\
\text { Nur an einer Stelle läßt sich eine } \\
\text { Penetration der Kapsel nachweisen als } \\
\text { Ausdruck eines minimal invasiven } \\
\text { Tumorwachstums. } \\
\text { - Beurteilung: } \\
\text { onkozytäres Schilddrüsenkarzinom }\end{array}$ & $\begin{array}{l}\mathrm{fT} 3 \text {, fT4, TSH und TPO-AK } \\
\text { im Normbereich; } \\
\text { Calcitonin und CEA } \\
\text { im Normbereich }\end{array}$ \\
\hline
\end{tabular}




\begin{tabular}{|c|c|c|c|c|}
\hline Patient & $\begin{array}{l}\text { Sonographie } \\
\text { Knotengröße } \\
\end{array}$ & Zytologie & Histologie & Labor \\
\hline $\begin{array}{l}\text { 4. ) I. S. } \\
23 \text { Jahre, } \\
\text { weiblich }\end{array}$ & $\begin{array}{l}\text { - echoarmer Knoten } \\
\text { - Durchmesser: } \\
2,5 \times 1,3 \times 1,8 \mathrm{~cm}\end{array}$ & $\begin{array}{l}\text { - nur sehr wenige Elemente des } \\
\text { Schilddrüsengewebes mit regressiven } \\
\text { Veränderungen } \\
\text { - Beurteilung: } \\
\text { Das Punktat ist zytologisch nicht } \\
\text { ausreichend beurteilbar. }\end{array}$ & $\begin{array}{l}\text { - pT2 N0M0 } \\
\text { - Tumordurchmesser: } 2,2 \mathrm{~cm} \\
\text { - Teilweise papilläre Formationen. } \\
\text { Zum Teil stärkergradig vernarbte und } \\
\text { sklerosierte Bereiche mit invasiver } \\
\text { Ausbreitung des Tumors. } \\
\text { Teilweise kapselartige, schmale } \\
\text { Begrenzung. } \\
\text { - Immer wieder finden sich lymphozytäre } \\
\text { Infiltrate. } \\
\text { - Beurteilung: } \\
\text { papilläres Schilddrüsenkarzinom }\end{array}$ & $\begin{array}{l}\text { fT3, fT4 und TSH } \\
\text { im Normbereich; } \\
\text { TPO-AK: } 7056 \mathrm{U} / \mathrm{ml} \text {; } \\
\text { Calcitonin und CEA } \\
\text { im Normbereich }\end{array}$ \\
\hline $\begin{array}{l}\text { 5.) E. M. } \\
68 \text { Jahre, } \\
\text { weiblich }\end{array}$ & $\begin{array}{l}\text { - echoarmer Knoten } \\
\text { - Durchmesser: } \\
\text { 7,0 x } 3,6 \times 3,0 \mathrm{~cm} \\
\text { übrige Schilddrüse: } \\
\text { typ. echoarmes Bild einer } \\
\text { Autoimmunthyreoiditis } \\
\text { (TPO-AK über 8000) }\end{array}$ & $\begin{array}{l}\text { - Wenige nackte Follikelepithelkerne. } \\
\text { Fleckförmig etwas Kolloid. } \\
\text { - Beurteilung: } \\
\text { kein Hinweis auf Malignität }\end{array}$ & $\begin{array}{l}\text { - pT4 N1M1 } \\
\text { - Tumordurchmesser: 7,0 x } 3,5 \text { x 3,0 cm } \\
\text { - über die Veränderungen einer chron. } \\
\text { lymphozytären Thyreoiditis Hashimoto } \\
\text { hinaus destruierende atypische } \\
\text { lymphoidzellige Infiltration. } \\
\text { - Beurteilung: } \\
\text { malignes Non-Hodgkin-Lymphom } \\
\text { (MALT-Lymphom) }\end{array}$ & $\begin{array}{l}\text { fT3 und fT4 im } \\
\text { Normbereich; } \\
\text { TPO-AK: > } 8000 \mathrm{U} / \mathrm{ml} \text {; } \\
\text { Calcitonin und CEA } \\
\text { im Normbereich }\end{array}$ \\
\hline $\begin{array}{l}\text { 6.) T. K. } \\
61 \text { Jahre, } \\
\text { weiblich }\end{array}$ & $\begin{array}{l}\text { - echokomplexer Knoten } \\
\text { - Durchmesser: } \\
2,3 \times 2,0 \times 1,7 \mathrm{~cm}\end{array}$ & $\begin{array}{l}\text { - dünner Kolloidniederschlag } \\
\text { - Mäßig viele Follikelepithelien und } \\
\text { zahlreiche kleine Lymphozyten. } \\
\text { Abschnittsweise regelrechte } \\
\text { Zentroblasten. } \\
\text { - Das Zellbild entspricht einer } \\
\text { lymphozytären Thyreoiditis. } \\
\text { - Beurteilung: } \\
\text { kein Hinweis auf Malignität }\end{array}$ & $\begin{array}{l}\text { - pT2 N0M0 } \\
\text { - Tumordurchmesser: } 2 \mathrm{~cm} \\
\text { - Neben follikulären findet man auch } \\
\text { papilläre Strukturen. Innerhalb der } \\
\text { papillären Bereiche sieht man } \\
\text { Sklerosierungen. } \\
\text { Herdförmig zeigen sich mitteldichte } \\
\text { lymphozytäre Infiltrate. } \\
\text { - Beurteilung: } \\
\text { papilläres Schilddrüsenkarzinom }\end{array}$ & $\begin{array}{l}\text { fT3, fT4, TSH und TPO-AK } \\
\text { im Normbereich; } \\
\text { Calcitonin und CEA } \\
\text { im Normbereich }\end{array}$ \\
\hline
\end{tabular}




\begin{tabular}{|c|c|c|c|c|}
\hline Patient & $\begin{array}{l}\text { Sonographie } \\
\text { Knotengröße }\end{array}$ & Zytologie & Histologie & Labor \\
\hline $\begin{array}{l}\text { 7.) K. W. } \\
52 \text { Jahre, } \\
\text { weiblich }\end{array}$ & $\begin{array}{l}\text { - echokomplexer Knoten } \\
\text { - Durchmesser: } 2,3 \mathrm{~cm}\end{array}$ & $\begin{array}{l}\text { - fleckförmig, etwas Kolloid, } \\
\text { eingestreut wenige Follikelepithelien } \\
\text { - Beurteilung: } \\
\text { Das Punktat ist zytologisch nicht } \\
\text { beurteilbar. }\end{array}$ & $\begin{array}{l}\text { - papilläres Schilddrüsenkarzinom } \\
\text { (pT2 N0M0) } \\
\text { - Tumordurchmesser: 2,2 cm } \\
\text { - Der Tumor weist fibröse Areale auf } \\
\text { sowie herdförmige lymphozytäre } \\
\text { Infiltrate. Auch das benachbarte } \\
\text { Schilddrüsenparenchym zeigt } \\
\text { herdförmige Lymphozyteninfiltrate. } \\
\text { - Der Tumor ist nicht gekapselt. } \\
\text { Es zeigen sich papilläre sowie auch } \\
\text { follikuläre Formationen. } \\
\text { - Die Tumorzellen haben z. T. einen } \\
\text { onkozytären Aspekt. Es finden sich } \\
\text { z. T. lymphozytäre Infiltrate. } \\
\text { Die Tumorkapsel ist teilweise } \\
\text { infiltriert. } \\
\text { - Beurteilung: mäßig differenziertes } \\
\text { papilläres Karzinom }\end{array}$ & $\begin{array}{l}\mathrm{fT} 3 \text {, fT4 und TSH } \\
\text { im Normbereich; } \\
\text { TPO-AK: } 718 \mathrm{U} / \mathrm{ml} \text {; } \\
\text { Calcitonin und CEA } \\
\text { im Normbereich }\end{array}$ \\
\hline $\begin{array}{l}\text { 8.) M. H. } \\
\text { 41 Jahre, } \\
\text { weiblich }\end{array}$ & $\begin{array}{l}\text { - echoarmer Knoten } \\
\text { - Durchmesser: } \\
\text { 3,0 x 2,8 x 3,5 cm }\end{array}$ & $\begin{array}{l}\text { - Sehr wenig Kolloid. } \\
\text { Wenige Elemente eines mikro } \\
\text { follikulär gebauten Schilddrüsen- } \\
\text { gewebes. } \\
\text { - Beurteilung: } \\
\text { Verdacht auf follikuläre Neoplasie }\end{array}$ & $\begin{array}{l}\text { - pT2 N0M0 } \\
\text { - Tumordurchmesser: } 3,2 \mathrm{~cm} \\
\text { - umschriebene Kapselinvasion des } \\
\text { Tumors } \\
\text { - Beurteilung: minimal invasives } \\
\text { follikuläres Schilddrüsenkarzinom }\end{array}$ & $\begin{array}{l}\mathrm{fT} 3 \text {, fT4, TSH und TPO-AK } \\
\text { im Normbereich; } \\
\text { Calcitonin und CEA } \\
\text { im Normbereich }\end{array}$ \\
\hline $\begin{array}{l}\text { 9.) L. S } \\
\text { 77 Jahre, } \\
\text { weiblich }\end{array}$ & $\begin{array}{l}\text { - echoarmer Knoten } \\
\text { - Durchmesser: } \\
3,3 \text { x } 2,9 \text { x } 2,5 \mathrm{~cm}\end{array}$ & $\begin{array}{l}\text { - Kolloid mit erhöhter Viskosität } \\
\text { (Kautschukkolloid), zahlreiche } \\
\text { follikuläre Zellen. } \\
\text { - vereinzelt angedeutet papillär } \\
\text { konfigurierte Zellverbände } \\
\text { - stellenweise intranukleäre Zyto- } \\
\text { plasmaeinschlüsse } \\
\text { - zusätzlich zahlreiche Lymphozyten } \\
\text { als Zeichen einer lymphozytären } \\
\text { Begleitthyreoiditis } \\
\text { - Beurteilung: } \\
\text { papilläres Schilddrüsenkarzinom }\end{array}$ & $\begin{array}{l}\text { - pT2 N0M0 } \\
\text { - Tumordurchmesser: } 3,5 \mathrm{~cm} \\
\text { - überwiegend kleinfollikuläre } \\
\text { Strukturen } \\
\text { - z. T. Milchglaskerne } \\
\text { - herdförmige Sklerosierungen und } \\
\text { angedeutet papilläre Formationen } \\
\text { - Der Knoten ist von einer Kapsel } \\
\text { umgeben. } \\
\text { - Beurteilung: } \\
\text { follikuläre Variante eines } \\
\text { papillären Schilddrüsenkarzinoms }\end{array}$ & $\begin{array}{l}\mathrm{fT} 3 \text {, fT4, TSH und TPO-AK } \\
\text { im Normbereich; } \\
\text { Calcitonin und CEA } \\
\text { im Normbereich }\end{array}$ \\
\hline
\end{tabular}




\begin{tabular}{|c|c|c|c|c|c|}
\hline & Patient & $\begin{array}{l}\text { Sonographie } \\
\text { Knotengröße }\end{array}$ & Zytologie & Histologie & Labor \\
\hline 10.) & $\begin{array}{l}\text { A. A. } \\
\text { 35 Jahre, } \\
\text { weiblich }\end{array}$ & $\begin{array}{l}\text { - echokomplexer Knoten } \\
\text { - Durchmesser: } \\
5,5 \times 2,1 \times 3,5 \mathrm{~cm}\end{array}$ & $\begin{array}{l}\text { - eingedicktes Kolloid } \\
\text { - mäßig viele Follikelzellen } \\
\text { - Beurteilung: } \\
\text { Regressiv verändertes } \\
\text { Schilddrüsengewebe. } \\
\text { Kein Hinweis auf Malignität. }\end{array}$ & $\begin{array}{l}\text { - pT3 N0M0 } \\
\text { - Tumordurchmesser: } 4,3 \text { x } 4,5 \text { x } 2,0 \mathrm{~cm} \\
\text { - atypische follikuläre Tumorformationen } \\
\text { - mehrfach atypische Mitosen } \\
\text { - zum Teil Kapseleinbruch des Tumors } \\
\text { - Beurteilung: } \\
\text { gekapseltes follikuläres } \\
\text { Schilddrüsenkarzinom }\end{array}$ & $\begin{array}{l}\mathrm{fT} 3 \text {, fT4, TSH und TPO-AK } \\
\text { im Normbereich; } \\
\text { Calcitonin und CEA } \\
\text { im Normbereich }\end{array}$ \\
\hline 11.) & $\begin{array}{l}\text { I. C. } \\
68 \text { Jahre, } \\
\text { weiblich }\end{array}$ & $\begin{array}{l}\text { - echokomplexer Knoten } \\
\text { - Durchmesser: } \\
7,0 \text { x } 6,0 \text { × } 8,0 \mathrm{~cm}\end{array}$ & $\begin{array}{l}\text { - spindelzellige Zellkerne } \\
\text { - kein Nachweis von Schilddrüsen- } \\
\text { elementen } \\
\text { - Beurteilung: } \\
\text { spindelzelliger mesenchymaler Tumor }\end{array}$ & $\begin{array}{l}\text { - pT4 NXMX } \\
\text { - Tumordurchmesser: } 7 \mathrm{~cm} \\
\text { - epithelialer Tumor } \\
\text { - z. T. positive Reaktion mit Antikörpern } \\
\text { gegen Thyreoglobulin } \\
\text { - daneben Spindelzellkomponente mit } \\
\text { atypischen Mitosen } \\
\text { - Beurteilung: } \\
\text { gering differenziertes } \\
\text { Schilddrüsenkarzinom (sogenanntes } \\
\text { insuläres Karzinom) mit Anteilen eines } \\
\text { anaplastischen Schilddrüsenkarzinoms }\end{array}$ & $\begin{array}{l}\text { fT3, fT4 und TSH } \\
\text { im Normbereich; } \\
\text { TPO-AK: }>8000 \mathrm{U} / \mathrm{ml} \text {; } \\
\text { Calcitonin und CEA } \\
\text { im Normbereich }\end{array}$ \\
\hline 12.) & $\begin{array}{l}\text { E. M. } \\
87 \text { Jahre, } \\
\text { weiblich }\end{array}$ & $\begin{array}{l}\text { - echokomplexer Knoten } \\
\text { - Durchmesser: 5,6 cm }\end{array}$ & $\begin{array}{l}\text { - fleckförmig verteiltes hochvisköses } \\
\text { Kolloid } \\
\text { - zahlreiche Follikelepithelien, z. T. mit } \\
\text { papillären Formationen intranukleäre } \\
\text { Zytoplasmaeinschlüsse } \\
\text { - eingestreut histiozytäre Riesenzellen } \\
\text { - Beurteilung: } \\
\text { papilläres Schilddrüsenkarzinom }\end{array}$ & $\begin{array}{l}\text { - pT4 NXM0 } \\
\text { - Tumordurchmesser: } 4,2 \mathrm{~cm} \\
\text { - zum Teil invasive Ausbreitung eines } \\
\text { papillären Tumors in die } \\
\text { Schilddrüsenkapsel bis in den Bereich } \\
\text { angrenz. Fettgewebes. } \\
\text { - Beurteilung: } \\
\text { papilläres Schilddrüsenkarzinom }\end{array}$ & $\begin{array}{l}\text { fT3, fT4 und TPO-AK } \\
\text { im Normbereich; } \\
\text { Calcitonin und CEA } \\
\text { im Normbereich }\end{array}$ \\
\hline
\end{tabular}




\begin{tabular}{|c|c|c|c|c|c|}
\hline & Patient & $\begin{array}{l}\text { Sonographie } \\
\text { Knotengröße } \\
\end{array}$ & Zytologie & Histologie & Labor \\
\hline 13.) & $\begin{array}{l}\text { W. E. } \\
78 \text { Jahre, } \\
\text { männlich }\end{array}$ & $\begin{array}{l}\text { - echokomplexer Knoten } \\
\text { - Durchmesser: } \\
\text { 3,5 x 2,9 x 2,8 cm }\end{array}$ & $\begin{array}{l}\text { - stellenweise Kolloid } \\
\text { - relativ zellarmes Bild mit wenigen } \\
\text { Follikelepithelien } \\
\text { - Punktat für eine sichere Beurteilung } \\
\text { nicht ausreichend. } \\
\text { - Beurteilung: } \\
\text { kein Hinweis auf Tumorzellen bei } \\
\text { nicht ausreichender Beurteilbarkeit }\end{array}$ & $\begin{array}{l}\text { - pT2 N0M0 } \\
\text { - Tumordurchmesser: } 3,5 \mathrm{~cm} \\
\text { - follikuläre Strukturen } \\
\text { - bindegewebige Kapsel } \\
\text { - Nachweis einer Kapselgefäßinfiltration } \\
\text { des Tumors. } \\
\text { - Beurteilung: minimal invasives } \\
\text { gekapseltes follikuläres } \\
\text { Schilddrüsenkarzinom } \\
\end{array}$ & $\begin{array}{l}\mathrm{fT} 3 \text {, fT4, TSH und TPO-AK } \\
\text { im Normbereich; } \\
\text { Calcitonin und CEA } \\
\text { im Normbereich }\end{array}$ \\
\hline 14.) & $\begin{array}{l}\text { M. F. } \\
54 \text { Jahre, } \\
\text { weiblich }\end{array}$ & $\begin{array}{l}\text { - echokomplexer Knoten } \\
\text { - Durchmesser: } \\
\text { 3,0 x } 2,9 \text { x } 2,6 \mathrm{~cm}\end{array}$ & $\begin{array}{l}\text { - hochvisköses Kolloid } \\
\text { - zahlreiche Follikelzellen, die in } \\
\text { papillären Formationen vorliegen } \\
\text { - vereinzelt intranukleäre Zyto- } \\
\text { plasmaeinschlüsse } \\
\text { - Beurteilung: } \\
\text { papilläres Schilddrüsenkarzinom }\end{array}$ & $\begin{array}{l}\text { - pT2 N0M0 } \\
\text { - Tumordurchmesser: } 2,7 \mathrm{~cm} \\
\text { - papilläre Formationen } \\
\text { - intranukleäre Zytoplasmaeinschlüsse } \\
\text { - Beurteilung: } \\
\text { papilläres Schilddrüsenkarzinom }\end{array}$ & $\begin{array}{l}\text { fT3, fT4 und TSH } \\
\text { im Normbereich; } \\
\text { TPO-AK: } 300 \mathrm{U} / \mathrm{ml} \text {; } \\
\text { Calcitonin und CEA } \\
\text { im Normbereich }\end{array}$ \\
\hline 15.) & $\begin{array}{l}\text { G. H. } \\
\text { 43 Jahre, } \\
\text { weiblich }\end{array}$ & $\begin{array}{l}\text { - echoarmer Knoten } \\
\text { - Durchmesser: } \\
\text { 2,4 x 1,0 x 2,0 cm }\end{array}$ & $\begin{array}{l}\text { - Spuren von Kolloid } \\
\text { - mäßig viele Follikelzellen in } \\
\text { dominant mikrofollikulärer } \\
\text { Anordnung } \\
\text { - Beurteilung: } \\
\text { dominant mikrofollikulär } \\
\text { proliferiertes Schilddrüsengewebe, } \\
\text { das allerdings nicht ganz die Kriterien } \\
\text { der follikulären Neoplasie erfüllt }\end{array}$ & $\begin{array}{l}\text { - pT2a N0M0 } \\
\text { - Tumordurchmesser: } 1,7 \mathrm{~cm} \\
\text { - Überwiegend follikulär aufgebaute } \\
\text { Epithelien mit Milchglaskernen. } \\
\text { Vereinzelt Mitosen. } \\
\text { - an wenigen Stellen papilläre Strukturen } \\
\text { - Beurteilung: } \\
\text { follikuläre Variante eines papillären } \\
\text { Schilddrüsenkarzinoms }\end{array}$ & $\begin{array}{l}\text { fT3, fT4 und TSH } \\
\text { im Normbereich; } \\
\text { TPO-AK: } 1440 \mathrm{U} / \mathrm{ml} \text {; } \\
\text { Calcitonin und CEA } \\
\text { im Normbereich }\end{array}$ \\
\hline 16.) & $\begin{array}{l}\text { H. R. } \\
79 \text { Jahre, } \\
\text { männlich }\end{array}$ & $\begin{array}{l}\text { - echokomplexer Knoten } \\
\text { - Durchmesser: } 3,5 \mathrm{~cm}\end{array}$ & $\begin{array}{l}\text { - wenig Kolloid } \\
\text { - kein beurteilbares Zellmaterial } \\
\text { - Beurteilung: } \\
\text { Punktat nicht beurteilbar }\end{array}$ & $\begin{array}{l}\text { - pT2 N0M0 } \\
\text { - Tumordurchmesser: } 3,5 \mathrm{~cm} \\
\text { - teils gekapselter Tumor mit follikulären } \\
\text { und papillären Strukturen } \\
\text { - vielfach Milchglaskerne } \\
\text { - z. T. Fibrosierungen und herdförmige } \\
\text { Verkalkungen } \\
\text { - Beurteilung: } \\
\text { papilläres Schilddrüsenkarzinom }\end{array}$ & $\begin{array}{l}\mathrm{fT} 3 \text {, fT4, TSH und TPO-AK } \\
\text { im Normbereich; } \\
\text { Calcitonin und CEA } \\
\text { im Normbereich }\end{array}$ \\
\hline
\end{tabular}




\begin{tabular}{|c|c|c|c|c|}
\hline Patient & $\begin{array}{l}\text { Sonographie } \\
\text { Knotengröße } \\
\end{array}$ & Zytologie & Histologie & Labor \\
\hline $\begin{array}{l}\text { 17.) G. G. } \\
68 \text { Jahre, } \\
\text { weiblich }\end{array}$ & $\begin{array}{l}\text { - echoarmer Knoten } \\
\text { - Durchmesser: } \\
8,0 \text { x 5,0 x 7,0 cm }\end{array}$ & $\begin{array}{l}\text { - mikrofollikuläre Follikelepithelien } \\
\text { mit Zeichen der Faservermehrung } \\
\text { - Beurteilung: } \\
\text { Nicht ausreichend für die Diagnose } \\
\text { einer follikulären Neoplasie. } \\
\text { Kein Hinweis auf Tumorzellen. }\end{array}$ & $\begin{array}{l}\text { - pT4 N1bMX } \\
\text { - Tumordurchmesser: } 8 \text { x } 5 \text { x } 7 \mathrm{~cm} \\
\text { - follikuläres Tumorwachstum, grob } \\
\text { invasiv wachsend, stellenweise insulär } \\
\text { - Das Tumorwachstum überschreitet } \\
\text { teilweise die Schilddrüsenkapsel. } \\
\text { - Beurteilung: } \\
\text { grob invasives follikuläres } \\
\text { Schilddrüsenkarzinom, stellenweise } \\
\text { Insulär }\end{array}$ & $\begin{array}{l}\mathrm{fT} 3 \text {, fT4, TSH und TPO-AK } \\
\text { im Normbereich; } \\
\text { Calcitonin und CEA } \\
\text { im Normbereich }\end{array}$ \\
\hline $\begin{array}{l}\text { 18.) D. M. } \\
65 \text { Jahre, } \\
\text { männlich }\end{array}$ & $\begin{array}{l}\text { - echokomplexer Knoten } \\
\text { - Durchmesser: } \\
\text { 5,2 x 3,5 x 3,8 cm }\end{array}$ & $\begin{array}{l}\text { - eingedicktes Kolloid } \\
\text { - mäßig viele Follikelzellen in } \\
\text { dominant mikrofollikulärer } \\
\text { Anordnung } \\
\text { - Beurteilung: } \\
\text { teils mikrofollikulär proliferiertes } \\
\text { Schilddrüsengewebe. } \\
\text { Die Kriterien einer follikulären } \\
\text { Neoplasie sind nicht voll erfüllt. }\end{array}$ & $\begin{array}{l}\text { - pT3 N0M0 } \\
\text { - Tumordurchmesser: 5,2x3,5x3,5 cm } \\
\text { - mikrofollikulärer Tumor mit binde- } \\
\text { gewebiger Kapsel und fokalem } \\
\text { Nachweis einer Kapselinvasion } \\
\text { - Beurteilung: } \\
\text { minimal invasives follikuläres } \\
\text { Schilddrüsenkarzinom }\end{array}$ & $\begin{array}{l}\text { fT3, fT4, TSH und TPO-AK } \\
\text { im Normbereich; } \\
\text { Calcitonin und CEA } \\
\text { im Normbereich }\end{array}$ \\
\hline $\begin{array}{l}\text { 19.) A. F. } \\
\text { 49 Jahre, } \\
\text { weiblich }\end{array}$ & $\begin{array}{l}\text { - echoarmer Knoten } \\
\text { - Durchmesser: } 2,3 \mathrm{~cm}\end{array}$ & $\begin{array}{l}\text { - sehr wenig Kolloid } \\
\text { - nur vereinzelt Follikelepithelien } \\
\text { - zahlreiche lymphatische Zellen im } \\
\text { Sinne einer Autoimmunthyreoiditis } \\
\text { - einzelne histiozyt. Riesenzellen } \\
\text { - vereinzelt kleine intranukleäre } \\
\text { Zytoplasmaeinschlüsse } \\
\text { - Beurteilung: } \\
\text { Autoimmunthyreoiditis, } \\
\text { Verdacht auf papilläres } \\
\text { Schilddrüsenkarzinom }\end{array}$ & $\begin{array}{l}\text { - pT4 N0M0 } \\
\text { - Tumordurchmesser: } 1,7 \mathrm{~cm} \\
\text { - papilläre Strukturen mit teils gering } \\
\text { differenzierten follikulären Anteilen } \\
\text { - umschriebener Schilddrüsenkapsel- } \\
\text { durchbruch in das angrenzende } \\
\text { Fettgewebe } \\
\text { - ausgeprägte Zeichen einer } \\
\text { Autoimmunthyreoiditis } \\
\text { - Beurteilung: } \\
\text { papilläres Schilddrüsenkarzinom, } \\
\text { Autoimmunthyreoiditis }\end{array}$ & $\begin{array}{l}\text { fT3, fT4 und TSH } \\
\text { im Normbereich; } \\
\text { TPO-AK: } 4966 \text { U/ml; } \\
\text { Calcitonin und CEA } \\
\text { im Normbereich }\end{array}$ \\
\hline
\end{tabular}




\begin{tabular}{|c|c|c|c|c|c|}
\hline & Patient & $\begin{array}{l}\text { Sonographie } \\
\text { Knotengröße } \\
\end{array}$ & Zytologie & Histologie & Labor \\
\hline 20.) & $\begin{array}{l}\text { B. B. } \\
\text { 36 Jahre } \\
\text { männlich }\end{array}$ & $\begin{array}{l}\text { - echokomplexer Knoten } \\
\text { mit Mikroverkalkungen } \\
\text { - Durchmesser: } \\
2,4 \times 1,6 \times 1,6 \mathrm{~cm}\end{array}$ & $\begin{array}{l}\text { - wenig Kolloid } \\
\text { - keine Schilddrüsenzellen } \\
\text { nachweisbar } \\
\text { - Beurteilung: } \\
\text { Punktat nicht beurteilbar }\end{array}$ & $\begin{array}{l}\text { - pT2 N0M0 } \\
\text { - Tumordurchmesser: } 1,7 \mathrm{~cm} \\
\text { - teilweise verzweigte papilläre } \\
\text { Strukturen } \\
\text { - Milchglaskerne } \\
\text { - zahlreiche Lymphozyten im Sinne } \\
\text { einer fokalen Thyreoiditis } \\
\text { - zusätzlich finden sich } 2 \text { weitere } \\
\text { papilläre Mikrokarzinome } \\
\text { (Durchmesser: } 4 \text { und } 9 \mathrm{~mm} \text { ) im } \\
\text { gleichen Schilddrüsenlappen } \\
\text { Beurteilung: } \\
\text { - multilokuläres papilläres } \\
\text { Schilddrüsenkarzinom }\end{array}$ & $\begin{array}{l}\text { fT3, fT4 und TSH } \\
\text { im Normbereich; } \\
\text { TPO-AK: } 2985 \mathrm{U} / \mathrm{ml} \text {; } \\
\text { Calcitonin und CEA } \\
\text { im Normbereich }\end{array}$ \\
\hline 21.) & $\begin{array}{l}\text { G. B. } \\
73 \text { Jahre, } \\
\text { männlich }\end{array}$ & $\begin{array}{l}\text { - echokomplexer Knoten } \\
\text { - Durchmesser: } \\
8,0 \times 5,0 \times 5,6 \mathrm{~cm}\end{array}$ & $\begin{array}{l}\text { - wenige eingedickte Kolloid- } \\
\text { partikel } \\
\text { - mäßig viele Follikelepithelien } \\
\text { Beurteilung: } \\
\text { Regressive Veränderungen. } \\
\text { Kein Hinweis auf Malignität. }\end{array}$ & $\begin{array}{l}\text { - pT3 N0M0 } \\
\text { - Tumordurchmesser: } 8,5 \mathrm{~cm} \\
\text { - follikuläre Tumorzellen mit } \\
\text { fokaler Knotenkapselinvasion } \\
\text { - Beurteilung: } \\
\text { follikuläres Schilddrüsenkarzinom }\end{array}$ & $\begin{array}{l}\text { fT3, fT4, TSH und TPO-AK } \\
\text { im Normbereich; } \\
\text { Calcitonin und CEA } \\
\text { im Normbereich }\end{array}$ \\
\hline 22.) & $\begin{array}{l}\text { H. D. } \\
68 \text { Jahre, } \\
\text { männlich }\end{array}$ & $\begin{array}{l}\text { - echokomplexer Knoten } \\
\text { - Durchmesser: } \\
5,6 \text { × 4,4 x } 3,4 \mathrm{~cm}\end{array}$ & $\begin{array}{l}\text { - Spuren von Kolloid } \\
\text { - dominant mikrofollikulär } \\
\text { gebautes Schilddrüsengewebe } \\
\text { - Beurteilung: } \\
\text { follikuläre Neoplasie }\end{array}$ & $\begin{array}{l}\text { - pT4 N0M0 } \\
\text { - Tumordurchmesser: } 5,5 \mathrm{~cm} \\
\text { - Beurteilung: } \\
\text { fokal follikulär aufgebautes, } \\
\text { zum Teil insuläres } \\
\text { Schilddrüsenkarzinom }\end{array}$ & $\begin{array}{l}\text { fT3, fT4, TSH und TPO-AK } \\
\text { im Normbereich; } \\
\text { Calcitonin und CEA } \\
\text { im Normbereich }\end{array}$ \\
\hline
\end{tabular}




\begin{tabular}{|c|c|c|c|c|}
\hline Patient & $\begin{array}{l}\text { Sonographie } \\
\text { Knotengröße }\end{array}$ & Zytologie & Histologie & Labor \\
\hline $\begin{array}{l}\text { 23.) I. S. } \\
70 \text { Jahre, } \\
\text { weiblich }\end{array}$ & $\begin{array}{l}\text { - echokomplexer Knoten } \\
\text { - Durchmesser: } \\
4,8 \text { x } 4,0 \text { x } 5,2 \mathrm{~cm}\end{array}$ & $\begin{array}{l}\text { - zahlreiche Follikelzellen in dominant } \\
\text { mikrofollikulärer Anordnung } \\
\text { - vereinzelt intranukleäre } \\
\text { Zytoplasmaeinschlüsse } \\
\text { - Beurteilung: } \\
\text { follikuläre Neoplasie }\end{array}$ & $\begin{array}{l}\text { - pT3 N0M0 } \\
\text { - Tumordurchmesser: max. } 5,0 \mathrm{~cm} \\
\text { - mikrofollikuläre Strukturen, zum } \\
\text { Teil mit milchglasartigen Zellkernen } \\
\text { - Kapselinvasion } \\
\text { - herdförmig papilläre Formationen } \\
\text { - Beurteilung: } \\
\text { papilläres Schilddrüsenkarzinom } \\
\text { in der überwiegend follikulären } \\
\text { Variante }\end{array}$ & $\begin{array}{l}\text { fT3, fT4 und TSH } \\
\text { nicht erhöht; } \\
\text { TPO-AK: } 2307 \mathrm{Um} / \mathrm{l} \text {; } \\
\text { Calcitonin und CEA } \\
\text { im Normbereich }\end{array}$ \\
\hline $\begin{array}{l}\text { 24.) A. R. } \\
\text { 49 Jahre, } \\
\text { männlich }\end{array}$ & $\begin{array}{l}\text { - echokomplexer Knoten } \\
\text { - Durchmesser: } \\
\text { 3,4 x 2,6 x 2,7 cm }\end{array}$ & $\begin{array}{l}\text { - mäßig zellreich } \\
\text { - Hinweise auf regressive } \\
\text { Veränderungen. } \\
\text { - Beurteilung: } \\
\text { Regressive Veränderungen. } \\
\text { Kein Hinweis auf Tumorzellen. }\end{array}$ & $\begin{array}{l}\text { - pT2 N0M0 } \\
\text { - Tumordurchmesser: max. } 3,2 \mathrm{~cm} \\
\text { - dichtgepackte papilläre Strukturen } \\
\text { - nur angedeutete Milchglaskernbildung } \\
\text { - Beurteilung: } \\
\text { papilläres Schilddrüsenkarzinom }\end{array}$ & $\begin{array}{l}\mathrm{fT} 3 \text {, fT4, TSH und TPO-AK } \\
\text { im Normbereich; } \\
\text { Calcitonin und CEA } \\
\text { im Normbereich }\end{array}$ \\
\hline
\end{tabular}




\section{Diskussion}

Bei der hohen Zahl von Schilddrüsenknoten ist das Erkennen des seltenen Schilddrüsenkarzinoms häufig schwierig. Bildgebende Verfahren wie Sonographie und Szintigraphie weisen eine relativ geringe Sensitivität und Spezifität in Bezug auf das Schilddrüsenkarzinom auf, sind jedoch unverzichtbar in der Diagnostik von Schilddrüsenknoten. Sie tragen wesentlich dazu bei, Knoten zu diagnostizieren und $\mathrm{zu}$ beschreiben und sie sind zudem in der Lage, ein geringes oder aber ein erhöhtes Malignitätsrisikos eines Knotens zu erkennen.

Sonographisch echoarme oder echokomplexe Knoten, die sich in der Szintigraphie nicht als fokale Autonomie identifizieren lassen, weisen ein deutlich höheres Malignitätsrisiko auf als echonormale oder echoreiche Knoten. Etwa 90 bis $95 \%$ aller Schilddrüsenkarzinome zeigen ein echoarmes oder echokomplexes Ultraschallbild $(57,58,59,60,62)$.

Bei Nachweis einer unscharfen Randbegrenzung eines echoarmen oder echokomplexen Knotens steigt das Risiko einer malignen Entartung deutlich an.

Die Mehrzahl der differenzierten Schilddrüsenkarzinome zeigt allerdings eine scharfe Randbegrenzung $(61,62)$.

Sonographisch nachweisbare Mikroverkalkungen in Knoten können Hinweis auf ein papilläres (Psammonkörper), grobschollige Verkalkungen können Ausdruck eines medullären Schilddrüsenkarzinoms sein. Andererseits sind Verkalkungen häufig auch in benignen knotigen Läsionen zu finden $(57,61,62)$.

Der Ultraschall ist somit lediglich in der Lage, gewisse Hinweise zu geben, ob ein Knoten möglicherweise ein erhöhtes Malignitätsrisiko aufweist.

Weitere diagnostische Verfahren sind somit erforderlich, um die Dignität eines Knotens genauer einschätzen zu können. 
Experten schätzen, dass 1 von 1000 Schilddrüsenknoten maligne ist (44). Bei szintigraphisch kalten Knoten liegt die in der Literatur angegebene Malignitätsrate bereits bei $5 \%$ (4).

In der Literatur wird der „kalte” Knoten nicht genauer definiert. Man begnügt sich mit der relativ unscharfen Definition, dass es sich bei einer szintigraphisch „kalten” Läsion um einen hypofunktionellen Knoten handelt. Ein hypofunktioneller Knoten weist eine gegenüber dem umliegenden Schilddrüsengewebe verminderte Nuklidspeicherung auf. Diese Speicherung kann mäßig- oder mittelgradig vermindert sein, sie kann aber auch vollständig fehlen.

In unserer Studie haben wir uns auf die Untergruppe szintigraphisch kalter Knoten beschränkt, die keinerlei Nuklidspeicherung aufwies („vollständig kalter” Knoten).

Unsere Vermutung, dass es sich bei szintigraphisch „,vollständig kalten” Knoten häufiger um maligne Läsionen handelt als in der Literatur gemeinhin angegeben, hat sich bestätigt. Bei $21 \%$ aller vollständig kalten Knoten war ein Schilddrüsenkarzinom Ursache der fehlenden Nuklidbelegung. Bei allen Schilddrüsenkarzinomen zeigte sich im Ultraschall ein echoarmer oder aber ein echokomplexer Knoten.

Ein diagnostisches Problem stellen Knoten in einer Knotenstruma dar, die sich szintigraphisch nicht differenzieren lassen, die also weder „heiß” noch „kalt” erscheinen. Hinter einem szintigraphisch nicht diffenzierbaren Knoten kann sich ein kompensiertes autonomes Adenom verbergen, das erst mit Hilfe einer Suppressionsszintigraphie zur Darstellung kommt. Es kann sich jedoch auch um einen prinzipiell „kalten” Knoten handeln, der in der Szintigraphie nicht als solcher dargestellt werden kann.

Bei $23 \%$ unserer Schilddrüsenkarzinompatienten der letzten 5 Jahre war die maligne Läsion szintigraphisch nicht darstellbar (siehe Tabelle 8). 
Bei etwa $1 / 3$ dieser Patienten wurde die OP-Indikation gestellt wegen des Verdachts auf ein C-Zell-Karzinom bei erhöhten CEA- und Calcitonin-Werten mit entsprechend pathologischem Ausfall des Pentagastrin-Tests.

Durch darüber- oder darunterliegendes normales Schilddrüsengewebe kann ein an sich kalter Knoten „überstrahlt” werden, da die Szintigraphie ein Summationsbild der in der Schilddrüse gespeicherten Radioaktivität darstellt.

Diese Einschränkungen in der szintigraphischen Beurteilbarkeit von Knoten ergeben sich vor allem immer dann, wenn kleinere Knoten mit einem Durchmesser von weniger als $2 \mathrm{~cm}$ vorliegen und wenn ventral und dorsal noch genügend funktionell intaktes Schilddrüsengewebe vorliegt. Bei einer sehr großen Knotenstruma (Struma nodosa Grad III) können gelegentlich auch Knoten mit einem Durchmesser von 2 bis $3 \mathrm{~cm}$ nicht immer szintigraphisch erfasst werden.

Unsere Ergebnisse sprechen dafür, dass allein die Konstellation „sonographisch echoarmer oder echokomplexer Knoten” und „vollständig fehlende Nuklidbelegung" in der Szintigraphie - unabhängig vom zytologischen Befund - ein relativ hohes Malignitätsrisiko darstellt (21\% Wahrscheinlichkeit).

Als Hochrisikogruppe erwies sich das Kollektiv der Männer über 65 Jahre.

$75 \%$ dieser Patienten hatten ein Schilddrüsenkarzinom (6 von 8). Obwohl die Patientenzahl relativ niedrig war (8 männliche Patienten über 65 Jahre), ist das vorliegende Ergebnis als eindeutiger Hinweis zu werten, dass gerade in dieser Patientengruppe das Risiko eines Schilddrüsenkarzinoms sehr hoch ist.

Der untersuchende Arzt sollte daher bei diesem Kollektiv die Indikation für eine Schilddrüsenoperation trotz des höheren Lebensalters - auch bei fehlendem Malignitätsnachweis in der Zytologie - großzügig stellen. 
Die vorliegende Arbeit belegt, dass sonographisch echoarme oder echokomplexe Knoten mit vollständig fehlender Nuklidbelegung ein erhöhtes Risiko in Bezug auf eine maligne Entartung aufweisen. Dieses Patientenkollektiv ist klar definiert und ist einfach erkennbar. Diese Risikokonstellation macht es dem untersuchenden Arzt relativ leicht, auch bei negativer Zytologie, die Indikation für eine Schilddrüsenoperation (Hemithyreoidektomie der betroffenen Seite) zu stellen.

Unsere Daten zeigen allerdings auch, dass mindestens $23 \%$ unserer Schilddrüsenkarzinompatienten szintigraphisch nicht differenzierbare Knoten aufwiesen (22 Fälle bei 96 Schilddrüsenkarzinomen).

Weitere 25\% unserer Schilddrüsenkarzinompatienten (24 Fälle bei 96 Schilddrüsenkarzinomen) hatten große Knotenstrumen (Struma multinodosa Grad II und III) mit sonographisch zahlreichen und zum Teil schwer abgrenzbaren Knotenbildungen. Szintigraphisch fanden sich über die Schilddrüse unregelmäßig verteilt kühle und kalte Areale. Eine Punktionszytologie wurde in diesen Fällen in der Regel nicht durchgeführt, da multiple Punktionen nicht vertretbar waren.

Vergleichbares gilt für die oben erwähnte Gruppe der szintigraphisch nicht differenzierbaren Knoten. Auch hier fanden sich in der Regel - bei Struma nodosa Grad II bis III - zahlreiche Knoten. Sämtliche Knoten einer Struma multinodosa zu punktieren ist dem Patienten nicht zumutbar und in der Praxis auch nicht durchführbar, zumal das Risiko der malignen Entartung eines dieser Knoten mit $5 \%$ oder geringer angesehen werden muss.

Bei dieser relativ großen Gruppe von Patienten (48\% der Karzinompatienten) erfolgte die Indikation für eine Operation entweder wegen des Verdachts auf ein C-Zell-Karzinom oder aber - bei fehlendem Karzinomverdacht - wegen der Knotenund Strumagröße, nicht selten in Verbindung mit einer multifokalen Autonomie. In diesen Fällen war das Karzinom somit ein Zufallsbefund. Die Unsicherheit, wenig über das Malignitätsrisiko der Knoten aussagen zu können, hat bei nicht wenigen dieser Patienten die Empfehlung für die Durchführung einer Operation mitbestimmt. 


\section{Papilläre Mikrokarzinome}

Papilläre Mikrokarzinome (Synonym: okkultes Karzinom) stellen eine Besonderheit unter den Schilddrüsenkarzinomen dar. Sie haben definitionsgemäß einen Tumordurchmesser unter $10 \mathrm{~mm}$ (T1N0M0).

Fast immer stellen sie einen Zufallsbefund dar im Rahmen einer Schilddrüsenoperation aus anderen Gründen. Erst bei der histologischen Aufarbeitung des operativ entfernten Schilddrüsengewebes findet sich dann gelegentlich das Mikrokarzinom.

Die Häufigkeit ist vielfach von der pathologischen Untersuchungstechnik abhängig. Okkulte papilläre Mikrokarzinome werden bei gezielten Untersuchungen am normalen Sektionsgut in 6 bis 37 \% der Fälle aufgefunden $(64,65,66)$.

Obwohl papilläre Mikrokarzinome sich histologisch nicht vom manifesten papillären Karzinom unterscheiden, entfaltet es offenbar häufig kein malignes Potential.

Warum offenbar nur ein kleiner Teil der okkulten papillären Mikrokarzinomen zum wachsenden Malignom mit malignem biologischem Verhalten wird, ist unbekannt. Möglicherweise ist für ein Fortschreiten malignen Wachstums ein zusätzlicher genetischer Defekt im Genom einer Zelle des Mikrokarzinoms notwendig.

Wegen des günstigen biologischen Verhaltens ist bei Auffinden eines papillären Mikrokarzinoms postoperativ keine Radiojodtherapie erforderlich. 


\section{Probleme der zytologischen Diagnostik}

Grundsätzlich gilt, dass sich papilläre Schilddrüsenkarzinome im Gegensatz zu follikulären Karzinomen zytologisch deutlich problemloser diagnostizieren lassen (siehe 2.2.3.1).

Wir wissen heute, dass eine fokale Thyreoiditis in der Umgebung des Knotens als möglicher Hinweis für das Vorliegen eines papillären Schilddrüsenkarzinoms angesehen werden kann. Bei follikulären Karzinomen fehlt eine peritumoröse fokale Thyreoiditis.

Unsere Ergebnisse (siehe Tabelle 10, papilläre Schilddrüsenkarzinome und Autoimmunthyreoiditis) weisen daraufhin, dass szintigraphisch vollständig kalte, sonographisch echoarme/echokomplexe Knoten ein erhöhtes Risiko aufweisen, ein papilläres Schilddrüsenkarzinom zu sein, wenn die TPO-AK erhöht sind und/oder zytologische Hinweise auf eine fokale Autoimmunthyreoiditis vorliegen.

Der Nachweis einer umschriebenen Thyreoiditis in der Umgebung eines kalten Knotens sollte zumindest Anlass für eine Kontrollpunktion sein. Sollte auch die Wiederholungspunktion nicht weiter führen, würden wir nach unseren Erfahrungen zu einer Schilddrüsenoperation raten.

Der Nachweis von Psammonkörpern (in ca. 30 \% der Punktate bei papillären Karzinomen nachweisbar) im zytologischen Ausstrich macht das Vorliegen eines papillären Schilddrüsenkarzinoms wahrscheinlich (39).

In ca. 50 bis $90 \%$ der papillären Neoplasien finden sich zytologisch intranukleäre Zytoplasmaeinschlüsse sowie Milchglaskerne (39). Diese nukleären Auffälligkeiten sind spezifisch für das papilläre Schilddrüsenkarzinom und bei Nachweis dieser Veränderungen kann ein papilläres Karzinom als weitgehend gesichert angesehen werden.

Probleme in der zytologischen Diagnostik ergeben sich jedoch, wenn das papilläre Karzinom nur wenige Papillen aber überwiegend follikuläre Formationen aufweist (Lindsay-Tumor). 
Fehlen Psammonkörper und/oder die typischen Kernveränderungen, so ist es nicht möglich, die zytologische Verdachtsdiagnose eines papillären Schilddrüsenkarzinoms zu stellen. Bei Nachweis eines zellreichen Punktats würde der Zytopathologe den Verdacht auf eine follikuläre Neoplasie stellen. Im Falle stärkerer regressiver Veränderungen der malignen Läsion kann gelegentlich der typische Zellreichtum eines Malignoms fehlen. Ein solcher Befund würde die Verdachtsdiagnose eines Malignoms zusätzlich erschweren (bei gleichzeitigem Fehlen von Psammonkörpern und Kernveränderungen).

Ein weiteres Problem der zytologischen Diagnostik stellt das ,faserreiche papilläre Schilddrüsenkarzinom" dar, das ca. $5 \%$ aller papillären Neoplasien ausmacht. Wegen der Zellarmut dieser malignen Läsionen wird der zytologische Verdacht auf ein Malignom nur in etwa $40 \%$ der Fälle gestellt.

Im Gegensatz zu den papillären Neoplasien ist die zytologische Erfassung eines follikulären Schilddrüsenkarzinoms ausgesprochen schwierig (39). Über die Problematik der follikulären Neoplasie wurde bereits berichtet (siehe 2.2.2.4 sowie 2.2.3.2). Eine zytologische Unterscheidung zwischen mikrofollikulärem Adenom und minimal invasivem follikulärem Schilddrüsenkarzinom ist nicht möglich.

Bei den zytologisch als nicht suspekt eingestuften follikulären Karzinomen (4 von 8) fand sich der Befund einer mikrofollikulären Proliferation, die allerdings die Kriterien einer follikulären Neoplasie nicht ganz erfüllte (zum Teil reichlich Kolloid, zum Teil nur teilweise mikrofollikuläre Proliferation).

Problematisch ist nach Auffassung der Untersucher nicht die zytologische Diagnose einer follikulären Neoplasie. Diese Diagnose bedeutet für den Patienten ein Risiko von 20 bis $25 \%$, ein follikuläres Schilddrüsenkarzinom zu haben. Die Indikation für die Operation ist in diesen Fällen eindeutig $(39,64)$.

Schwierig wird es bei der nicht geringen Zahl von Fällen, die die Kriterien der Diagnose einer „follikulären Neoplasie” nicht voll erfüllen (mikrofollikuläre Proliferation). Der Zellgehalt des Punktats kann durch regressive Veränderungen im punktierten follikulären Knoten zum Teil vermindert sein. 
Bei diesen diagnostischen Grenzfällen ist ein minimal invasives follikuläres Schilddrüsenkarzinom nicht auszuschließen. Die Zytologie stößt hier an ihre Grenzen. Das zytologische Bild einer mikrofollikulären Proliferation ohne die Diagnose einer „follikulären Neoplasie” muss zumindest als Risikoindikator angesehen werden. In jedem Fall sollte eine nochmalige Punktion an zwei verschiedenen Regionen des Knotens erfolgen. Letztlich muss der untersuchende Arzt aufgrund weiterer Kriterien entscheiden, ob eine Operationsindikation vorliegt (Ultraschallbefund, Szintigraphiebefund, weitere Risikokonstellation).

\section{Probleme bei der Punktion von Knoten}

Alle kalten Knoten wurden direkt im Anschluss an das Szintigramm punktiert.

Nach vorheriger Ultraschallmarkierung wurden große, gut palpable Knoten punktiert. Bei kleineren oder schwer tastbaren Knoten erfolgte die Punktion soweit möglich unter permanenter sonographischer Kontrolle. Bereits hier traten gelegentlich Probleme auf.

Bei Patienten mit einem kurzen Hals oder bei sehr Adipösen war es nicht in jedem Fall möglich, das Ultraschallgerät so zu positionieren, dass die Nadelspitze exakt verfolgt werden konnte. Bei diesen Fällen war somit nicht sicher garantiert, dass der Knoten von der Nadel richtig getroffen wurde.

Am Ende der Punktion, bei noch liegender Nadel innerhalb des Knotens, erfolgt der Druckausgleich, indem der Kolben in die Ausgangsstellung zurückgleitet. Hierdurch wird vermieden, dass beim Herausziehen der Nadel nicht repräsentatives Zellmaterial der Umgebung des Knotens aspiriert wird.

Unser Beispiel (siehe 2.3.3.2, Abbildung 10 und 11) zeigt ein Foto eines zytologischen Ausstrichs eines follikulären Schilddrüsenkarzinoms. Bei diesem Ausstrich fand sich ein zellreiches Bild mit zahlreichen mikrofollikulären Zellen. Die zytologische Diagnose einer follikulären Neoplasie wurde nicht gestellt, da sich reichlich Kolloid fand. Dieser Kolloidreichtum sprach gegen das Vorliegen einer follikulären Neoplasie. Tatsächlich fand sich histologisch ein follikuläres Schilddrüsenkarzinom. 
In Ausnahmefällen kann möglicherweise ein follikuläres Karzinom vermehrt Kolloid produzieren. Wahrscheinlicher ist jedoch, dass in diesem Fall beim Herausziehen der Nadel aus dem Knoten vermehrt Kolloid aus der Tumorumgebung in die Kanüle kam, was letztlich zu einer Verfälschung des zytologischen Befundes geführt haben dürfte.

Die Verdachtsdiagnose einer follikulären Neoplasie unterblieb somit.

Aufgrund von Literaturempfehlungen (40) ließen die Autoren größere Blutbeimengungen auf dem Objektträger abtropfen. Dann erst erfolgte der Ausstrich.

Da die Ergebnisse der Treffsicherheit unserer zytologischen Präparate zum Teil unbefriedigend waren (siehe unten), wurden nach Beendigung der Studie keine Blutbeimengungen auf den Objektträgern mehr verworfen.

Nach Aussage der Zytopathologin Frau Dr. I. Ruschenburg / Universitätsklinikum Göttingen, die sämtliche Punktate untersuchte, kam es seither zu einer deutlichen Vermehrung der Zellzahl auf den Objektträgern und damit zu einer ihrer Meinung nach verbesserten Beurteilbarkeit. Dennoch erfüllten ca. $87 \%$ der von uns gelieferten Punktate im Rahmen der vorliegenden Studie die geforderten Qualitätskriterien im Hinblick auf Zellzahl und Follikelgruppen.

Eine der Konsequenzen unserer Ergebnisse ist es, in Zukunft keine Blutbeimengungen mehr zu verwerfen, da diese ganz offenbar zahlreiche Follikelzellen enthalten, die für die Beurteilbarkeit des Punktats von Bedeutung sein könnten. In einer prospektiven Studie wird dieser Teilaspekt weiter untersucht werden. 


\section{„Nicht diagnostische" Punktate}

Ein diagnostisches Dilemma stellt die Gruppe der zytologischen Präparate dar, die keine ausreichende Diagnostik erlauben (,nicht diagnostische” Punktate).

Nach amerikanischen Studien $(41,42)$ beträgt die Zahl nicht diagnostischer Zytologien auch in hochspezialisierten Zentren (Majo-Klinik) 10 bis $20 \%$.

Hinzu kommt, dass mindestens $5 \%$ der Feinnadelpunktate mit ausreichender Zellzahl keine Unterscheidung zwischen benigne und maligne erlauben $(41,42)$.

Letztlich ist somit nur bei 75 bis $80 \%$ aller punktierten Knoten unter den optimalen Bedingungen eines spezialisierten Zentrums eine ausreichende Aussage über die Dignität der Knoten möglich. Was die Treffsicherheit der Punktion anbetrifft, so werden die ,nicht diagnostischen” Punktate nicht mit in die Berechnung einbezogen. Auf diese Weise werden Treffsicherheiten in der Größenordnung von $95 \%(41,42,43)$ publiziert.

In einer Studie der Majo-Klinik (41) mit 153 Patienten „nicht diagnostischer” Feinnadelaspiration wurden 27 operiert. Gründe für die Operationsindikation werden nicht aufgeführt. Bei 10 dieser 27 operierten Patienten (37\%) fand sich ein Schilddrüsenkarzinom.

Diese überraschend hohe Zahl veranlasste Gharib (43) zu der Empfehlung, die Malignomgefährdung dieser Gruppe nicht zu unterschätzen. Er empfiehlt eine Schilddrüsenoperation bei „nicht diagnostischen” Punktaten zumindest in folgenden Fällen:

1. Zysten mit einer Größe über $4 \mathrm{~cm}$

2. bei soliden größeren Knoten (ohne Größenangabe)

3. bei Risikofaktoren für das Vorliegen von Malignität

Die Treffsicherheit der Zytologie bei unserem Patientengut lag lediglich bei $57 \%$ und war damit deutlich unter den Zahlen der Majo-Klinik.

$\mathrm{Ob}$ die Methode der Ausstrichtechnik (Abtropfen von Blutbeimengungen) eine Rolle gespielt hat ist unklar. Diese Frage wird zurzeit in einer prospektiven Studie mituntersucht. 
Die Qualität unserer Punktate war nach Aussage der Zytopathologin Dr. Ruschenburg gut. Die Zellzahl war bei 87 \% der Präparate nach den derzeit gültigen Qualitätskriterien ausreichend.

Die Technik der Punktion erfolgte nach den üblichen Empfehlungen.

Täglich werden in der Praxis 4 bis 5 Punktionen durchgeführt, so dass eine ausreichende Übung und zudem jahrelange Erfahrung gegeben sind.

$\mathrm{Zu}$ berücksichtigen ist, dass für eine ausreichende statistische Bewertung die Fallzahl der Karzinome zu gering ist. Allerdings zeigt sich ein eindeutiger Trend dahingehend, dass die hohen Treffsicherheiten amerikanischer Studien sich offenbar nicht ohne weiteres auf den Praxisalltag einer spezialisierten deutschen Praxis mit ausreichender Punktionserfahrung übertragen lassen.

Es bleibt somit eine ungeklärte Diskrepanz zwischen unseren Ergebnissen und den Ergebnissen insbesondere der amerikanischen Literatur.

Amerikanische Schilddrüsenspezialisten bevorzugen bei tastbaren Schilddrüsenknoten vor den bildgebenden Verfahren die Feinnadelaspiration $(42,43)$.

Sie punktieren Knoten zwei bis viermal in verschiedenen Regionen. Möglicherweise erzielen sie dadurch eine höhere Ausbeute an Zellen und ermöglichen damit dem Zytopathologen eine bessere Aussage.

\section{Wertigkeit der Punktionszytologie großer Knotenstrumen}

Die Punktionszytologie ist ein unverzichtbares diagnostisches Verfahren, um die Malignitätsgefährdung von Schilddrüsenknoten beurteilen zu können. Bei positivem Nachweis oder auch bei begründetem zytologischem Verdacht auf das Vorliegen eines Schilddrüsenkarzinoms führt der Chirurg eine Thyreoidektomie durch.

Probleme der Treffsicherheit der Punktionszytologie wurden bereits erörtert. Darüberhinaus besteht bei nicht wenigen, multinodösen Knotenstrumen oft das Problem der „Unübersichtlichkeit”. Nicht selten haben wir multinodöse Strumen II. und III. Grades mit ausgeprägten regressiven Veränderungen vor uns. 
Im Ultraschall finden sich häufig zahlreiche, zum Teil schwer abgrenzbare Knoten. Im Szintigramm zeigen sich hypofunktionelle und oft auch hyperfunktionelle Areale.

Eine konkrete Malignitätsgefährdung eines einzelnen Knotens ist durch die bildgebenden Verfahren meist nicht erkennbar. Sonographie und Szintigraphie tragen in diesen Fällen oft nicht dazu bei, punktionswürdige Knoten zu identifizieren.

Dem Patienten ist nicht zumutbar, sämtliche kühlen und kalten Areale „durchzupunktieren”, zumal dieses auch medizinisch wenig Sinn ergäbe.

Etwa $45 \%$ aller Schilddrüsenkarzinome unseres Patientenguts fallen in diese Gruppe der großen, unübersichtlichen multinodösen Strumen.

Die Operationsindikation ergab sich häufig durch beginnende Funktionsstörungen auf dem Boden einer disseminierten oder multifokalen Autonomie in Verbindung mit einer deutlich vergrößerten Knotenstruma. Die Befürchtung, dass zusätzlich ein Schilddrüsenkarzinom nicht ganz auszuschließen sei, mag im Einzelfall die Operationsindikation mit beeinflusst haben.

Punktionen wurden bei diesen Strumen, die Dickendurchmesser von 3 bis $5 \mathrm{~cm}$ aufwiesen, in der Mehrzahl der Fälle wegen fehlenden konkreten Malignom verdachts nicht durchgeführt.

Dies bedeutet, dass bei ca. $50 \%$ unserer Schilddrüsenkarzinompatienten das Malignom ein „Zufallsbefund” war und dass bei der Hälfte der Schilddrüsenkarzinompatienten in der Regel keine Punktionszytologie erfolgte.

Befasst man sich näher mit der angloamerikanischen Literatur zu diesem Thema (41, 42, 43), so entsteht der Eindruck, dass das o. g. „diagnostische Dilemma” der großen Knotenstrumen dort nicht besteht. Die Punktionszytologie ist in den USA, oft vor den bildgebenden Verfahren, wegweisend in der Beurteilung der Dignität (und damit der OP-Indikation) von Schilddrüsenknoten. 
In den USA wird häufiger punktiert als bei uns, sowohl was die Gesamtzahl der Knoten als auch die Zahl der Punktionen eines einzelnen Knotens anbetrifft ( 2 bis 4 Punktionen innerhalb eines einzelnen Knotens).

Ganz offenbar besteht ein grundlegender Unterschied zwischen „deutschen” und „amerikanischen” Knotenstrumen.

In Deutschland haben wir häufig große multinodöse Strumen mit regressiven Veränderungen vor uns. Bei der Vielzahl dieser Strumen findet sich immer wieder ein Schilddrüsenkarzinom als Zufallsbefund.

Anders ist die Situation in den USA. Hier bestehen keine Jodmangelstrumen. In den dortigen Knotenstrumen finden sich vor allem solitäre Knoten (zumeist klonaler Herkunft) oder aber Strumen mit einigen wenigen, „übersichtlichen” Knoten in einer meist „übersichtlichen” Struma ohne regressive Veränderungen.

Die Wahrscheinlichkeit einer malignen Entartung der meist klonalen Knoten ist in den USA größer als bei unseren so häufigen multinodösen Jodmangelstrumen, die oft - neben klonalen Knoten - polyklonale, hyperplastische Knoten aufweisen.

Die deutlich bessere „Übersichtlichkeit” amerikanischer Knotenstrumen erleichtert die punktionszytologische Diagnostik, da die in Frage kommenden Knoten in der Regel gut erfassbar sind. Die hohe Treffsicherheit amerikanischer Feinnadelpunktate dürfte zumindest teilweise darauf zurückzuführen sein.

Auch durch eine verbesserte Treffsicherheit dürfte bei uns in Deutschland durch die Punktionszytologie keine wesentliche Verbesserung der präoperativen Karzinomdiagnostik zu erwarten sein. Zuviele Knotenstrumen entziehen sich durch ihre Größe und „Unübersichtlichkeit” der zytologischen Diagnostik.

Diese relativ große Patientengruppe wird uns auch in Zukunft vor ein diagnostisches Dilemma stellen. Die Operationsindikation ist in diesen Fällen oft eher vage und nicht selten von der Erfahrung oder der „Intuition” des untersuchenden Arztes abhängig. 


\section{Welche Konsequenzen sind aus den vorliegenden Ergebnissen zu ziehen?}

1. Nach dem Punktat sollten Blutbeimengungen auf dem Objektträger nicht verworfen werden (die Validität dieser Beobachtung wird derzeit in einer weiteren Studie überprüft).

2. Jeder szintigraphisch kalte Knoten sollte mindestens zweimal in unterschiedlichen Regionen punktiert werden.

3. Punktionen von Knoten sollten, soweit anatomisch möglich, unter Ultraschallkontrolle erfolgen.

4. Sonographisch echoarme und echokomplexe Knoten in einer großen Knotenstruma, die sich in szintigraphisch hypofunktionellen Arealen befinden, sollten - gegebenenfalls mehrfach - punktiert werden, trotz der o. g. Einschränkungen.

5. Knotenstrumen sollten wenn möglich von einem erfahrenen Spezialisten untersucht werden.

6. Die Operationsindikation bei großen multinodösen Strumen II. und III. Grades sollte - unter Berücksichtigung des Lebensalters und der Operationsrisiken relativ großzügig gestellt werden.

Dieses gilt in ganz besonderem Maße für Risikogruppen $(42,43)$ :

- Männer über 65 Jahre

- Patienten unter 20 Jahre

- frühere Bestrahlung im Halsbereich

- Schilddrüsenkarzinom in der Familie

- deutliche Zunahme des Schilddrüsenvolumens 
7. Szintigraphisch vollständig kalte Knoten, die sich sonographisch echoarm oder echokomplex darstellen, sollten auch bei negativer Zytologie als malignitätssuspekt angesehen werden. Patienten mit dieser Konstellation stellen eine Risikogruppe dar. Dieses Risiko erhöht sich, wenn sie zu einer der o. g. Risikogruppen (Punkt 6) gehören. Dieses gilt in ganz besonderem Maße für die als Hochrisikogruppe anzusehenden Männer über 65 Jahre.

Nach unserer Auffassung sollten Patienten, die zur „Risikogruppe der vollständig kalten Knoten” gehören, auch bei negativer Zytologie einer Operation zugeführt werden.

Aus der vorliegenden retrospektiven Studie haben sich weitere neue Fragestellungen ergeben. Hierzu haben wir eine prospektive Studie begonnen, in die zum Zeitpunkt der Drucklegung dieser Arbeit 55 Patienten eingeschlossen worden sind. 


\section{Zusammenfassung}

Bei der hohen Prävalenz von Schilddrüsenknoten in Deutschland um $22 \%$ ist das Erkennen eines Schilddrüsenkarzinoms in einer Knotenstruma schwierig. In der 99m-Technetium-Pertechnetat-Szintigraphie kann man unterschiedliche Grade der Nuklidminderbelegung bis zum vollständig kalten Knoten beobachten.

Ziel der retrospektiven Analyse war es, nach sonographischem Ausschluss einer Schilddrüsenzyste die Häufigkeit maligner Läsionen in vollständig kalten Knoten herauszufinden.

130 Patienten mit echoarmen/echokomplexen Knoten und vollständig fehlendem Tc-Uptake innerhalb dieser Knoten wurden punktionszytologisch untersucht. 112 Patienten wurden operiert und histologisch abgeklärt.

Bei 24 von 112 Patienten (21 \%) fanden sich Schilddrüsenkarzinome (14 papilläre, 8 follikuläre, 1 anaplastisches Schilddrüsenkarzinom sowie 1 Non-Hodgkin-Lymphom). Die Tumorknotengröße betrug 2,2 bis 8,0 cm (im Mittel 3,5 cm).

Lediglich 48\% der zytologischen Präparate waren suspekt oder eindeutig einem Schilddrüsenkarzinom zuzuordnen. Bei 3 von 24 Karzinombefunden war die Zytologie nicht ausreichend beurteilbar. Bei den restlichen 20 Patienten zeigte die Zytologie ausreichendes Zellmaterial. Ca. 56 \% der benignen vollständig kalten Knoten waren follikuläre Adenome (49 von 88). Die restlichen $44 \%$ waren hyperplastische Knoten (38 von 88). Auffällig ist der hohe Anteil an Schilddrüsenkarzinomen bei Männern über 65 Jahre: 6 von 8 männlichen Patienten über 65 Jahre hatten ein Schilddrüsenkarzinom (75\%).

\section{Schlussfolgerung}

Szintigraphisch vollständig kalte, sonographisch echoarme oder echokomplexe Knoten über $2 \mathrm{~cm}$ Größe müssen auch bei negativer Zytologie als malignitätssuspekt angesehen werden. Patienten mit dieser Konstellation stellen eine Risikogruppe dar. Dieses gilt in ganz besonderem Maße für die als Hochrisikogruppe anzusehenden kalten Knoten bei Männern über 65 Jahre.

Patienten mit der beschriebenen Risikokonstellation sollten grundsätzlich einer Operation zugeführt werden. 


\section{Literaturverzeichnis}

1 Hampel R, Kühlberg T, Klein K, (1995):

Strumaprävalenz in Deutschland größer als bisher angenommen.

Med. Klin 90: 324-329

2 Tan GH, Gharib H (1997):

Thyroid incidentalomas: management approaches to nonpaplable nodules discovered incidentally on thyroid imaging.

Am Intern Med 126: 226-231

3 Wang C, Crapo LM (1997):

The epidemiology of thyroid disease and implications for screening. Endocrinol Metab Clin North Am 26: 189-218

4 Belfiore A, La Rosa GL, La Porta GA (1992):

Cancer risk in patients with cold thyroid nodules:

relevance iodine intake, sex, age and multinodularity.

Am I Med 93 (4): 363-9

5 Dai G, Levy O, Carrasco N (1996):

Cloning and characterization of the thyroid iodine transporter.

Nature 379: 458-460

6 Eskandaris S, Loo DDF, Dai G, Levy O, Wright EM, Carrasco N (1997):

Thyroid $\mathrm{Na}^{+} / \mathrm{J}^{-}$Symporter.

I Biol Chem 272 (43): 27230-27238

7 Smanik PA, Liu Q, Furminger TL, Ryuk, Xings (1996):

Cloning of the human sodium jodide symporter.

Biochem Biophys Res Comm 226: 339-345 
8 Levy 0; Dai G, Riedel C, Amzel LM, Carrasco N (1997):

Characterization of the $\mathrm{Na}^{+} / \mathrm{J}$ Symporter

with an anti-COOH terminus antibody.

Biochemistry 94: 5568-5573

9 Riedel C, Levy O, Carrasco N (2001):

Post-transcriptional regulation of the sodium/jodide symporter by thyrotropin.

I Biol Chem: 276 (24): 21458-63

10 Kogai T, Curcio F, Hyman S, Cornford EM, Brent GA, Hershan IM (2000):

Induction of follicle formation in long-term cultured normal human thyroid cells treated with thyreotropin stimulates jodide uptake but not sodium/jodide symporter messenger RNA and protein expression. I Endocrinol 167: 125-135

11 Spitzweg C, Heufelder AE, Morris IC (2000):

Thyroid jodine transport.

Thyroid 10: 321-330

12 Castro MR, Bergert ER, Beito TG, McIver BD, Goellner IR, Morris IC (1999): Development of monoclonal antibodies against the human sodium jodide symporter: Immunohistochemical characterization of this protein in thyroid cells.

I Clin Endrocrinol Metab 84: 2957-2962

13 Caillou B, Troalen F, Baudin E, Talbott M, Filetti S, Schlumberger M, Bidart IM (1998):

$\mathrm{Na}^{+} / \mathrm{J}$ Symporter distribution in human thyroid tissues:

An immunohistochemical study.

I Clin Endocrinol Metab 83: 4102-4106 
14. Joba W, Spitzweg C, Schriever K, Heufelder AE (1999):

Analysis of human sodium/jodide symporter, thyroid transcription factor-1, and paired-box-protein-8-gene expression in benign thyroid diseases.

Thyroid 9: 455-466

15 Russo D, Bulotta S, Bruno R, Arturi F, Giannasio P, Derwahl M, Bidart JM, Schlumberger M, Filetti S (2001):

Sodium/jodide symporter (NJS) and pendrin are expressed differently in hot and cold nodules of thyroid toxic multinodular goiter. Eur I Endocrinol 145: 591-597

16 Tonacchera M, Viacava P, Agretti P, de Marco G, Perri A, di Cosmo C, de Servi M, Miccoli P, Lippi F, Naccarato AG, Pinchera A, Chiovato L, Vitti P (2001):

Beningn nonfunctioning thyroid adenomas are characterized by a defective targeting to cell membrane or a reduced expression of the sodium jodide symporter protein.

I Clin Endocrinol Metab 87: 352-357

17 Smanik PA, Lio Q, Furminger TL, Ryuk, Xing S, Mazzaferri EL, Ihiang SM (1996):

Cloning of the human sodium jodide symporter. Biochem Biophys Res Commun 226: 339-345

18 Spitzweg C, Morris IC (2002):

The sodium jodide symporter: its pathophysiological and therapeutic implications.

Clin Endocrinol 57: 559-574 
19 Castro MR, Bergert ER, Beito TG, Roche PC, Ziesmer SC, Jhiang SM, Goellner IR, Morris IC (1999):

Monoclonal antibodies against the human sodium jodide symporter:

Utility for immunocytochemistry of thyroid cancer.

I Endocrinol 163: 495-504

20 Patel A, Ihiang S, Dogra S, Terrell R, Powers PA, Fenton C, Dinauer CA Tuttle RM, Francis GL (2002):

Differentiated thyroid carcinoma that express sodium-jodide symporter have a lower risk of recurrence for children and adolescents.

Pediatr Res 52: 737-744

21 Schwartzman RA, Cidlowski IA (1993):

Apoptosis: the biochemistry and molecular biology of programmed cell death.

Endocr Rev 14: 133-151

22 Studer H, Derwahl M (1995):

Mechanisms of nonneoplastic endocrine hyperplasia -

a changing concept: a review focused on the thyroid gland.

Endor Rev 16: 411-426

23 Bröcker M, de Buhr I, Papageorgion G, Schatz H, Derwahl M (1996):

Effects of apoptosis - related proteins in thyroid tumors and

thyroid carcinoma cell lines.

Exp Clin Endocrinol Diabetes 104: 20-23 
24 Hamacher C, Studer H, Zbaeren I, Schatz H, Derwahl M (1995):

Expression of functional stimulatory guanine nucleotide binding protein in nonfunctioning thyroid adenomas is not correlated to adenylate cyclase activity and growth of these tumors. I Clin Endocrinol Metab 80: 1724-1732

25 Studer H, Gerber H, Zbaeren I, Peter HI (1992):

Histomorphological and immunohistochemical evidence that human nodular goiters grow by episodic replication of multiple clusters of thyroid follicular cells.

I Clin Endocrinol Metab 75: 1151-1158

26 Gerber H, Zbaeren I, Kopp P, Aeschimann S, Maciel R, Studer H (1992): Human nodular goiters grow by episodic replication of disseminated cell cohorts expressing several growth factors at the same time. I Endocr Invest 15 [Suppl 2]: Abstract 95

27 Berg IP, Glattre E, Haldorsen T, Hostmark AT, Bay IG, Johansen AF, Jellum E (1994):

Longchain serum fatty acids and risk of thyroid cancer: a population-based-case-control study in Norway. Cancer Cans Cont 5: 433-439

28 Prevostel C, Alvaro V, de Boisvilliers F, Martin A, Iaffiol C, Ioubert D (1995):

The natural protein kinase $\mathrm{C}$ alpha mutant is present in human thyroid neoplasms.

Oncogene 11: 669-674 
29 Fey MF, Peter HI, Hinds HL, Zimmermann A, Liechti-Gallati S, Gerber H, Studer H, Tobler A (1992):

Clonal analysis of human tumors with M27 beta, highly informative polymorphic $\mathbf{x}$ chromosomal probe.

I Clin Invest 89: 1438-1444

30 Kopp P, Kimura ET, Aeschimann S, Oestreicher M, Tobler A, Fey MF, Studer H (1994):

Polyclonal and monoclonal thyroid nodules coexist within human multinodular goiters.

I Clin Endocrinol Metab 79: 134-139

31 Derwahl M (1994):

Molekulare Aspekte in der Pathogenese von Knoten und Adenomen der Schilddrüse.

Schweiz Med Wochenschr 124: 1613-1618

32 Studer H, Peter HI, Gerber H (1989):

Natural heterogeneity of thyroid cells:

the basis for understanding thyroid function and nodular goiter growth. Endocr Rev 10: 125-135

33 Huber G, Derwahl M, Kaempf I, Peter HI, Gerbe H, Studer H (1990): Generation of intercellular heterogeneity of growth and function in cloned rat thyroid cells (FRTL-5).

Endocrinology 26: 1639-1645

34 Derwahl M (1998):

Von der diffusen Struma zur Knotenstruma.

Der Internist 39: 577-583 
35 Bishop IM (1991):

Mollecular themes in oncogenesis.

Cell 64: 235-248

36 Peter HI, Gerber H, Studer H, Smeds S (1985):

Pathogenesis of heterogeneity in human multinodular goiter. A study on growth and function of thyroid tissue transplanted onto nude mice. I Clin Invest 76: 1992-2002

37 Belfiore A, La Rosa G, Padova G, Sava L, Ippolito O, Vigneri R (1987):

The frequency of cold thyroid nodules and thyroid malignancies in patients from an iodine-deficient area.

Cancer 60: 3096-3102

38 Paschke R, Fuehrer D, Holzapfel HP, Ruschenburg I (2001):

Diagnostik des Schilddrüsenknotens.

Dt. Ärztebl. 98: A 2427-2437 [Heft 38]

39 Droese M

Punktionszytologie der Schilddrüse.

Schattauer Verlag Stuttgart, New York 1995

40 Pfannenstiel P, Hotze LA, Saller B

Schilddrüsenkrankheiten.

BMV 1999

41 Chow LS, Gharib H, Goellner IR, van Heerden IA (2001):

Nondiagnostic thyroid fine-needle aspiration cytology:

management dilemmas.

Thyroid 11: 1147-51 
42 Gharib H, Goellner Jr (1993):

Fine-needle aspiration biopsy of the thyroid: an appraisal.

Ann Intern Med 118: 282-289

43 Gharib H (1997):

Changing concepts in the diagnosis and management of thyroid nodules. Endocrinol Metab Clin North Am 26 (4): 777-800

44 Mann K (2002):

Diagnostik und Therapie differenzierter Schilddrüsenkarzinome. Internist 43: 174-185

45 Levy O, De La Vieja A, Carrasco N (1998):

The $\mathrm{Na}^{+} / \mathrm{J}^{-}$Symporter (NJS): Recent advances.

I Bioenergetics Biomemb 30: 195-206

46 Kashima K, Yokoyama S, Noguchi S, Murakami N, Yamashita H, Nakayama I (1998):

Chronic thyreoiditis as a fovarable prognostic factor in papillary thyroid carcinoma.

Thyroid 8: 197-202

47 Unger K, Zitzelsberger H, Salvatore G, Santoro M, Bogdanova T, Braselmann H, Kastner P, Zurnadzhy L, Tronko N, Hutzler P, Thomas G (2004):

Heterogeneity in the distribution of ret/ptc rearrangements within individual postchernobyl papillary thyroid carcinomas.

I Clin Endocrinol Metab 89: 4272-4279 
48 Führer D (2001):

A nuclear receptor in thyroid malignancy:

Is PAX-8 / PPARa the Holy Grail of follicular thyroid cancer?

European Journal of Endocrinology 144 (2001): 453-456

49 Kroll TG, Sarraf P, Pecciarini L, Chen Ch-J, Mueller E, Spiegelman BM, Fletcher JA (2000):

PAX-8 - PPARG1 fusion oncogene in human thyroid carcinoma.

Science 289: 1357-1360

50 Rodrigues RF, Roque L, Rosa-Santos J, Cid O, Soares J (2004):

Chromosomal imbalance associated with anaplastic transformation of follicular thyroid carcinomas.

British Journal of Cancer (2004): 90, 192-196

51 Wynford - Thomas D (1997):

Origin and progression of thyroid epithelial tumours:

cellular and molecular mechanisms.

Horm Res 47: 145-157

52 Suarez HG (1998):

Genetic alterations in human epithelial thyroid tumours.

Clin Endocrinol 48: 531-546

53 Wreesmann VB, Ghossein R, Snehal G, Harris C, Schnaser E, Shaha A, Tuttle M, Shah J, Rao P, Singh B (2002):

Genome - wide appraisal of thyroid cancer progression.

Am I Pathol 161: 1549-1556 
54 Gasbarri A, Martegani MP, Del Prete F, Lucante T, Natali PG, Bartolazzi A (1999):

Galectin - 3 and CD44V6 isoforms in the preoperative evaluation of thyroid nodules.

I Clin Oncol 1999; 17: 3494-3502

55 Bartolazzi A, Gasbarri A, Papotti M, Bussolati G, Lucante T, Khan A, Inohara H, Marandino F, Orlandi F, Nardi F, Vecchione A, Tecce R, Larsson O (2001):

Application of an immunodiagnostic method for improving preoperative diagnosis of nodular thyroid lesions.

Lancet 2001; 357: 1644-1650

56 Specht MC, Tucker ON, Hocever M, Gonzalez D, Teng L, Fahey TJ (2002):

Cycloxygenase-2-expression in thyroid nodules.

Journal of Clinical Endocrinology \& Metabolism 87: 358-363

57 Pfannenstiel P, Hotze L.A. (1998):

Der „kalte” Schilddrüsenknoten.

Verhandlungsbericht des 16. Wiesbadener Schilddrüsengespräches: 30-32

58 Behan M, Murtagh HB (1982):

Correlation of ultrasonographic and pathological

findings in thyroid disease.

Ultrasound Med. Biol. 8, Suppl. I (1982)

59 Durante E (1980):

Ultrasonic tissue characterization of thyroid disease.

Staffen`s Scientific Publishing Company 
60 Wiedemann W (1993):

Sonographie und Szintigraphie der Schilddrüse.

Lehrbuch und Atlas Georg

Thieme Verlag

61 Maier R (1984):

Ultraschalldiagnostik der Schilddrüse.

Schattauer Verlag

62 Hörmann R (2001):

Schilddrüsenkrankheiten.

3. Auflage

Blackwell Wissenschaftsvertrag

63 Droese M (1976):

Zytologische Erfassung follikulärer Schilddrüsenkarzinome durch Feinnadelpunktion.

Med. Klin. 71 (1976), 908-911 (Nr. 21)

64 Reinwein D, Beuker G, Jockenhövel F:

Checkliste Endokrinologie und Stoffwechsel.

4. Auflage 2000

Georg Thieme Verlag Checkliste

65 Schäffer R (1986):

Aktuelle Gesichtspunkte zur histologischen Klassifikation, Verlauf und Prognose der Struma maligna.

Nuklearmediziner 9 (1986) 73

66 Goellner IR, Gharib H, Grant CS, Johnson DA (1987):

Fine needle aspiration cytology of the thyroid.

Acta Cytol. 31: 587-590 (1987) 


\section{$\underline{\text { Lebenslauf }}$}

Persönliche Daten:

Name: $\quad$ Graf

Vorname: Theresa Ingeborg Auguste-Luise

Geburtsdatum: $\quad 02.03 .1978$

Geburtsort: $\quad$ Freiburg i.Br., Bundesrepublik Deutschland

Familienstand: ledig

Eltern: $\quad$ Dr. med. Dieter Graf, Internist und Endokrinologe Angela Graf

Geschwister: $\quad$ Saskia Graf (24), cand. med.

Franziska Graf (21), stud. med.

Schulbildung:

1984 Grundschule Hasenburg in Lüneburg

Juni 1997 Gymnasium Oedeme in Lüneburg

Abschluss: Allgemeine Hochschulreife

Studium:

Beginn des

Medizinstudiums WS 1997 Universität Ulm

April 2000 Physikum in Ulm

März 2001 1. Staatsexamen

April 2003 2. Staatsexamen

Mai 2004 3. Staatsexamen

01.10.2004 Approbation

ab Oktober 2004 Facharztausbildung HNO

im Katholischen Klinikum Marienhof / St. Josef in Koblenz 